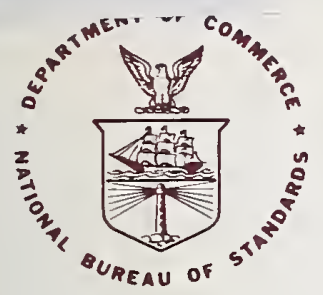

NBS

Publi-

cations

NBS TECHNICAL NOTE 1067

U.S. DEPARTMENT OF COMMERCE / National Bureau of Standards

\title{
Reference Flat Pulse Generator
}




\section{NATIONAL BUREAU OF STANDARDS}

The National Bureau of Standards' was established by an act of Congress on March 3, 1901. The Bureau's overall goal is to strengthen and advance the Nation's science and technology and facilitate their effective application for public benefit. To this end, the Bureau conducts research and provides: (1) a basis for the Nation's physical measurement system, (2) scientific and technological services for industry and government, (3) a technical basis for equity in trade, and (4) technical services to promote public safety. The Bureau's technical work is performed by the National Measurement Laboratory, the National Engineering Laboratory, and the Institute for Computer Sciences and Technology.

THE NATIONAL MEASUREMENT LABORATORY provides the national system of physical and chemical and materials measurement; coordinates the system with measurement systems of other nations and furnishes essential services leading to accurate and uniform physical and chemical measurement throughout the Nation's scientific community, industry, and commerce; conducts materials research leading to improved methods of measurement, standards, and data on the properties of materials needed by industry, commerce, educational institutions, and Government; provides advisory and research services to other Government agencies; develops, produces, and distributes Standard Reference Materials; and provides calibration services. The Laboratory consists of the following centers:

\section{Absolute Physical Quantities ${ }^{2}$ - Radiation Research - Chemical Physics - Analytical Chemistry - Materials Science}

THE NATIONAL ENGINEERING LABORATORY provides technology and technical services to the public and private sectors to address national needs and to solve national problems; conducts research in engineering and applied science in support of these efforts; builds and maintains competence in the necessary disciplines required to carry out this research and technical service; develops engineering data and measurement capabilities; provides engineering measurement traceability services; develops test methods and proposes engineering standards and code changes; develops and proposes new engineering practices; and develops and improves mechanisms to transfer results of its research to the ultimate user. The Laboratory consists of the following centers:

Applied Mathematics - Electronics and Electrical Engineering ${ }^{2}$ - Manufacturing Engineering - Building Technology - Fire Research - Chemical Engineering ${ }^{2}$

THE INSTITUTE FOR COMPUTER SCIENCES AND TECHNOLOGY conducts research and provides scientific and technical services to aid Federal agencies in the selection, acquisition, application, and use of computer technology to improve effectiveness and economy in Government operations in accordance with Public Law 89-306 (40 U.Ś.C. 759), relevant Executive Orders, and other directives; carries out this mission by managing the Federal Information Processing Standards Program, developing Federal ADP standards guidelines, and managing Federal participation in ADP voluntary standardization activities; provides scientific and technological advisory services and assistance to Federal agencies; and provides the technical foundation for computer-related policies of the Federal Government. The Institute consists of the following centers:

Programming Science and Technology-Computer Systems Engineering.

'Headquarters and Laboratories at Gaithersburg, MD, unless otherwise noted; mailing address Washington, DC 20234.

${ }^{2}$ Some divisions within the center are located at Boulder, CO 80303. 


\title{
Reference Flat Pulse Generator
}

\author{
J. R. Andrews \\ B. A. Bell \\ E. E. Baldwin
}

Electromagnetic Fields Division National Engineering Laboratory National Bureau of Standards

Boulder, Colorado 80303

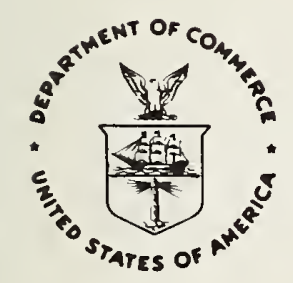

U.S. DEPARTMENT OF COMMERCE, Malcolm Baldrige, Secretary

NATIONAL BUREAU OF STANDARDS, Ernest Ambler, Director 
National Bureau of Standards Technical Note 1067

Natl. Bur. Stand. (U.S.), Tech. Note 1067, 72 pages (Oct. 1983)

CODEN: NBTNAE

U.S. GOVERNMENT PRINTING OFFICE

WASHINGTON: 1983

For sale by the Superintendent of Documents, U.S. Government Printing Office, Washington, DC 20402

Price $\$ 4.50$

(Add 25 percent for other than U.S. mailing) 


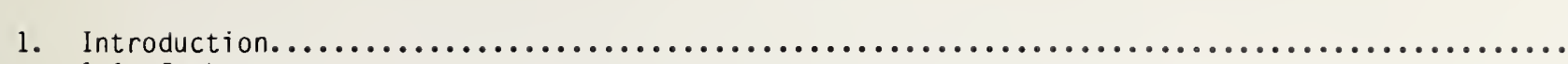

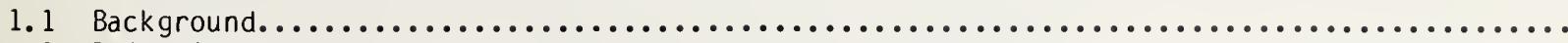

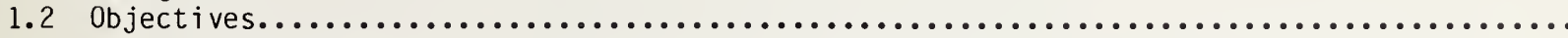

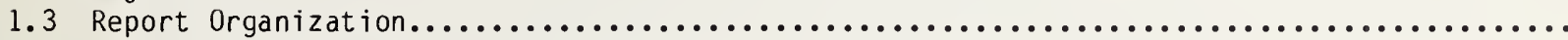

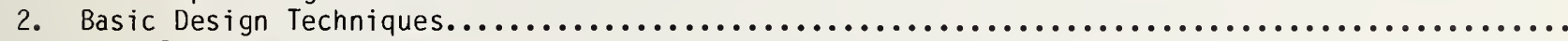

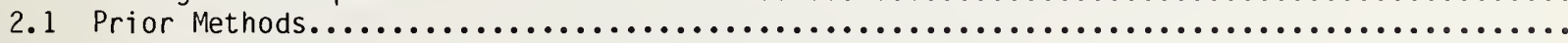

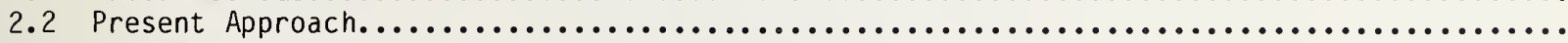

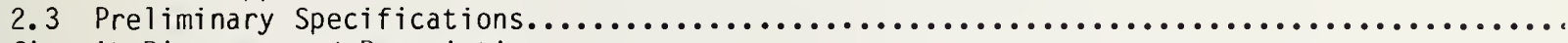

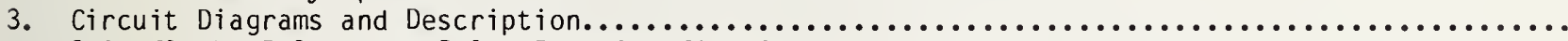

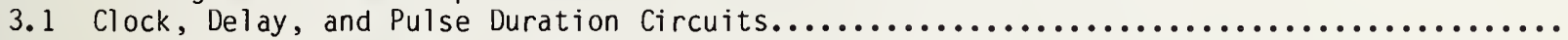

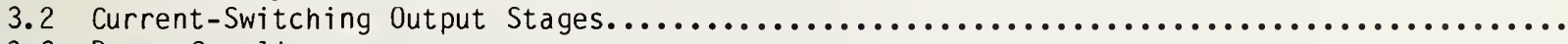

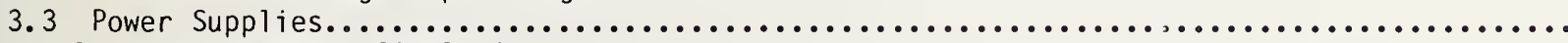

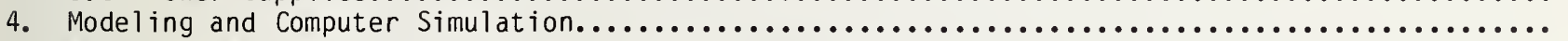

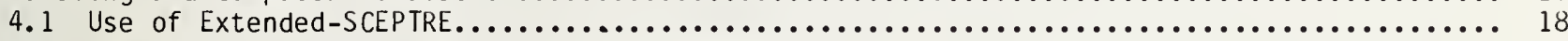

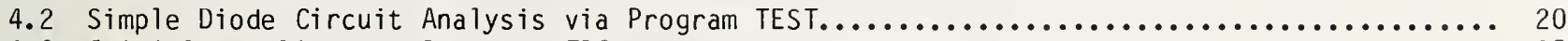

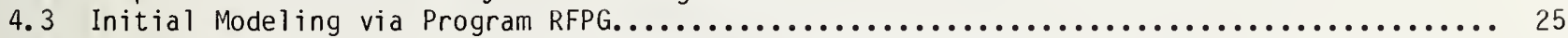

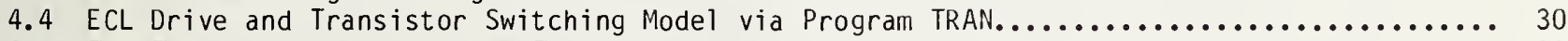

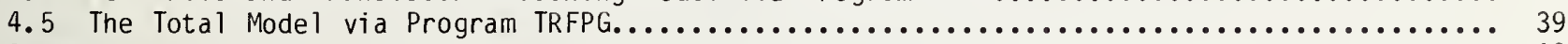

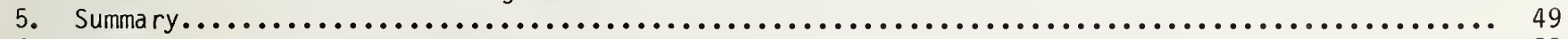

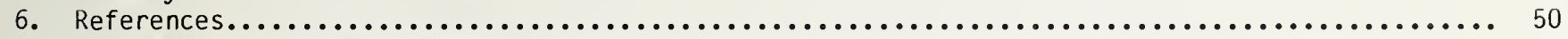

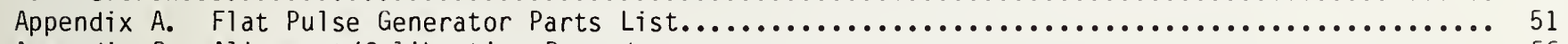

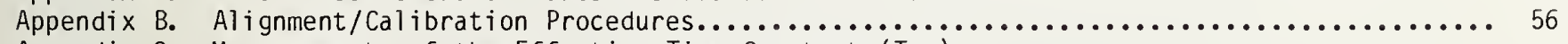

Appendix C. Measurements of the Effective Time Constant $\left(T_{B^{\prime}}\right)$

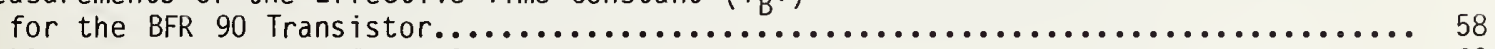

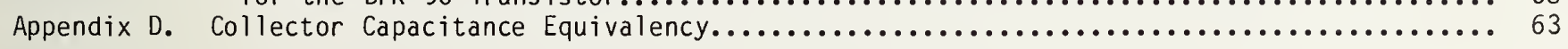



Reference Flat Pulse Generator

J. R. Andrews, * B. A. Bell, $\star \star$ and E. E. Baldwin ${ }^{\dagger}$

National Bureau of Standards

Boulder, Colorado 80303

A reference step-like pulse generator is described which has been developed at NBS. This generator can be used for accurately characterizing the step response of various kinds of transient recording equipment (oscilloscopes, waveform recorders, transient digitizers, etc.). tf Basic design principles are given as well as complete circuit diagrams and descriptions. An analysis of the output stage of the generator is presented together with the circuit models for developing a time-domain computer simulation program using extendedSCEPTRE. Preliminary specifications indicate that the NBS Reference Flat Pulse Generator provides a negative-going reference transition duration (90 to 10 percent) of 600 ps, \pm 20 percent with baseline perturbations of less than \pm 2 percent for less than 5 ns.

Key words: available waveform; baseline; circuit analysis; flat pulse generator; modeling; pulse delay; step response; topline; transfer standard; transition duration.

\section{Introduction}

1.1 Background

The need for a reference step-like waveform generator has become increasingly important for accurately characterizing the step response of oscilloscopes, transient recorders, and fast sampling channels of digital measurement instruments and automatic test equipment (ATE). The measurement system response can be subtracted from the reference waveform to give the measurement system distortion explicitly as a function of time (dynamic performance error). Equivalently, the reference waveform can be deconvolved from the response of the measurement system (to the reference waveform) in order to obtain the system impulse response. Here and in the remainder of this technical note a nominal load impedance of $50 \Omega$ has been assumed. When the load impedance is not $50 \Omega$, additional analysis is required (see, for example, ref. 1). By comparing the measurement waveforms and/or data with that of a reference waveform, the fidelity with which the measurement system can acquire the waveform can be determined. The dynamic performance of a measurement system is often desired, together with its ability to measure dc or steady-state quantities.

For example, it is well known that skin effect losses in shielded conductors and coaxial cables cause their step response to approach a final dc level asymptotically [2,3]. Since all physically realizable measuring devices require connectors, cables, wires, etc., transmission line effects on fast input signals are bound to occur. Hence, any measurement system will cause a certain amount of distortion to an applied signal which causes the acquired waveform to differ.

From a practical point of view, it is often desirable to be able to calibrate the dc voltage levels of the measurement system, as well as any time-dependent parameters. For this reason a voltage

* Presently with Picosecond Pulse Labs, Inc., P.0. Box 44, Boulder, Colorado.

**Electrosystems Division, National Engineering Laboratory.

f Formerly with the Electromagnetic Technology Division, National Engineering Laboratory.

tt Certain commercial equipment, instruments, or materials are identified in this paper in order to adequately specify the experimental procedure. Such identification does not imply recommendation or endorsement by the National Bureau of Standards, nor does it imply that the materials or equipment identified are necessarily the best available for the purpose. 
step function, whose beginning and ending dc levels are calibratable, has considerable merit as a reference standard, particularly if the transition between these two levels is also well-behaved and predictable. Such was the purpose for developing a Reference Flat Pulse Generator (RFPG) in the Electromagnetic Waveform Metrology Group at NBS [4].

\subsection{Objectives}

The main objective of developing an RFPG was to design, build, and model a pulse generator standard which can provide a step-like pulse waveform of known amplitude and flatness, together with a predictable transition duration between levels. Such a standard can then be used for the alignment and calibration of pulse waveform measuring instrumentation.

As shown in figure 1-1, the step response of, say, an oscilloscope typically contains three regions of interest in specifying its dynamic accuracy. The first one is the transition region in which the important parameter is the transition duration, $t_{r}$ (often referred to as rise time), which is the time required for the response to pass from the proximal (or 10 percent) level to the distal (or 90 percent) level [5]. It is oftentimes difficult to ascertain the 10 and 90 percent levels of input waveforms with sloping baselines and toplines. The calibratable beginning and ending levels (topline and baseline, respectively) of the RFPG avoids this difficulty.

The second region of interest is the perturbation region immediately following the transition. Ideally, the step response should smoothly and monotonically rise to the final dc (100 percent) level and remain there. In practice, there are usually some small bumps, wiggles, overshoot, ringing, etc. This region is usually described by the peak-to-peak amplitude, $V_{p}$, of the ringing (as a percentage of the full-scale step), and the time interval, $t_{p}$, required for the perturbations to disappear.

The third region of interest typically lasts over a relatively long settling time, $t_{s}$, wherein the response converges to (and stays within) a specified accuracy of the final dc value. Deperlding on charge storage and nonlinear saturation effects in the measurement and display circuits, and on the closeness to the final dc level, this parameter can be difficult to determine [6]. As shown in figure 1-1, $t_{p}$ and $t_{s}$ are both usually measured starting at the mesial (or 50 percent) level of the step response.

\subsection{Report Organization}

This report is divided into six sections and four appendices. Following this introductory section, sections 2 and 3 describe the design techniques, circuit details, and preliminary specifications of the RFPG. Section 4 contains the circuit modeling, selected program listings, and computersimulated waveforms for analyzing the subject generator using SCEPTRE [7]. Appendix A contains the list of parts used in the RFPG module. Appendix B provides the alignment procedure for making adjustments to the generator as a source for calibration purposes. Appendix $C$ describes time constant measurements taken on $r f$ switching transistors. Appendix D gives an analysis for approximating equivalent capacitors.

\section{Basic Design Techniques}

2. 1 Prior Methods

To date, there has not been available a flat pulse generation method which allows accurate determination (on a stable dc basis) of both the baseline and topline levels and well-characterized transition and perturbation regions (see fig. 1-1). Manufacturers in the past have built step generators 


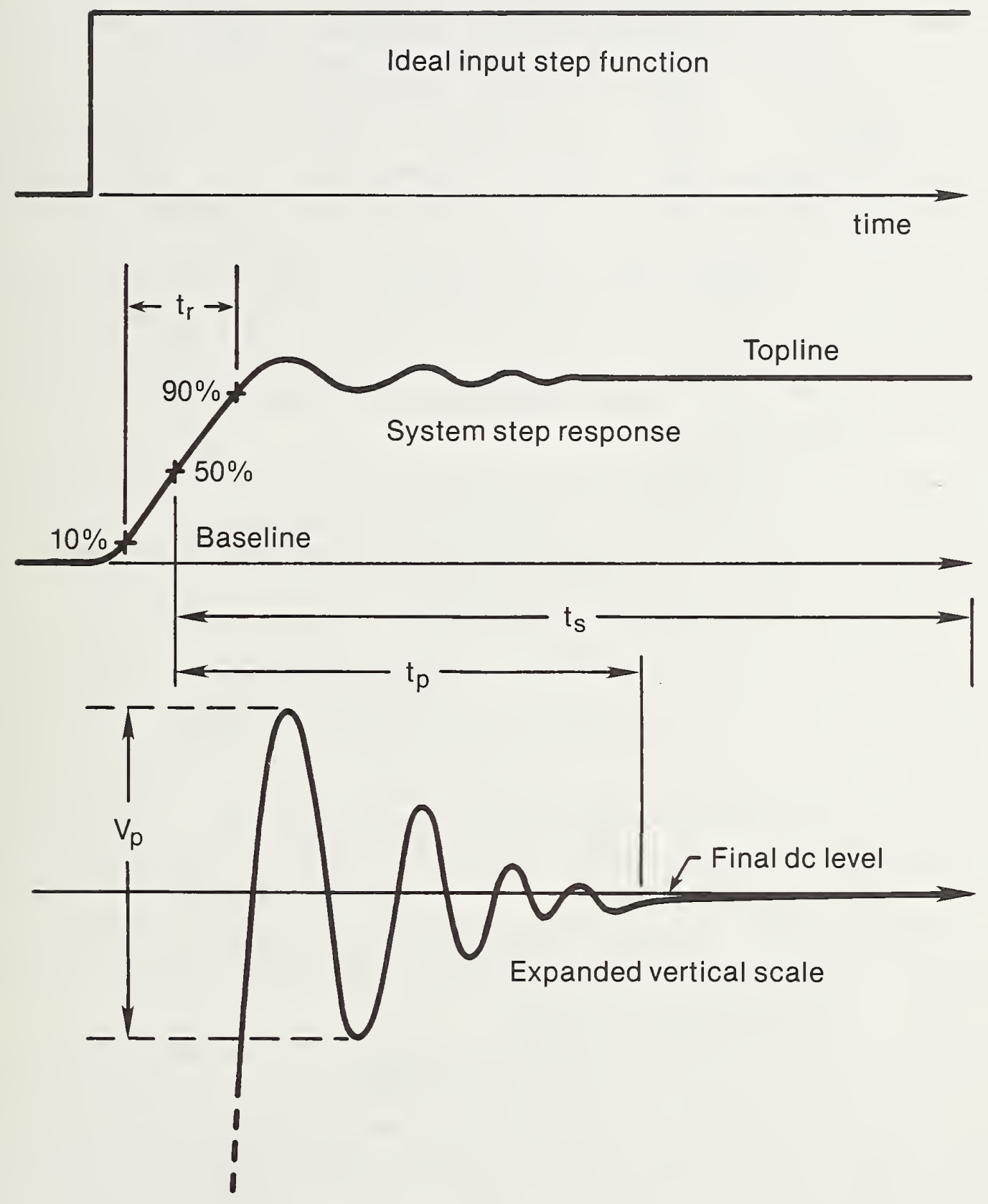

Figure 1-1. Anatomy of a step-like pulse. 
with varying success. In the subnanosecond region, tunnel diodes [8] or mercury wetted mechanical switches [9] have typically been used. Tunnel diodes provide the fastest switching times, with 20 ps being typical. Such diodes provide low-level pulses of the order of $1 / 4 \mathrm{~V}$. Their major limitation is the long-term sag in their output voltage due to internal heating of the junction. Thus, they cannot be used for accurate calibration transfer from dc.

High voltage (tens to hundreds of volts) pulses can be generated using mercury switches. Transition durations as short as 39 ps have been obtained [10]. Disadvantages of mercury switches are: low repetition rates, typically line frequency $(60 \mathrm{~Hz})$, limited life times, and pulse amplitude instabilities of the order of a percent. Another more subtle problem stems from the use of transmission lines in the pulse generator design. A typical mercury switch pulse generator, figure 2-1, consists of a dc power supply, a charging resistor $R_{C}$, a coaxial cable of impedance $R_{0}$ with electrical delay $l_{\text {ength }} T_{D}$ and the switch $\left[T_{D}=2 \ell /\left(V_{p} \cdot C\right)\right.$ where $\ell$ is the cable length in meters, $V_{p}$ is the propagation factor in percent, and $C$ is the speed of light in meters per second]. The cable is initially charged to the voltage $V_{b b}$. When the switch is closed the line is discharged into the load resistor $R_{L}$. Ideally, if $R_{L}=R_{0}$ then a rectangular output pulse will be produced [11]. The amplitude would be $1 / 2 V_{b b}$ and the duration would be 2 TD. This concept should produce an ideal pulse amplitude standard related precisely to a $d c$ measurement of $V_{b b}$. In practice, there are problems. First, $R_{0}$ is usually not well known, closer than perhaps one percent. Second, owing to skin effect and dielectric losses, real cables introduce significant pulse distortion which alters the waveshape from the ideal rectangular pulse and reduces the amplitude.

Earlier work at NBS addressed the problems of sag and distortion [10]. One of the common design defects with conventional pulse generators is the varying load on the generator's power supplies as the output pulse changes state. Depending on the dynamic regulation of the power supply, aberration in the form of sag may appear in the generated topline and/or baseline.

One technique used by Andrews $[10,12]$ to obtain a flac pulse consisted of a simple diode switch (fig. 2-2). Initially, the switch $S_{1}$ (in reality a PNP transistor operated in saturation or cutoff) is open. The constant current $I_{0}$ passes through the diode and $R_{1}$, producing the generator baseline voltage $-I_{0} R_{1}$. When the switch $S_{1}$ is closed, the diode becomes reverse biased, thus disconnecting $I_{0}$ from $R_{1}$. The output voltage thus changes rapidly to its topline value of zero volts. The pulse generator system has a source resistance equal to $R_{1}$. A constant current $I_{0}$ is always drawn from the independent power supply $-V$. Thus, the topline and baseline determining elements are completely free from power supply dynamic regulation problems. The only uncertainty in this circuit is in the transition region due to the switching sransients of $S_{1}$ and the charge storage time in the diode. By using a Schottky diode, the charge storage time may be minimized. With this circuit very flat pulses were obtained $20 \mathrm{~ns}$ after the positive-going transition.

To extend the flat pulse concept to the subnanosecond region, the mercury wetted switch was attractive [11]. Figure 2-3 shows such a flat pulse generator. Again, the power supply $(+V)$ provides a constant current $I_{0}$, regardless of the switch condition (open or closed). With the switch open, the baseline is zero volts. When the switch closes, the generator topline is $I_{0} R_{1}$. The equivalent generator source resistance is $R_{1}$. Unfortunately, the disadvantages of the mercury switches, as mentioned earlier, limited this approach.

Both of the above flat pulse generators also avoided the use of coaxial cables and their attendant distortion problems. Instead, the principle of design is the use of constant current sources steered to and away from the output load terminal via high-speed switching. The use of this technique 


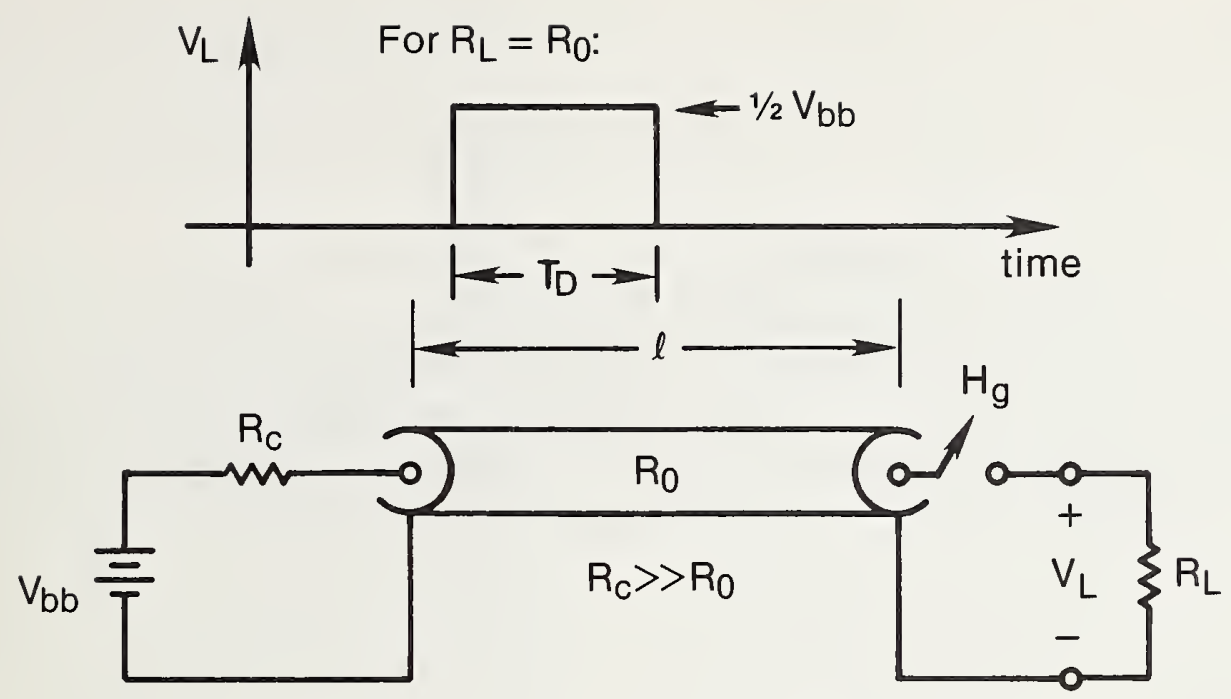

Figure 2-1. Typical mercury switch pulse generator.

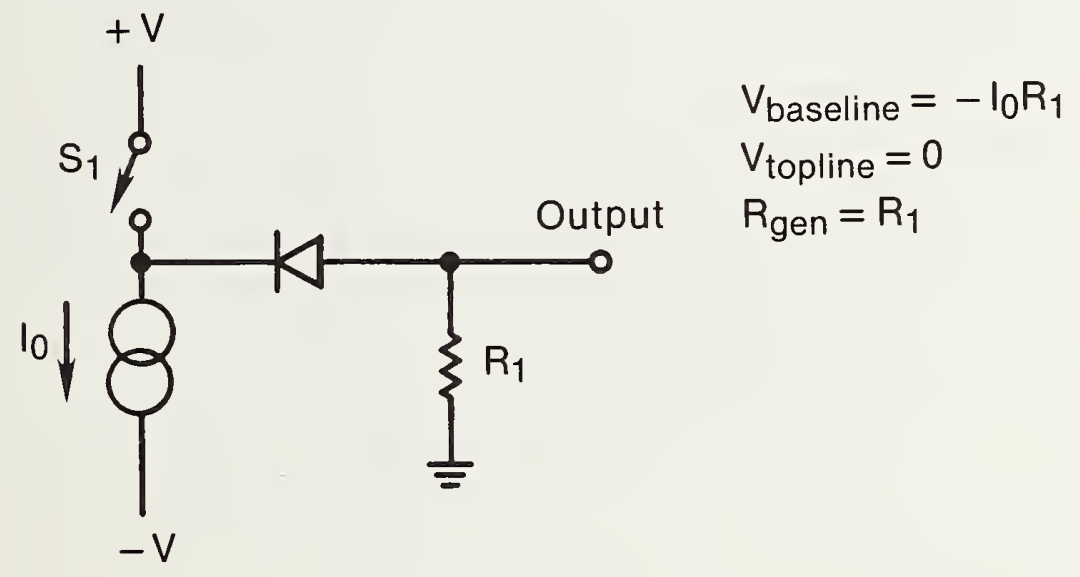

Figure 2-2. Diode switch flat pulse generator.

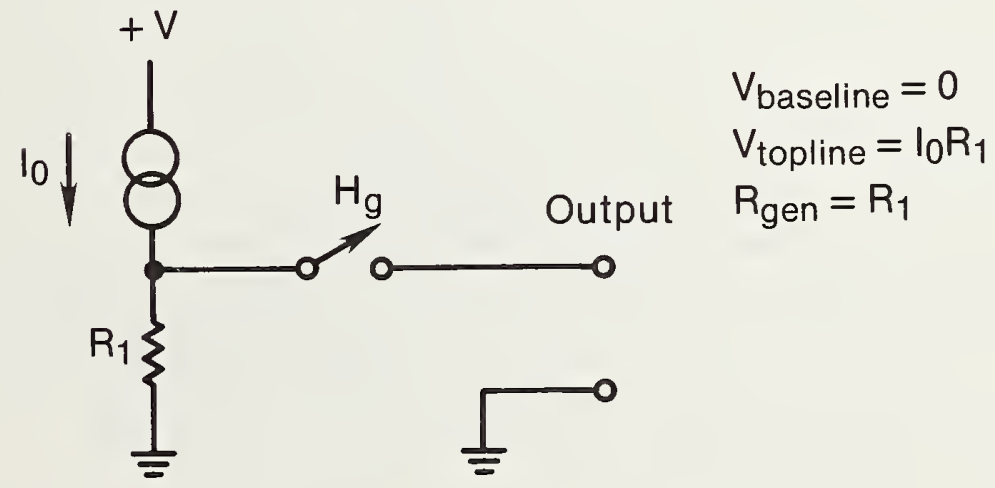

Figure 2-3. Mercury switch flat pulse generator. 
was recognized and implemented by Andrews in 1970 [12]. Figure 2-4 shows the basic design of the generator consisting of a constant current source $I_{1}$ feeding the $R_{1}$ resistor having a typical value of $50.0 \Omega$. The $I_{2}$ current source is turned off by means of the control gate so that a stable topline on the voltage output pulse is formed by $I_{1}$ through $R_{1}$. When the control pulse turns on current source $I_{2}$ such that

$$
I_{1}=I_{2}=I_{0} \text {, }
$$

then the current flow to $R_{1}$ is zero, so that the baseline voltage is (ideally) zero. By using the turn-off of an active device $\left(I_{2}\right)$, the transition in the output waveform is limited by the inherent device switching speed and output capacitance. Flat-top pulses having a transition duration (10 percent to 90 percent) of about 2 ns with around 5 percent to 10 percent aberrations were obtained by this method.

\subsection{Present Approach}

The present design approach used in the RFPG is shown in figure 2-5. The technique is very similar to the earlier concepts, particularly the one shown in figure 2-4. Two major improvements are provided, however, by the present approach with (1) inclusion of the output diode, and (2) control of the negative current source by means of switches S1 and S2. The switching at $t=t_{0}$ causes rapid turn off of the output diode by steering $I_{0}$ down through switch 52 . A stable baseline voltage of essentially zero volts is produced equal to the leakage current of the diode through $R_{1}$ in parallel with $R_{L}$ (typically, $-100 \mathrm{nA} \cdot 25 \Omega=-2.5 \mu \mathrm{V}$ ). With switch S1 closed and S2 open, the upper positive constant current source is steered through the output diode providing a constant, and therefore calibratable, topline voltage of $I_{0}$ through $R_{1}$ in parallel with $R_{L}$ (typically, $+20 \mathrm{~mA} \cdot 25 \Omega=+500 \mathrm{mV}$ ). The rapid transition from the topline to the baseline (less than 1 ns in the present RFPG), is caused by both the use of fast, rf-switching transistors for S1 and S2 and the sudden reverse bias seen by the output diode. For best results, the diode is a passivated, Schottky barrier type having low turn-on voltage and fast, charge-storage recovery time. Thus, this basic approach produces a fast step-like waveform generator having two known output levels with a constant output impedance $R_{1}$.

The actual electronic circuit used to implement this approach is shown symbolically in figure 2-6. Q8 functions as the dc current source $I_{d c} \cdot Q 1$ and $Q 2$ are the switches $S 1$ and $S 2$. Q1 and Q2 form an emitter-coupled differential-switch pair. They are driven in push-pull by the complementary outputs of an ECL logic OR gate U13. Q3 is the current source for the emitters of Q1 and Q2. Ie must be greater than $I_{d c}$. Initially, the base of Q1 is an ECL "1" $(-0.9 \mathrm{~V})$ and the base of Q2 is an ECL "0" $(-1.7 \mathrm{~V})$. Thus, Q2 is off and Q1 is on, conducting all the emitter current $\mathrm{I}_{\mathrm{e}}$ to ground. The current $I_{d c}$ from $Q 8$ all passes through $C R 3$ to $R_{g}$ creating an open circuit output of $1.00 \mathrm{~V}$ (20 mA $x \quad 50 \Omega$. CR3 is conducting while CR2 is reverse biased and nonconducting. At $t=t_{0} U 13$ receives a pulse. The complementary outputs from U13 rapidly switch Q1 off and Q2 on. Q2 now conducts all of the $30 \mathrm{~mA}$ emitter current $\mathrm{I}_{\mathrm{e}}$. Thus, the collector of $\mathrm{Q} 2$ tries to pull $30 \mathrm{~mA}$ from the node connecting CR3, CR2, and Q8. The only way for the nodal currents to balance is for Q8 to supply $20 \mathrm{~mA}$, CR3 to become nonconducting, and CR2 to turn on and supply $10 \mathrm{~mA}$. Thus, the desired function of turning off CR3 and disconnecting $I_{d c}$ from the output is accomplished.

In actual practice, only the negative-going transition from $500 \mathrm{mV}$ to $-2.5 \mu \mathrm{V}$ is considered as the reference step transition. It is far easier to control the transient behavior of CR 3 turning off than when it is turning back on. Figure 2-7 is a pair of photos taken of the main output pulse from the RFPG. 


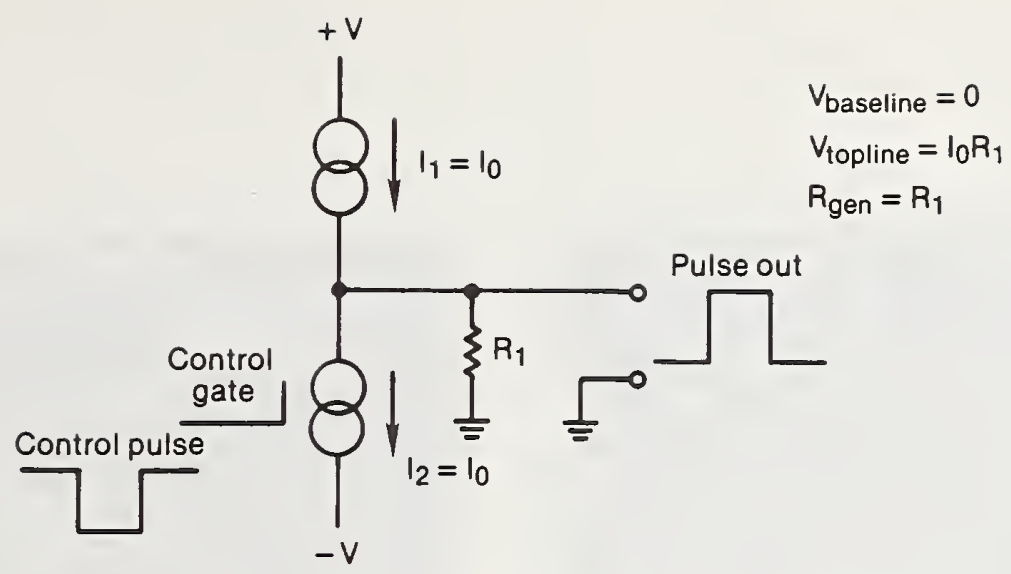

Figure 2-4. Stable reference flat top pulse generator.

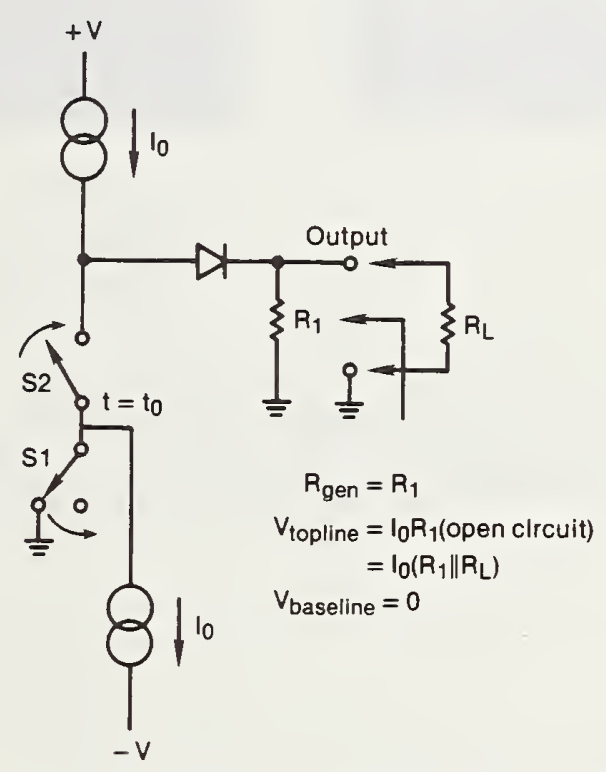

Figure 2-5. Present RFPG switching technique.

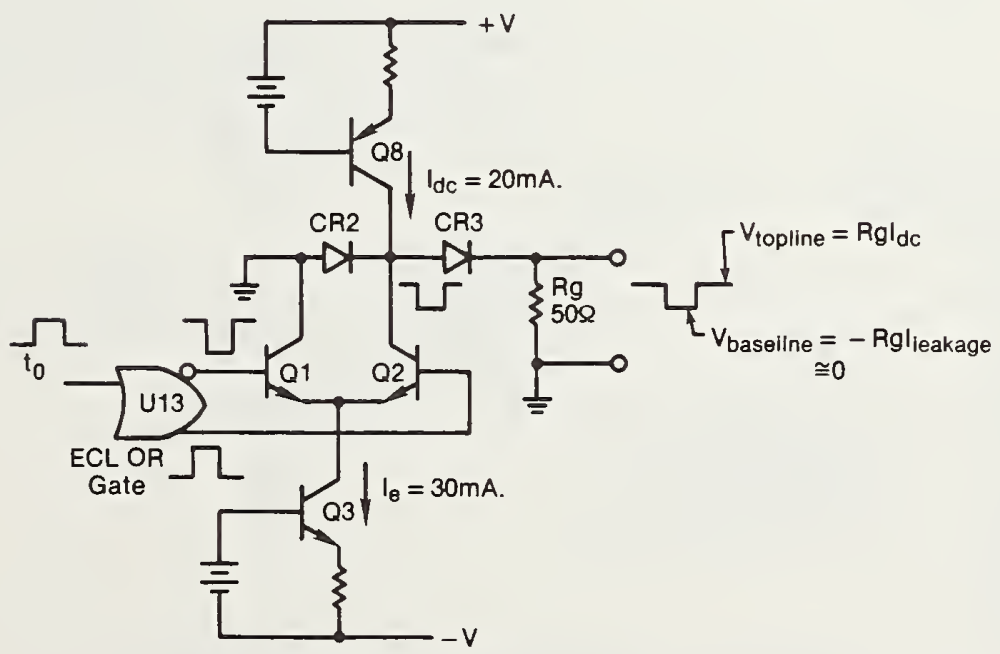

Figure 2-6. Output stage of the RFPG. 


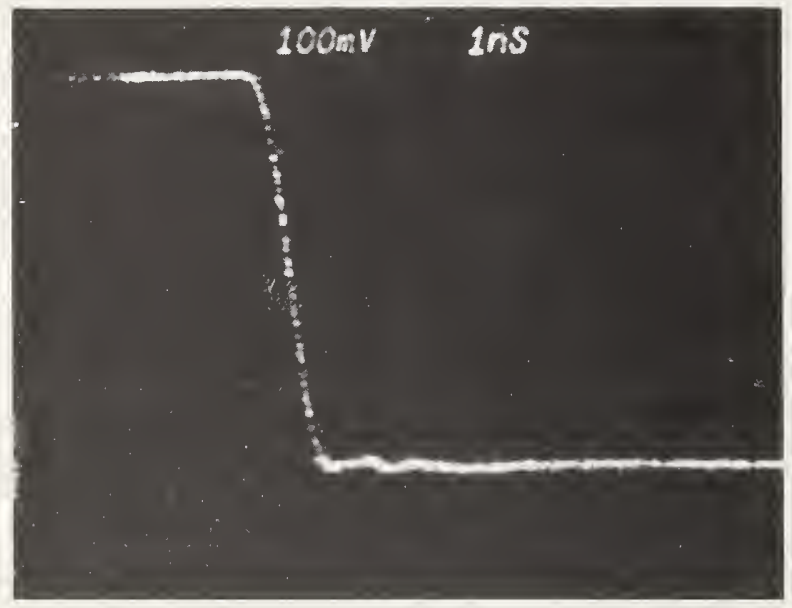

(a)

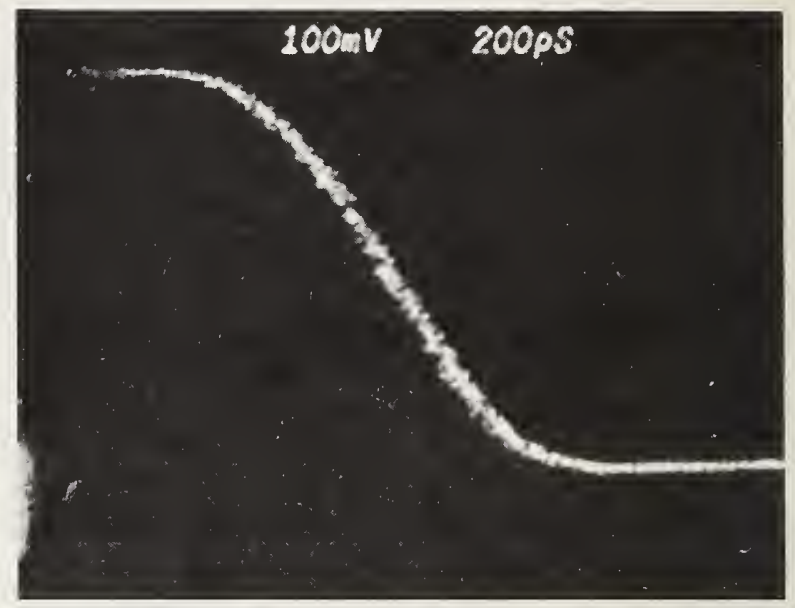

(b)

Figure 2-7. Photos of the main PULSE output from the prototype RFPG.

(a) $100 \mathrm{mV} / \mathrm{cm}$--vertical sensitivity; $1 \mathrm{~ns} / \mathrm{cm}$-horizontal time base.

(b) Same vertical sensitivity with expanded $200 \mathrm{ps} / \mathrm{cm}$ time base.

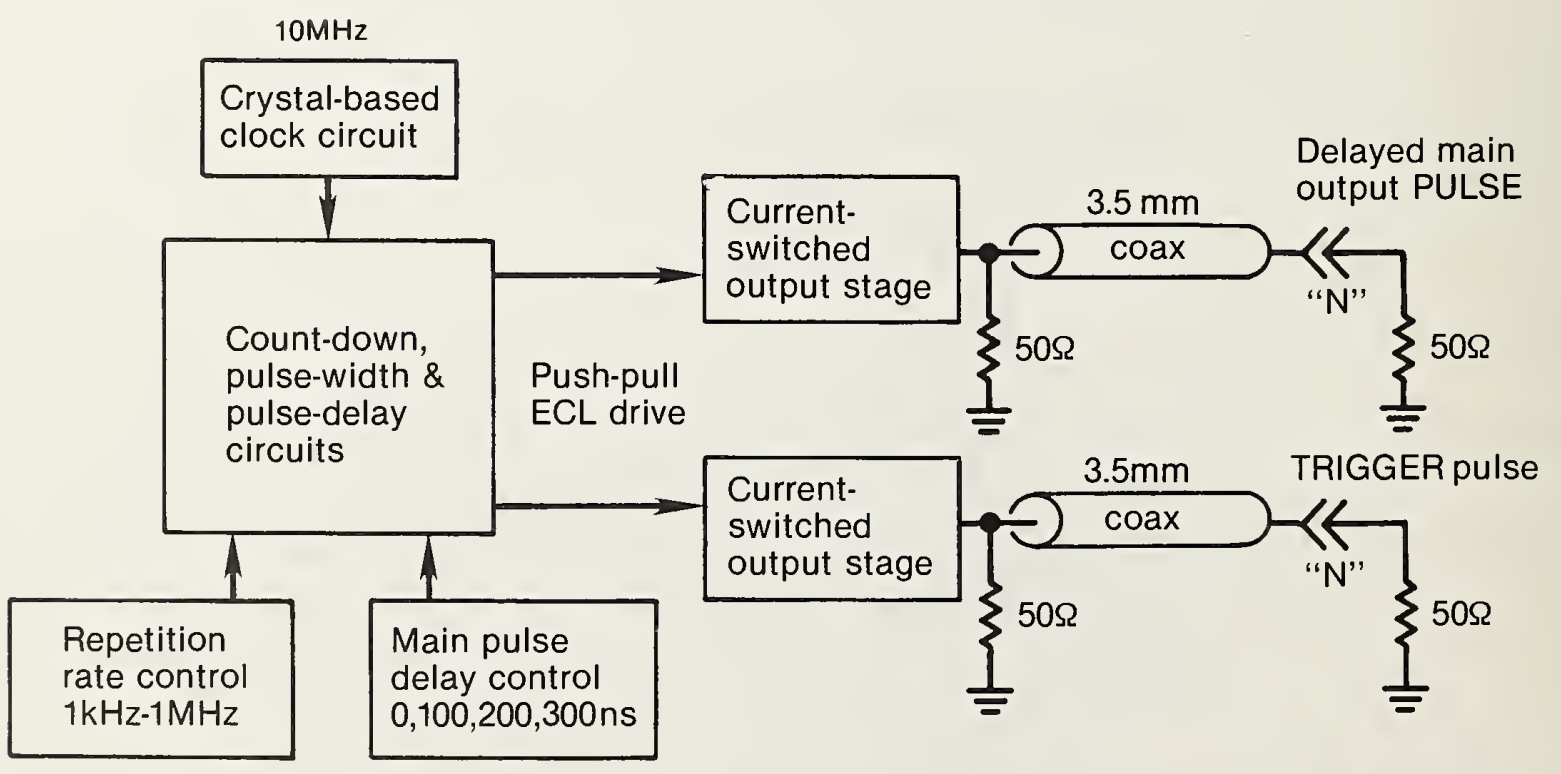

Figure 2-8. Block diagram of complete RFPG. 
A block diagram showing the complete RFPG is given in figure 2-8. The current-switched output stage, of course, is critical in producing the reference step-like output waveform, and has been briefly described above. The output pulse across the $50 \Omega$ generator source resistor is coupled to the front panel $\mathrm{N}$ type connectors via nominal $50 \Omega, 3.5 \mathrm{~mm}$ rigid coaxial lines. A trigger output pulse is also provided from an identical output stage. It has the same specifications as the delayed main output pulse, except for a 50 percent duty cycle (10 percent duty cycle for the main pulse). A $10 \mathrm{MHz}$ crystal-based clock circuit is counted down to provide for selectable pulse repetition rates with appropriate pulse-durations and selectable pulse delays for the main output pulse. The rep. rates, delays, and duty cycles are all determined by digitally counting the $10 \mathrm{MHz}$ (100 ns) clock pulses. These circuits are implemented in emitter-coupled logic (ECL) to provide fast transition edges with minimum jitter, particularly between the push-pul1 ECL drive to the current-switched output stages. Figure 2-9 above shows the front panel of the NBS Reference Flat Pulse Generator.

\subsection{Preliminary Specifications}

Specifications are common to the pulse output and the trigger output unless noted otherwise.

Baseline: $0.00 \mathrm{~V} \pm 10 \mu \mathrm{V}$

Topline: $1.00 \mathrm{~V}$ open circuit, \pm 0.1 percent

Source impedance: $50.0 \Omega, \pm 0.5$ percent

Reference transition: negative-going

Reference transition duration: 600 ps (90 percent to 10 percent), \pm 20 percent

Perturbations: Less than \pm 2 percent lasting for 5 ns or less

Second transition duration: 2 ns (10 percent to 90 percent), \pm 20 percent

Trigger to pulse delay: Selectable $0 \mathrm{~ns}, 100 \mathrm{~ns}, 200 \mathrm{~ns}$, or $300 \mathrm{~ns}, \pm 1 / 2 \mathrm{~ns}$

Jitter: 25 ps or less

Repetition rate: Selectable $1 \mathrm{MHz}, 100 \mathrm{kHz}, 10 \mathrm{kHz}$, or $1 \mathrm{kHz}, \pm 0.01$ percent

Duty cycle: 10 percent for pulse

50 percent for trigger

Internal working standards: $10 \mathrm{MHz}$ crystal oscillator for time base

LM399H active zener for dc voltage

Selected $50 \Omega$, SMA, microwave termination

Connectors: Type $\mathrm{N}$ female

Controls: Mode ov, dc ( 1 V O.C.), or pulse

Construction: TEK TM500 single-wide plug-in kit

Power requirements: Supplied by TM500 main frame

Figure 2-9. Front panel of the NBS Reference Flat Pulse Generator.

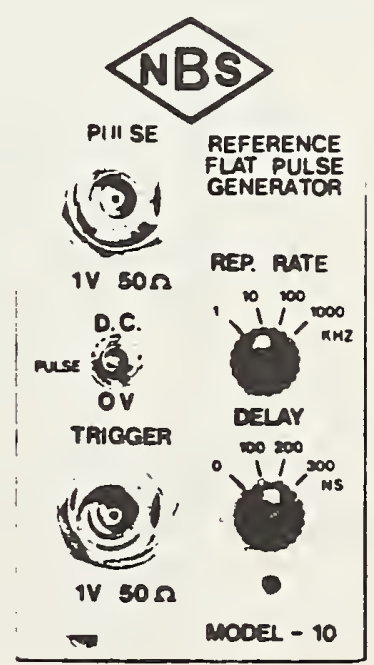


3. Circuit Diagrams and Description

3.1 Clock, Delay, and Pulse Duration Circuits

Figure 3-1 is the circuit diagram for the clock, delay, and duration circuits. Figures 3-2 through 3-5 are the timing diagrams. The internal time standard for the generator is a $10 \mathrm{MHz}$ crystal oscillator U1. The first section Ula provides a dc reference voltage to bias the second section U1b as a linear amplifier. The second section is a modified form of Colpitts crystal oscillator. The third section Ulc provides squaring and buffering.

The $10 \mathrm{MHz}$ clock is used to toggle a chain of $95 \mathrm{H} 90$ divided by $10 \mathrm{ICS}$, U2-U5. These counters provide the basic repetition rates of the generator. Sla is used to select either $1 \mathrm{MHz}, 100 \mathrm{kHz}$, $10 \mathrm{kHz}$, or $1 \mathrm{kHz}$. The output from Sla is labeled RESET. All the remaining logic functions are initiated by the negative going transition of the RESET square wave.

RESET and $\overline{C L K}$ are applied to the NOR gate U6a. When RESET goes to a "0", U6a then passes the $10 \mathrm{MHz} \overline{\mathrm{CLK}}$ pulses creating the GATED CLK signal. The first GATED CLK pulse toggles a "1" into the Trigger $D$ flip-flop U7a. The $\bar{Q}$ output is the $\overline{T R I G}$ signal.

The pulse delay function is obtained by successively dividing the GATED CLK pulses using divide by $2 \mathrm{flip}-\mathrm{fl}$ ops U7b and U8. The appropriate positive transition for $0 \mathrm{~ns}, 100 \mathrm{~ns}, 200 \mathrm{~ns}$, or $300 \mathrm{~ns}$ delay is selected via $\$ 2$ and used to toggle a "1" into U9a, a D flip-flop. The Q output is the DELAYED PULSE. The R-C networks (R1, C6, and C7; R2 and C8; and R3, C9, and C10) are adjustable delay networks used to compensate for the propagation delays in the various delay ICs.

The specifications call for a 10 percent duty cycle for the pulse output. Thus, the duration of the DELAYED PULSE is to be $100 \mathrm{~ns}, 1 \mu \mathrm{s}, 10 \mu \mathrm{s}$, or $100 \mu \mathrm{s}$, depending upon the repetition rate selected. This duration is accomplished by counting the appropriate number of $10 \mathrm{MHz}$ clock pulses and then clearing (pin 1) flip-flop U9a. When DELAYED PULSE goes to a "0", gate U6c then passes the GATED CLK pulses to a chain of divide by 10 dividers, U10 to U12. The output of the appropriate divider is selected by S1b and used to toggle a "1" into flip-flop U9b. The $Q$ output from U9b clears U9a and also U7b and U8 through the OR gate U6b. U7a and U9b are cleared by the positive transition of the RESET square wave. Incidentally, this action causes the duty cycle of the trigger pulse to be 50 percent. RESET is also passed through U6b to ensure that U7b and U8 are reset properly at initial poweron.

The $\overline{\text { TRIG }}$ and DELAYED PULSE signals are passed through separate buffers U13 and U14 to provide complementary, push-pull ECL drive to the trigger and pulse output stages. The operating states of these buffers are controlled by the MODE switch 53 .

\subsection{Current-Switching Output Stages}

Figure 3-6 is the schematic diagram of the output stages. These stages are identical; therefore, we will only discuss the trigger output stage. Section 2.2 described in detail the operation of this particular circuit using the symbolic diagram in figure 2-6.

U15 is the internal dc voltage working standard. It is a temperature-controlled, active zener voltage reference. U16, Q7, and Q8 function as the $20 \mathrm{~mA} \mathrm{dc}$ current source. A dc voltage differential of $2 \mathrm{~V}$ between the $+12 \mathrm{~V}$ bus and the $(+)$ input to $U 16$ is set by potentiometer R17. U16 forces the potential across R20 to also be $2 \mathrm{~V}$, thus establishing the emitter current of Q8 to be $20 \mathrm{~mA}$. Due to the high $\beta(300 \times 200)$ of the Darlington pair, Q7 and Q8, the composite collector current is almost identically the same as the $20 \mathrm{~mA}$ emitter current. 


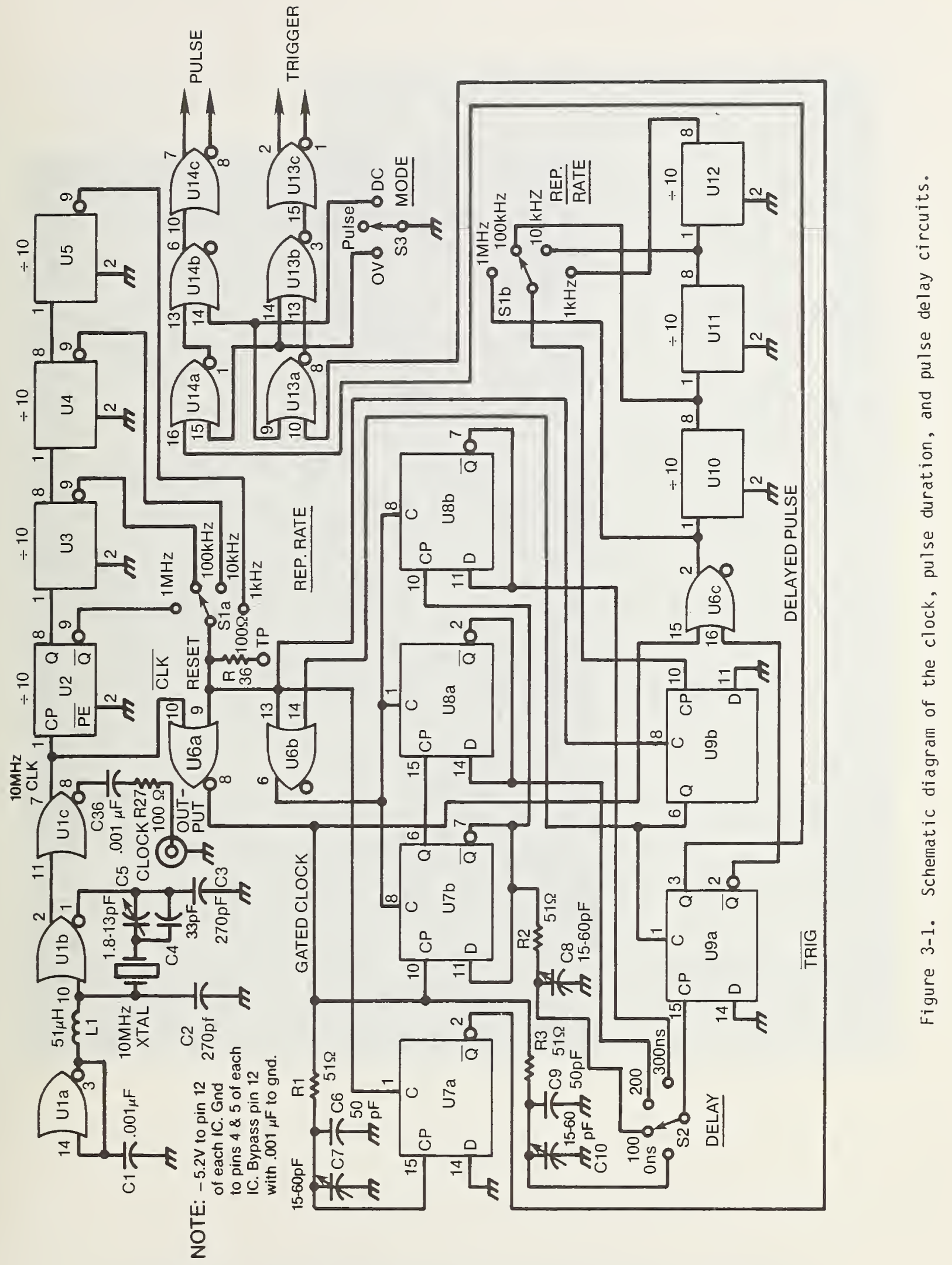


Reset (U6-9)

$\overline{\mathrm{CLK}}(U 1-7)$

Gated Clock

(filtered; U7-15)

$\overline{\text { TRIG }}(U 7-2)$

DELAY

(U9-3)

Delayed pulse (U9-3)

U6-2

U9-6

Gated clock (U6-8)

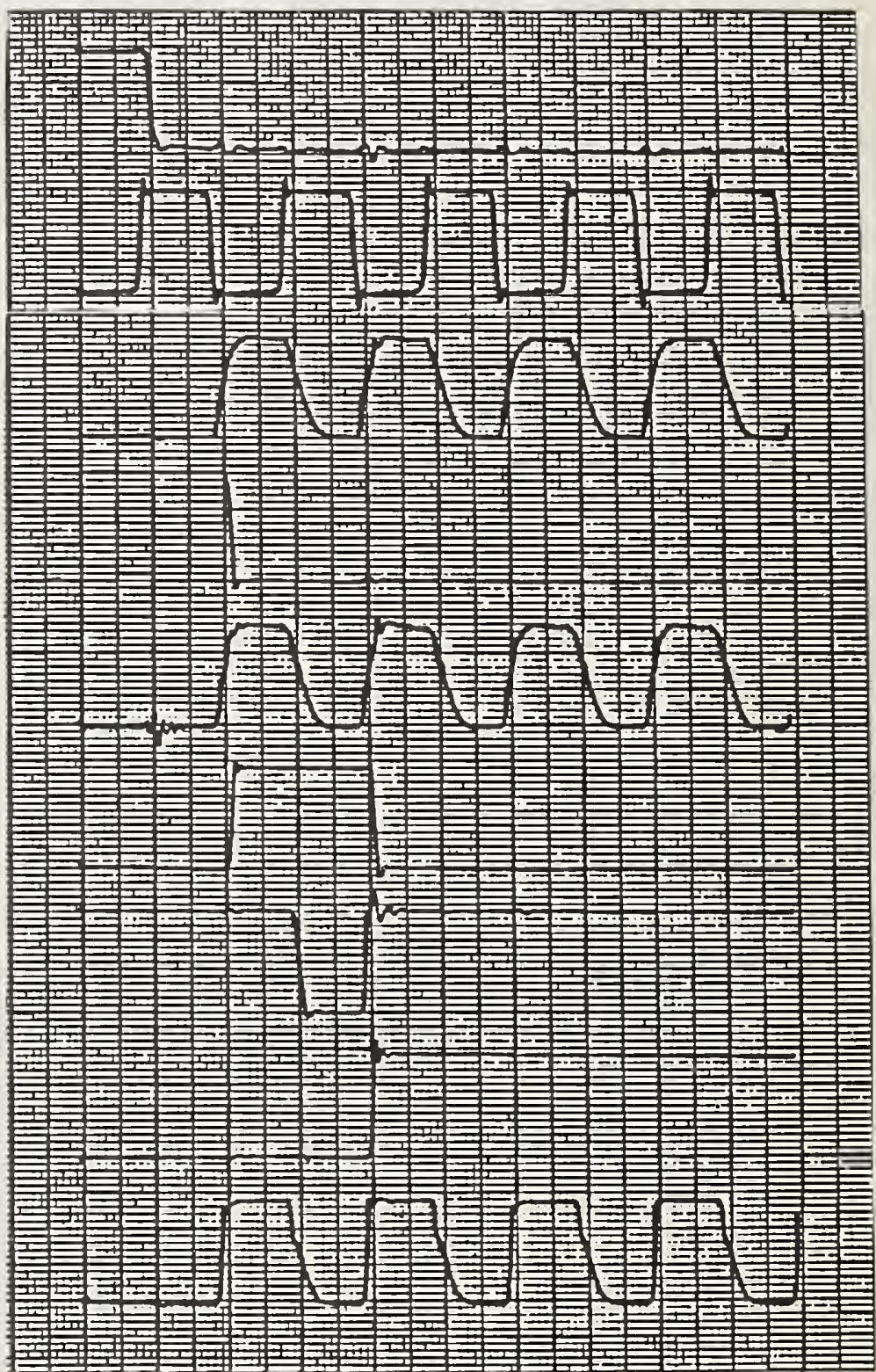

Figure 3-2. Timing diagrams for $1 \mathrm{MHz}$ repetition rate, 0 ns delay. 
Reset (U6-9)

Gated clock (U6-8)

$\overline{\text { TRIG }}(U 7-2)$

U7-6

U8-2

Delay (U9-15)

Delayed pulse (U9-3)

U6-2

U9-6

U6-6

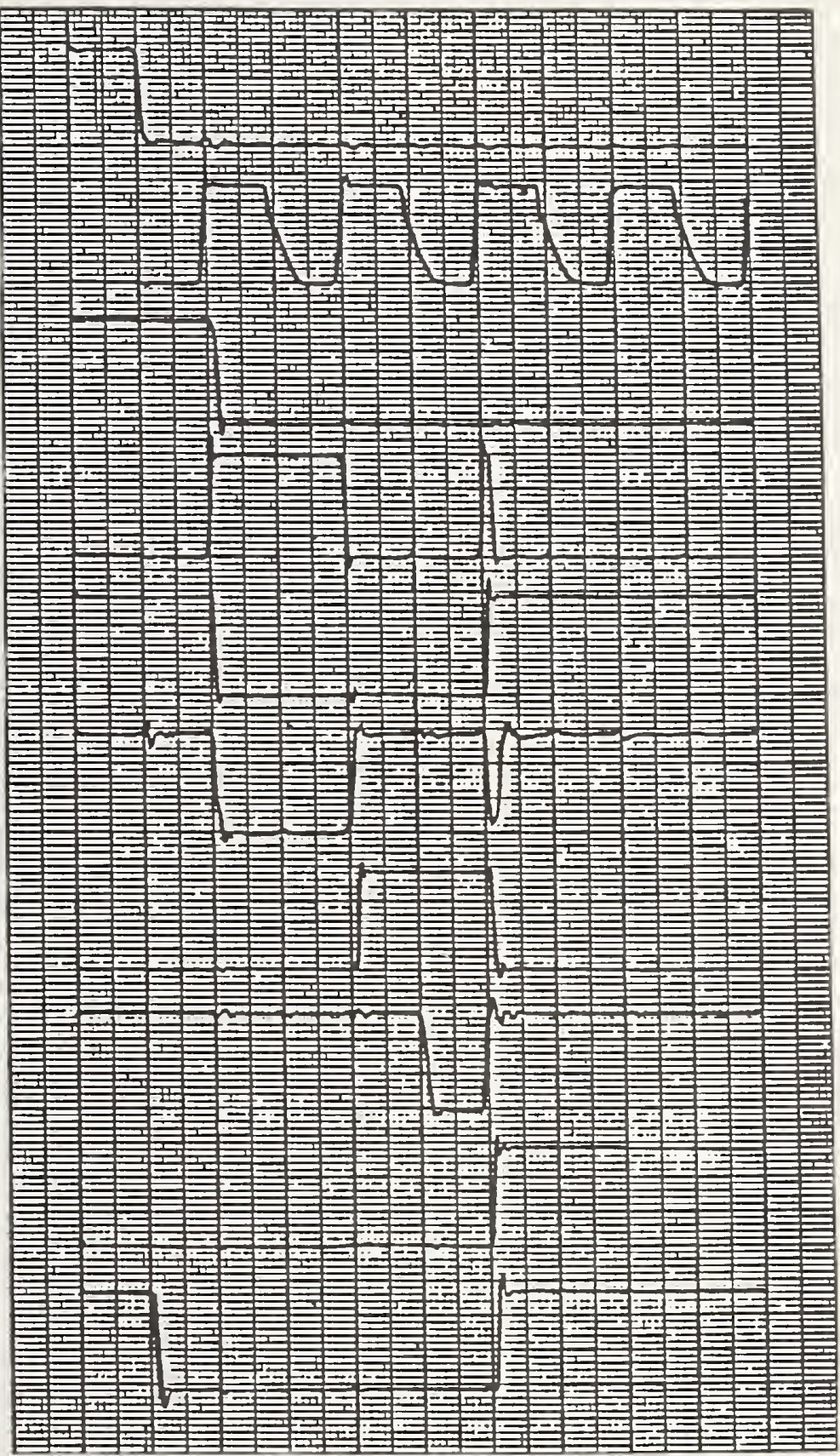

Figure 3-3. Timing diagrams for $1 \mathrm{MHz}$ repetition rate, $100 \mathrm{~ns}$ delay. 
Reset (U6-9)

Gated clock (U6-8)

$\overline{\text { TRIG }}(U 7-2)$

U7-6

U8-2

Delay (U9-15)

Delayed Pulse (U9-3)

U6-2

U9-6

U6-6

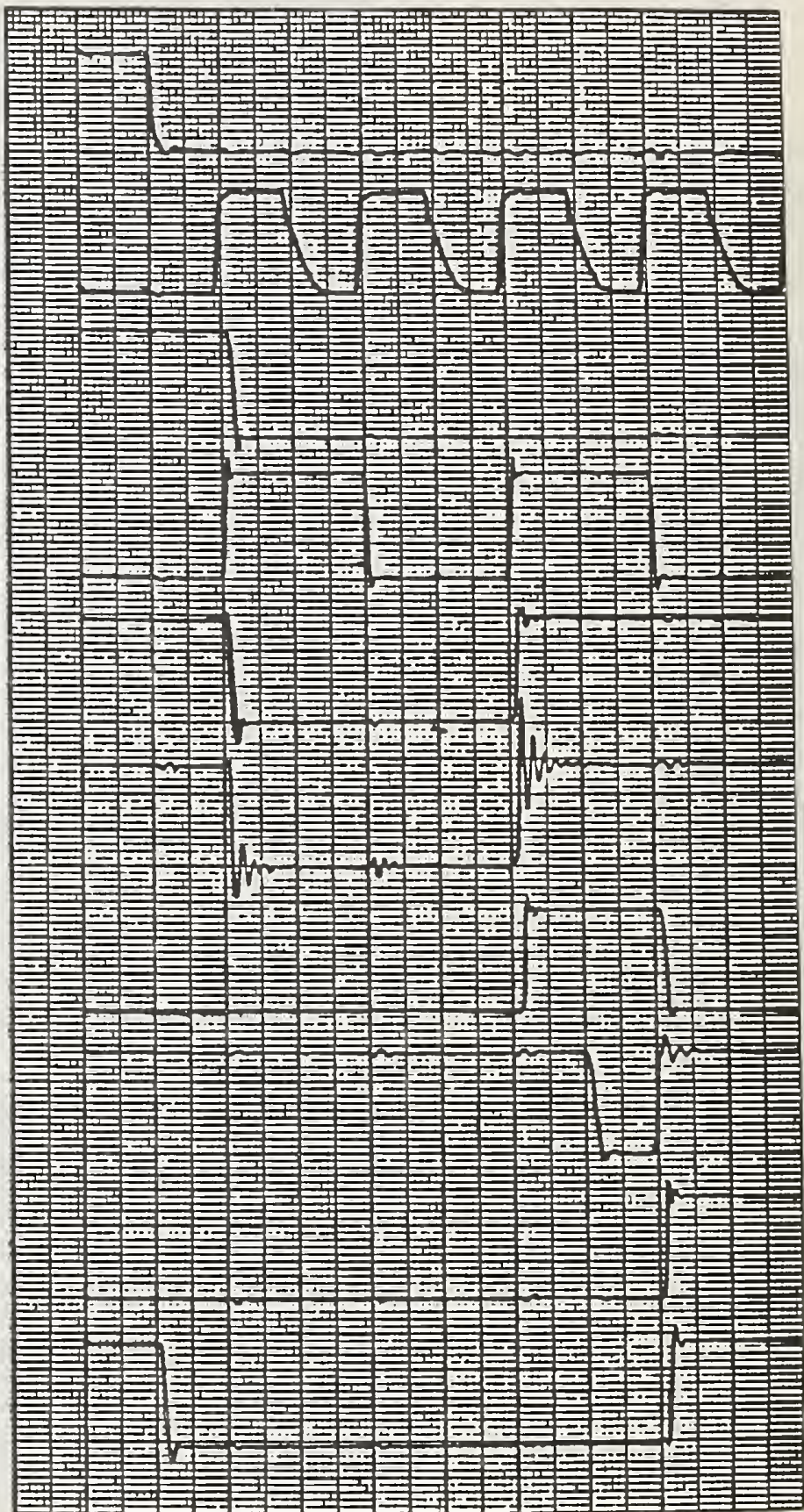

Figure 3-4. Timing diagrams for $1 \mathrm{MHz}$ repetition rate, 200 ns delay. 
Reset (U6-9)

Gated clock (U6-8)

$\overline{\text { TRIG }}(U 7-2)$

U $7-7$

บ8-7

Delayed pulse (U9-3)

U6-2

บ9-6

U6-6

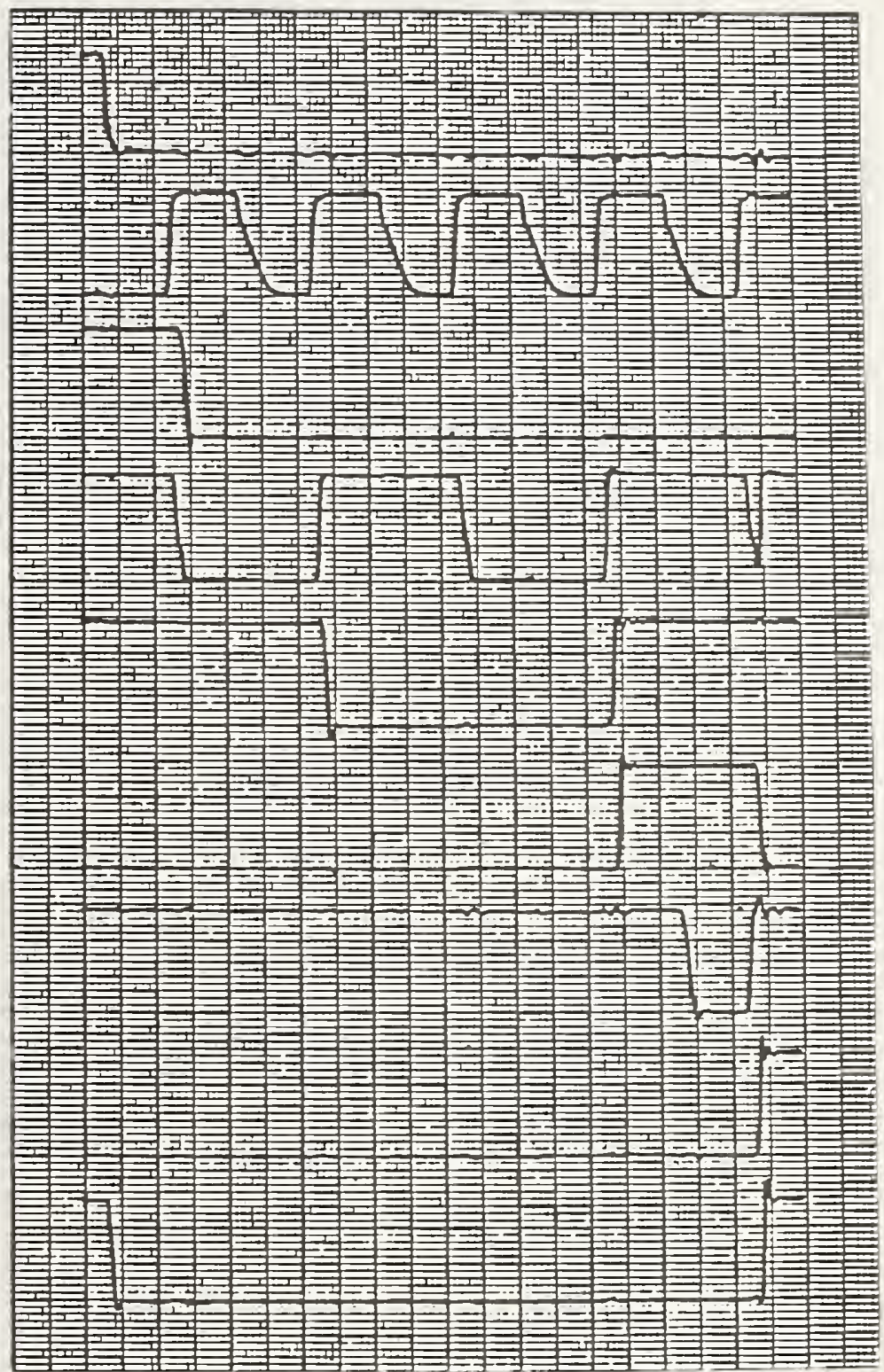

Figure 3-5. Timing diagrams for $1 \mathrm{MHz}$ repetition rate, $300 \mathrm{~ns}$ delay. 


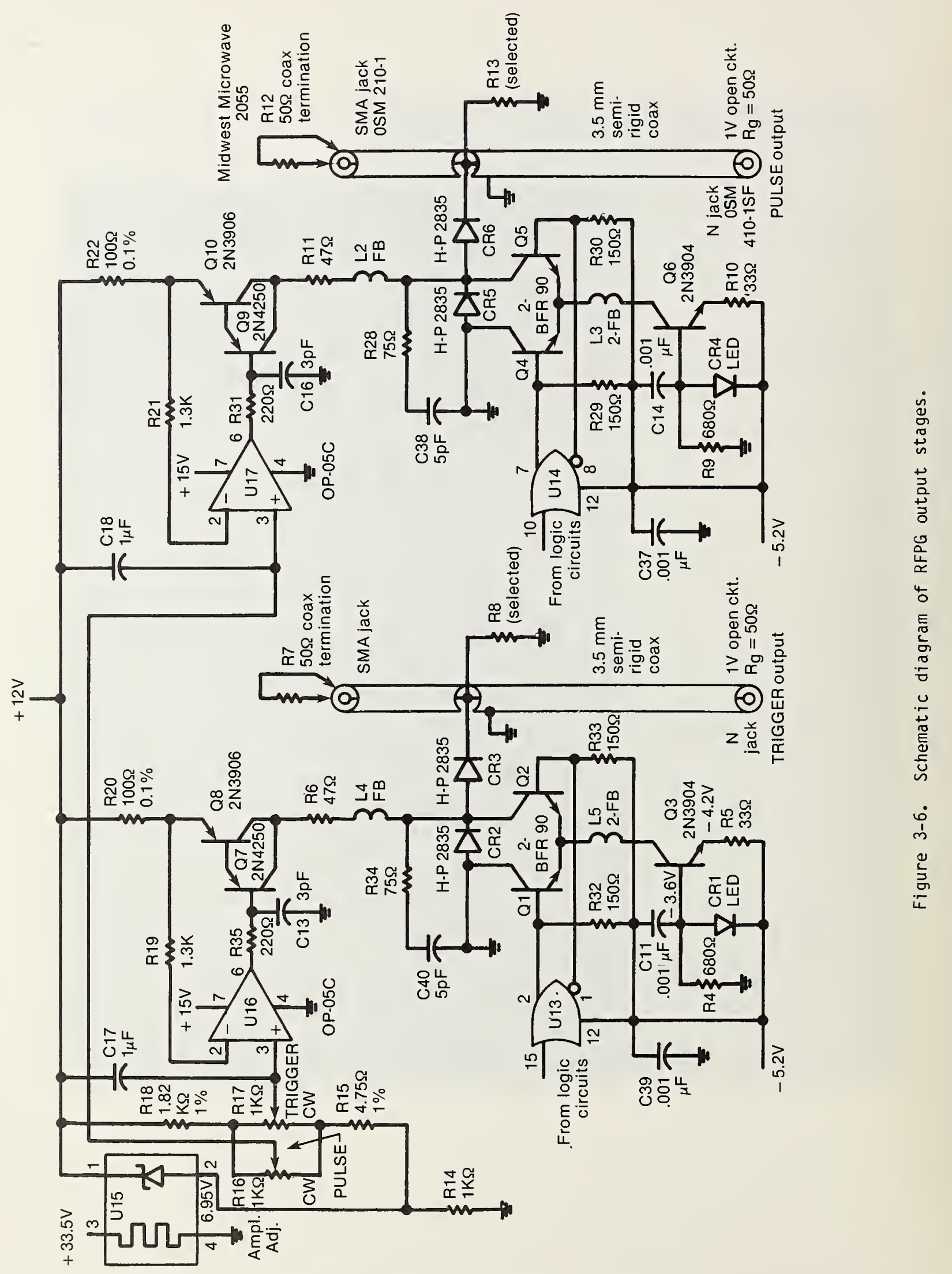




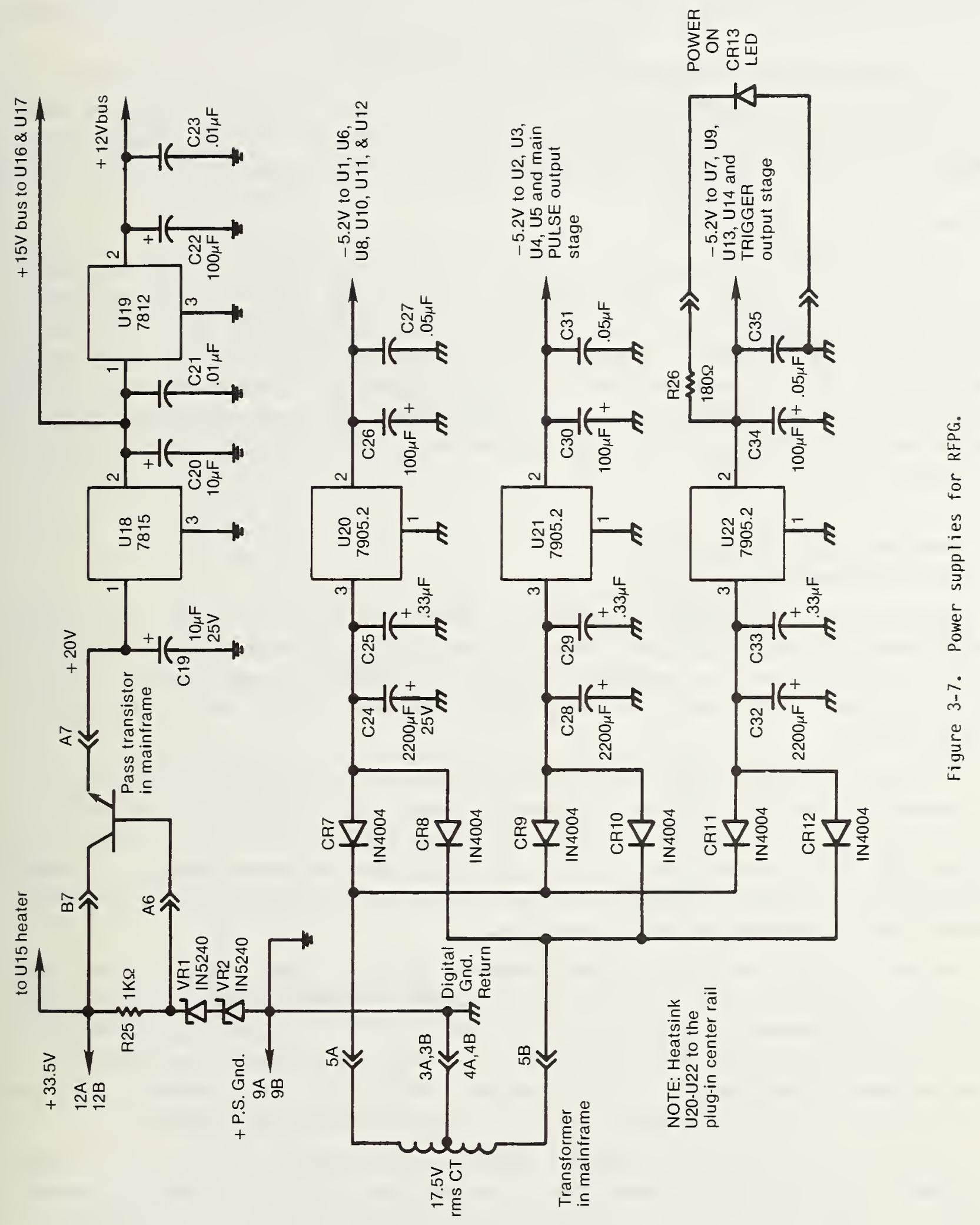


A less complex current source is used for the $30 \mathrm{~mA}$ emitter current for the differential switches Q1 and Q2. Q3 is the current source. CR1 is an LED which provides a $1.6 \mathrm{~V}$ reference voltage. This reference, minus Q3's base-emitter drop of $0.6 \mathrm{~V}$ sets the voltage across R5 at $1 \mathrm{~V}$. This voltage in turn forces the emitter current of Q3 to be $30 \mathrm{~mA}$. The collector current of Q3 is also approximately $30 \mathrm{~mA}$.

The other miscellaneous components are used primarily to control the switching transition. R32 and R33 improve the switching times of U13. L5 increases the output impedance of Q3 at high frequencies. R6 and L4 perform a similar function for Q7 and Q8. R35 and C13 eliminate a small amount of damped ringing present in Q7 and Q8. R34 and C40 eliminate a minor overshoot in the output waveform.

\subsection{Power Supplies}

Figure 3-7 is the schematic diagram of the power supplies for the generator. The requirements are: $+12 \mathrm{~V}$ at $45 \mathrm{~mA},+15 \mathrm{~V}$ at $55 \mathrm{~mA}$, and $-5.2 \mathrm{~V}$ at $1 \mathrm{~A}$ ( $1.4 \mathrm{~A}$ worst case). The TM-500 mainframe is used to supply raw $d c$ and ac power. The $+33 V$ supply is first preregulated to $+20 V$ using VR1, VR2, and a mainframe pass transistor. The $+20 \mathrm{~V}$ is then dropped to $+15 \mathrm{~V}$ using U18. U19 further drops the $+15 V$ to +12 V. $-5.2 V$ is supplied by three separate IC regulators, U20 through U22. The connections to the output stages and various ECL circuits are such as to evenly distribute the load currents. The top and bottom rails of the plug-in module housing the RFPG circuit card are used as heat sinks for U18 through U22.

4. Modeling and Computer Simulation

4.1 Use of Extended-SCEPTRE

The motivation for doing computer analysis and simulation of the RFPG is that in order to have a waveform generator standard, one needs a theoretical basis for how the electronics generate the various electrical waveshapes. Circuit modeling, using known or measured parameters for the circuit model, allows one to approximate the actual results and thereby predict the circuit performance from basic principles.

The circuit analysis programs developed for the RFPG were written using extended-SCEPTRE. The host computer for the extended-SCEPTRE software was a Control Data Corporation CYBER 170 , model 750 system. Waveshape generation by computer simulation of the RFPG was conveniently obtained by accessing the CYBER 170 via a graphics terminal over a multiplexed hardwired link at 9600 baud. A FORTRAN 66 program known as DISSPLA, available on the CYBER 170, provided the capability for plotting the transient analysis data obtained from a SCEPTRE run.

Besides the SCEPTRE application programs themselves, described in detail in the following sections, other procedural programis were utilized. For example, a FORTRAN program was available, known as PLOTSCP, which accessed the tape containing data from a SCEPTRE run, as well as the DISSPLA program, and provided options for title on graph, start and stop times, independent and dependent variables, number of available points, running average, vertical scaling, etc. Another program, similar to PLOTSCP, was utilized for outputting data via a terminal having a paper tape punch.

Figure 4-1 shows the outline of a typical SCEPTRE program. Between the /JOB and /EOR statements are typically a number of FORTRAN command instructions which set up the batch processing procedures needed by the CYBER $170 / 750$ system. The remainder of the program has somewhat of a fixed format with the various headings shown. Getting the proper entries under each of these headings is the main problem towards generating a successful SCEPTRE program. 


\section{PROGRAM NAME}

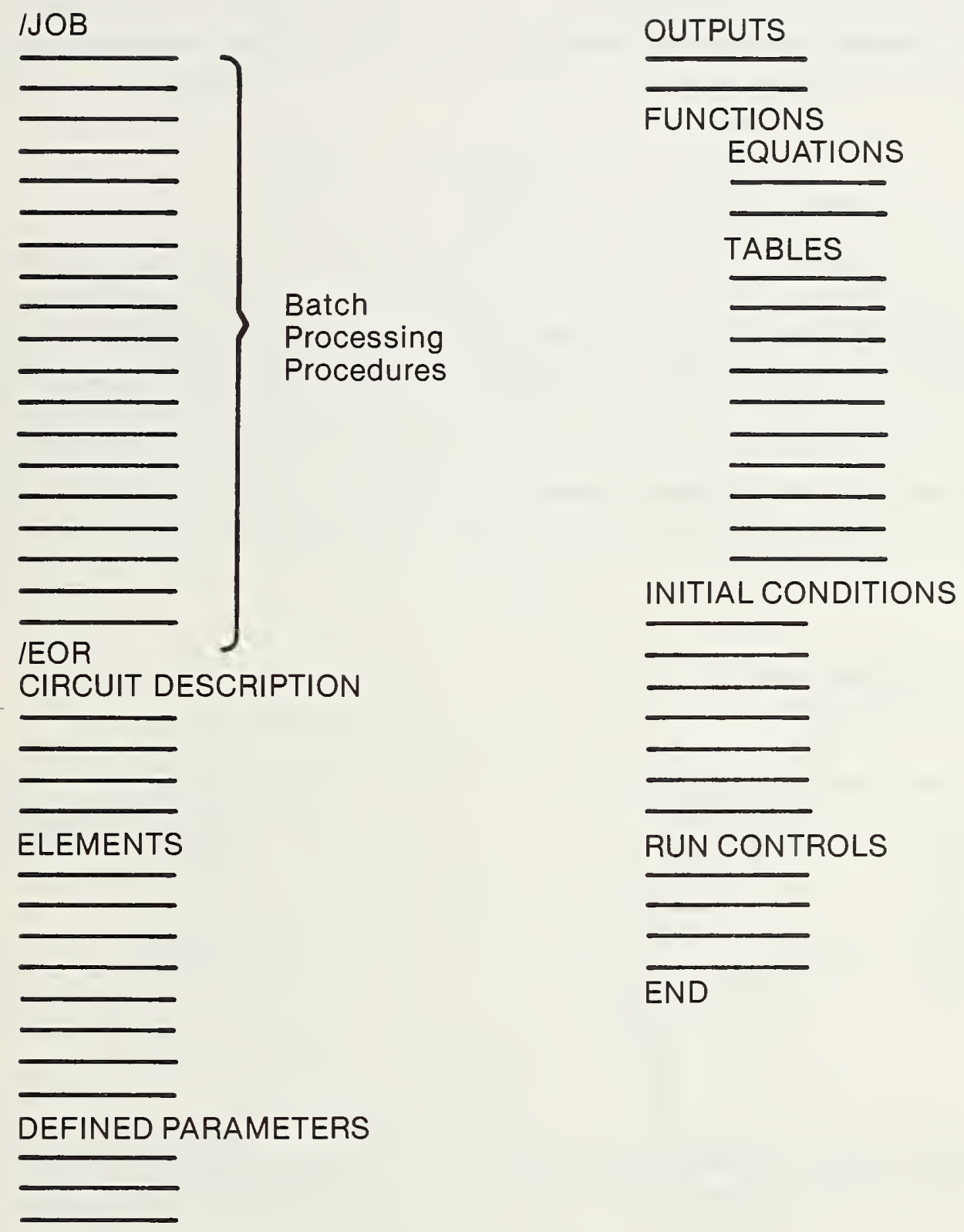

Figure 4-1. Typical SCEPTRE program. 
For the purpose of modeling the RFPG, the ability to utilize time-dependent, nonlinear circuit elements provided for in SCEPTRE was essential [13]. In particular, primary dependent current sources for ideal diodes proved to be especially convenient when combined with voltage or current dependent capacitors. Secondary dependent current sources with nonlinear, table-entered, dependencies permitted the development of an accurate model for the rf-switching transistors used in the output stage of the RFPG.

Run controls for the SCEPTRE programs were relatively simple in that transient solutions were the only mode of anarysis desired. Consequently, a stop time is the only required entry to specify the desired time interval for analysis. However, because the Runga-Kutta integration method was found to typically give the best results, this routine was also called for under the run controls section of the programs.

\subsection{Simple Diode Circuit Analysis via Program TEST}

As a simple example of using SCEPTRE for modeling transient response, figure 4-2 shows the SCEPTRE circuit for a diode in series with a load resistor, R. The diode is first modeled by its dynamic forward resistance, $r$, junction capacitance, $C$, and package inductance, L. El is the driving node voltage which is a time function, entered in the program by means of a table. By analogy to the RFPG output stage, this is a very simple model of the switching mode for the current sources and the output diode in series with the generator source resistor (in parallel with the output load resistor). Hence, by assuming appropriate initial conditions (voltage on $C$ and current through $L$ ), we can simulate the output voltage across $R$ for various input time functions of $E 1$.

E1T is the driving node voltage time function

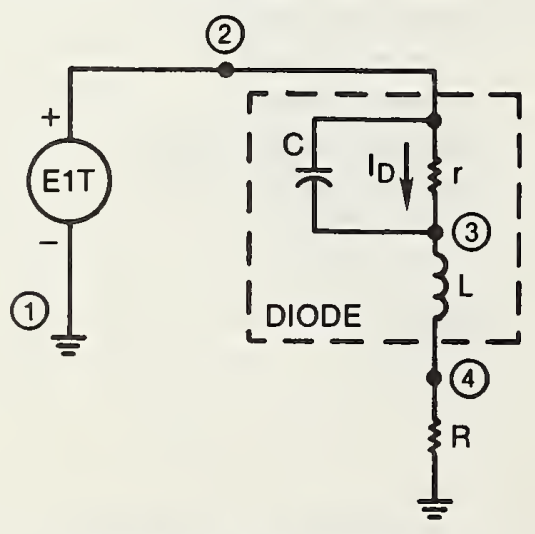

When using $I_{D}=I_{0}\left(\exp ^{\theta V_{D}}-1\right)$

$r=\left[\theta\left(I_{D}+I_{O}\right)\right]^{-1}$

$\cong \frac{1}{\theta I_{D}}$
Transfer function:

$$
\frac{V_{R}}{E 1}=\frac{\left(\frac{R}{R+r}\right)(r C s+1)}{\left(\frac{r}{R+r}\right) L C s^{2}+\left(\frac{L+R r C}{R+r}\right) s+1}
$$

Critical Damping:

or,

$$
r_{C}=\frac{L}{R C \pm 2 \sqrt{L C}}
$$

$$
R_{C}=\frac{L}{r C} \pm 2 \sqrt{L / C}
$$

For $R=0$ :

For $r=\infty$

$$
r_{C}=\frac{1}{2} \sqrt{L / C}
$$$$
R_{C}=2 \sqrt{L / C}
$$

Figure 4-2. Simple diode model for TEST program. 
Straightforward Laplace transform analysis of this circuit (assuming zero initial conditions) gives the transfer function,

$$
\frac{V_{R}}{E 1}=\frac{\left(\frac{R}{R+r}\right)(r C s+1)}{\left(\frac{r}{R+r}\right) L C s^{2}+\left(\frac{L+R r C}{R+r}\right) s+1},
$$

where $V_{R}$ is the voltage across $R$. For El a step function, it is well-known that the step response for such a second-order system will depend on the roots or pole locations of the denominator polynomial. These roots can, in general, be complex and are given by

$$
s_{1}, s_{2}=\frac{-\left(\frac{L+R r C}{R+r}\right) \pm \sqrt{\left(\frac{L+R r C}{R+r}\right)^{2}-4\left(\frac{r}{R+r}\right) L C}}{2\left(\frac{r}{R+r}\right) L C} .
$$

Critical damping occurs when the square root term is zero (equal real roots). Underdamping occurs when the quantity under the square root is negative (complex roots with both real and imaginary parts), and an overdamped response occurs when this quantity is positive (both roots real and unequal).

Further algebraic manipulations for the critically damped case provide the critical value for $r$,

$$
r_{C}=\frac{L}{R C \pm 2 \sqrt{L C}}
$$

or, for $R$,

$$
R_{C}=\frac{L}{r C} \pm 2 \sqrt{\frac{L}{C}} .
$$

For the extreme case where $\mathrm{R} \rightarrow 0$,

$$
r_{C}=\frac{1}{2} \sqrt{\frac{L}{C}},
$$

which is the well-known critical resistance of a parallel-tuned rLC circuit. Similarly, for the extreme case where $r \rightarrow \infty$,

$$
R_{C}=2 \sqrt{\frac{L}{C}},
$$

which is the well-known critical resistance for a series-tuned $R L C$ circuit. Letting $R=3 r_{C}$ in eq (3), so that $r_{c} /\left(R+r_{c}\right)=1 / 4$ in eq (2),

$$
r_{c 1}, r_{c 2}=\sqrt{\frac{L}{C}}, \frac{1}{3} \sqrt{\frac{L}{C}} .
$$

Typical values of $L$ and $C$ for the Schottky diodes used in the RFPG are 2 nH and 1 pF, respectively. Then, 


$$
\begin{aligned}
r_{c 1}, r_{c 2} & =\sqrt{\frac{2 \times 10^{-9}}{10^{-12}}}, \frac{1}{3} \sqrt{\frac{2 \times 10^{-9}}{10^{-12}}} \\
& =10 \sqrt{20}, \frac{10}{3} \sqrt{20} \\
& =44.72 \Omega, 14.91 \Omega .
\end{aligned}
$$

Corresponding $R$ values are $134.2 \Omega$ and $44.72 \Omega$.

Figure 4-3 shows the SCEPTRE program, TESTl, for analyzing the step response of the diode-load resistor circuit. As shown, El as a function of time is provided by table 1 which has five entries. By applying a negative $1 \mathrm{~V}$ step, the program thus simulates the output branch circuit of the RFPG (assuming negligible effects due to the $3.5 \mathrm{~mm}$ coaxial line). Because of the critical values chosen for $r$ (designated RS) and $R$ (designated RL), the initial conditions for the capacitor voltage and inductor current are the values given as $0.25 \mathrm{~V}$ and $0.01677 \mathrm{~A}$, respectively.

Figure 4-4 is a plot of the waveforms generated by program TEST1. As expected, these responses show critical damping of the R-r, L, C circuit described above. VRL, VRS, and VL are the voltage waveforms across $R L$, RS, and $L$, respectively. For the typical values used, it can be seen that the step response has died out in approximately 200 ps. Figure $4-5$ shows that with RL $=25 \Omega$ (the nominal value), the response is overdamped, settling in about $300 \mathrm{ps}$. With RL again at $44.72 \Omega$, but with a larger RS of $50 \Omega$, figure 4-6 displays the resulting underdamped waveforms.

The nonlinear I- $V$ characteristic of the diode, where its dynamic forward resistance varies inversely with the diode current, was then added to create the TEST2 program. Figures 4-7 and 4-8 show the typical characteristic for the particular Schottky barrier diode used in the RFPG [14]. Figure 4-9 is a listing of the TEST2 program which indicates how SCEPTRE allows the simple entry for the diode under ELEMENTS. The first argument inside the parenthesis is the value for $I_{0}$, the reverse "leakage" current, typically $100 \mathrm{nA}$. The second argument is the value for $\theta=\mathrm{e} / \mathrm{kT}$ which at room temperature $(300 \mathrm{~K})$ is the value 38.7. Note also the different initial conditions which must be satisfied in this case.

Figure 4-10 shows the resultant circuit waveforms with $r$ replaced by the diode equation. Since figure 4-5 shows an overdamped response for $r=R S \cong 15 \Omega$, figure 4-10 is somewhat startling at first. With a starting forward current of $0.0274 \mathrm{~A}(27.4 \mathrm{~mA})$, one would expect from figure 4-8 a more damped response since $r$ is typically less than $15 \Omega$ for diode currents of about 2 to $3 \mathrm{~mA}$ or more. However, figure 4-6 also supports the analysis that as $r$ increases, the response grows underdamped. Thus we see that the time-dependent variacion of $r$ in the case of the actual diode is such as to cause an undershoot in the negative step response, as the diode current cuts off.

Further investigation into the nonlinear effects of the Schottky diode used in the RFPG were pursued, as will be described in the following sections. As a final example of modeling the diode-load resistor output branch, however, figure 4-11 shows the listing for program TEST3 in which E1, the driving node voltage, is set up via table 1 to approximate the "double ramp" type of voltage waveform actually observed in the RFPG. Figure 4-12 gives a plot of the resultant waveforms generated by program TEST3. The time base is five times longer than before for TEST2 and the values for $C$ and $L$ changed by a factor of four. Nevertheless, the undershoot in the response (VRL) of the simulated waveform is seen to much more clearly approximate the actual observed output waveform (see fig. 2-7). 


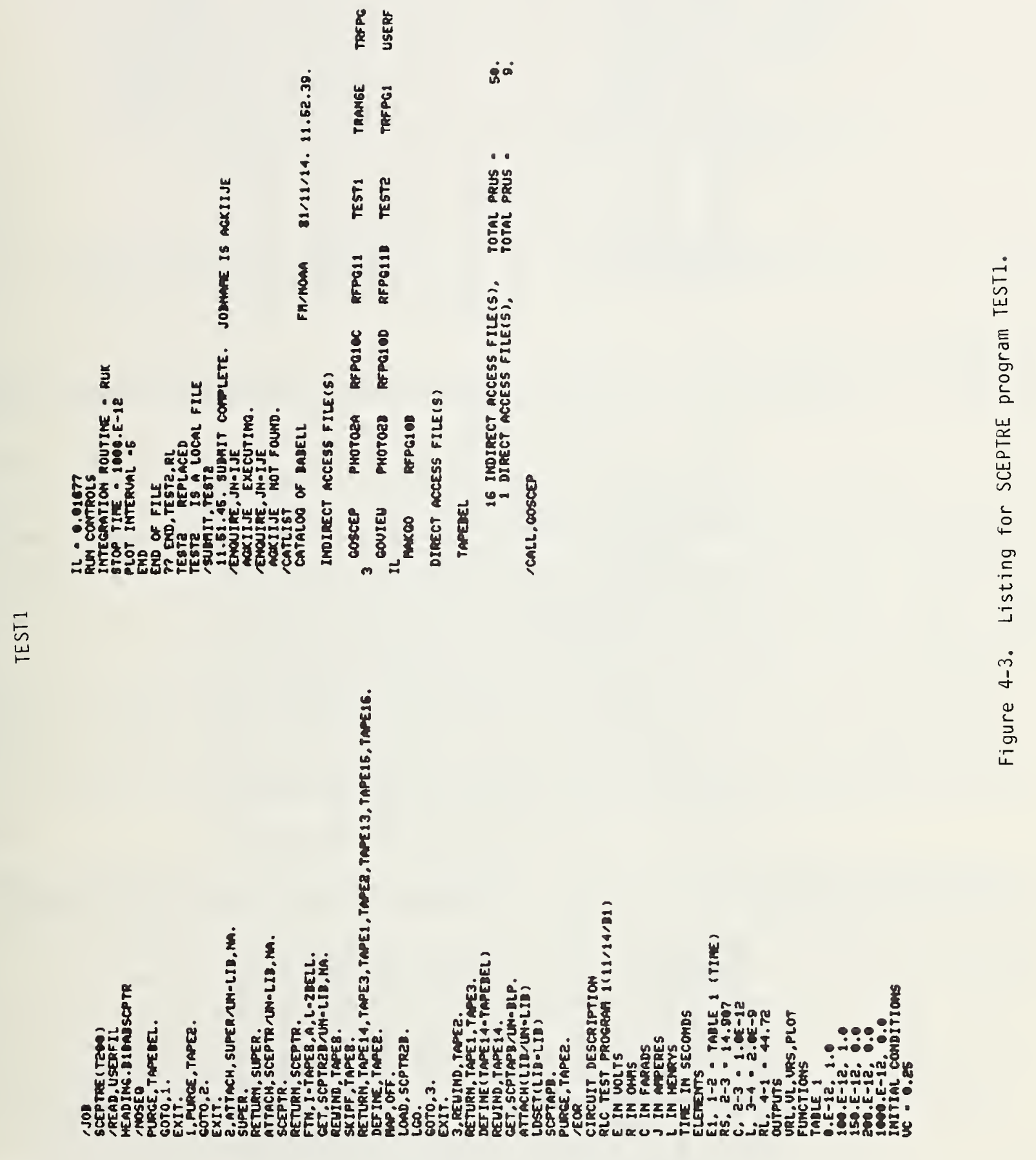




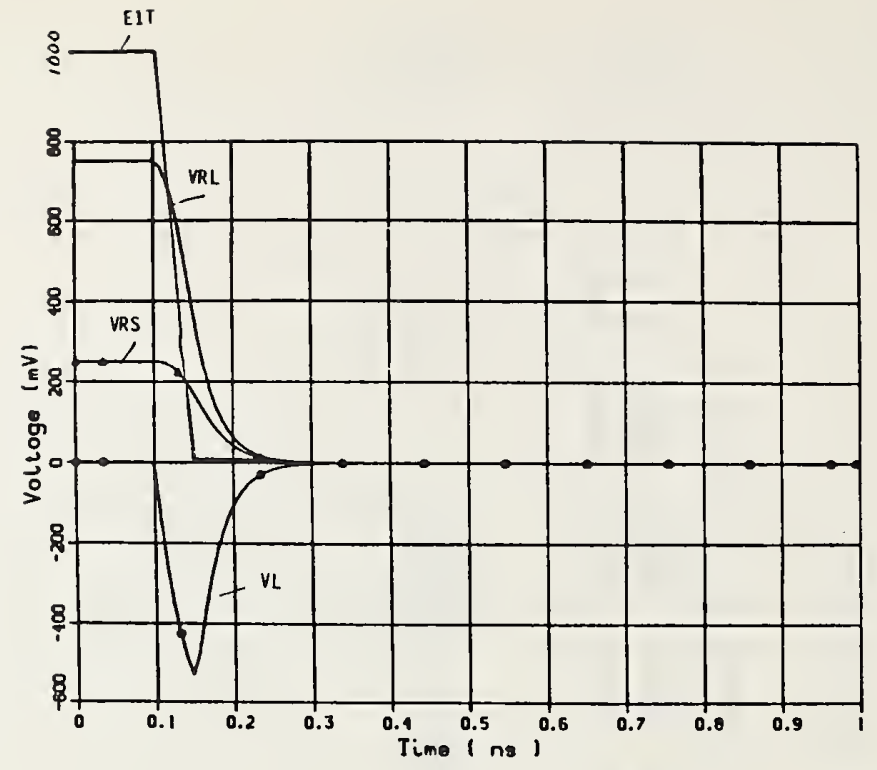

Figure 4-4. Step response from TESTl program. Critical damping with RS $=14.91 \Omega$ and $R L=44.72 \Omega$.

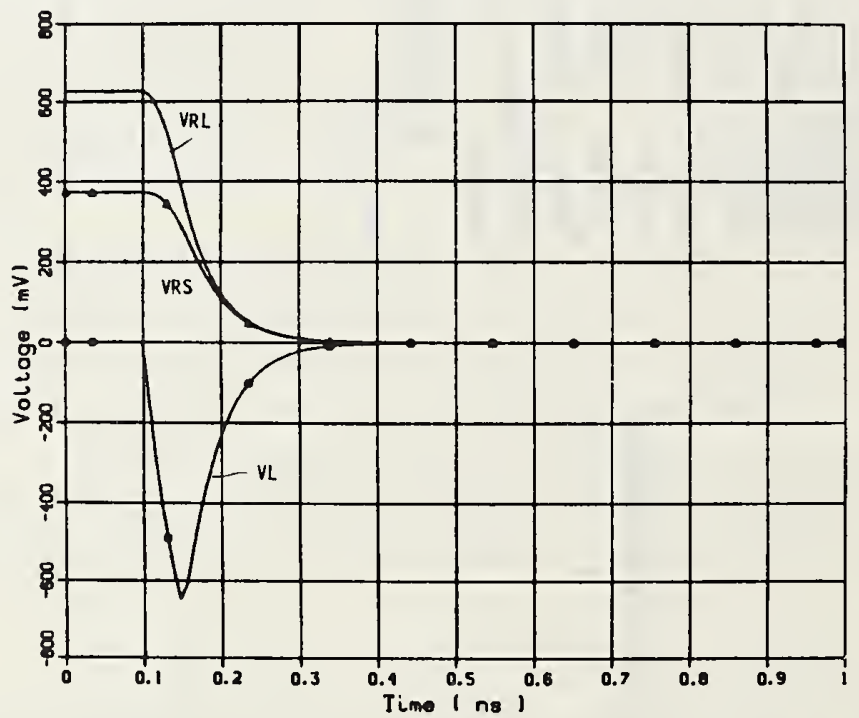

Figure 4-5. Step response from TESTl program. Overdamping with RS $=14.91 \Omega$ and $\mathrm{RL}=25.0 \Omega$.

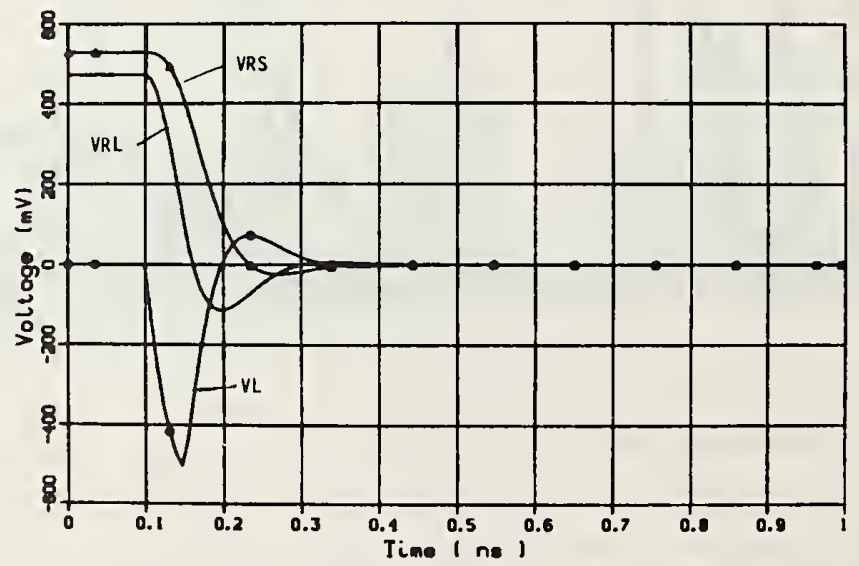

Figure 4-6. Step response from TEST1 program. Underdamping with RS $=50.0 \Omega$ and RL $=44.72 \Omega$. 


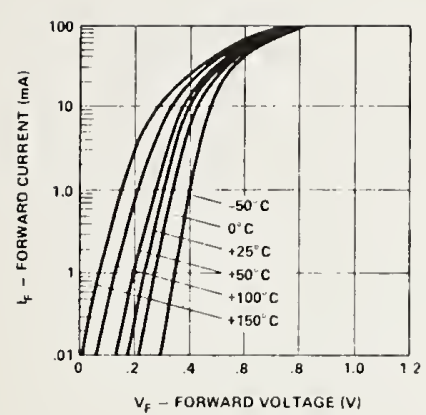

Figure 4-7. I-V curve showing typical temperature variations for $5082-2835$ Schottky diode.

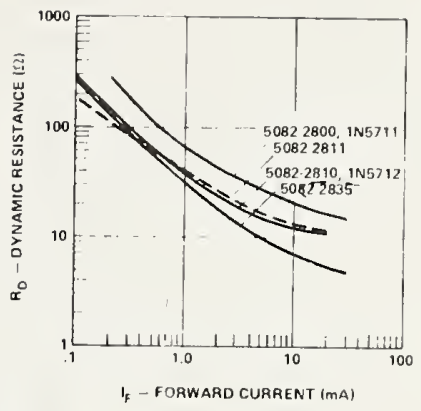

Figure 4-8. Typical dynamic resistance (RD) versus forward current $\left(I_{F}\right)$.

Thus it is that further modeling of the nonlinear RFPG output stage components was felt to be needed in order to derive the approximate driving node voltage waveform.

\subsection{Initial Modeling via Program RFPG}

As described in sections 2.2 and 3.2, the output stage of the RFPG consists of positive and negative current sources that are steered by means of transistor switches (see figs. 2-5, 2-6, and 3-6). An initial model that was used for simulating the output stage is shown in figure 4-13. Ideal diode current JD1 and associated components $\mathrm{Cl}, \mathrm{Ll}$, and $\mathrm{C} 4$, together with $\mathrm{R} 3$, form the output branch of the generator circuit. Similarly, JD2, C2, L2, and C5 represent the CR2 diode of figure 2-6 (CR2 and CR5 of fig. 3-6). Cl and C2 are the voltage dependent junction capacitance, L1 and L2 are the package inductance, and C4 and C5 are the package capacitance of the diodes [14]. R2 and C3 are the filter components for controlling part of the undershoot in the output waveform. $\mathrm{Jl}$ and $\mathrm{J} 2$ are the nominal $20 \mathrm{~mA}$ and $30 \mathrm{~mA}$ positive and negative constant current sources (33 mA value used in SCEPTRE program for J2). To simulate the action of the switching transistors time-dependent resistors R1T and R2T are utilized.

Several versions of the program for this model were developed in the process of experimenting with component values, appropriate initial conditions, and the switching times/resistance levels of the R1T and R2T resistors. Figure 4-14 shows the SCEPTRE program, RFPG10, which yielded fairly useful results. In the topological listing under ELEMENTS, the voltage dependence of $\mathrm{Cl}$ and $\mathrm{C} 2$ is provided by table 2 which uses typical values provided by the manufacturer's data sheet [14]. Tables 1 and 3 provide the resistance versus time dependence of R1T and R2T, approximating the complementary switching action of the BFR $90 \mathrm{rf}$ switching transistors. These devices are rated for a current gainbandwidth product, $\mathrm{f}_{T}=5 \mathrm{GHz}$ (typical) at $\mathrm{I}_{\mathrm{C}}=14 \mathrm{~mA}$. Under INITIAL CONDITIONS are shown the two initial inductor currents and five initial capacitor voltages.

Figure 4-15 gives the resultant plots of the transient step-like output voltage across $R 3$ and driving node voltage across C5 for the RFPG10 program. The flatness of the waveforms at $t=0_{+}$indicates that the assumed values of the initial conditions is good. The wrinkle in the transition region at about $0.45 \mathrm{~ns}$ is for the VC5 waveform which is identified by the black dots. There is a considerable (on the order of 20 percent) undershoot in the VR3 waveform which does not approximate reality very well. However, as demonstrated in section 4.2, this difference is probably due to lack of the 


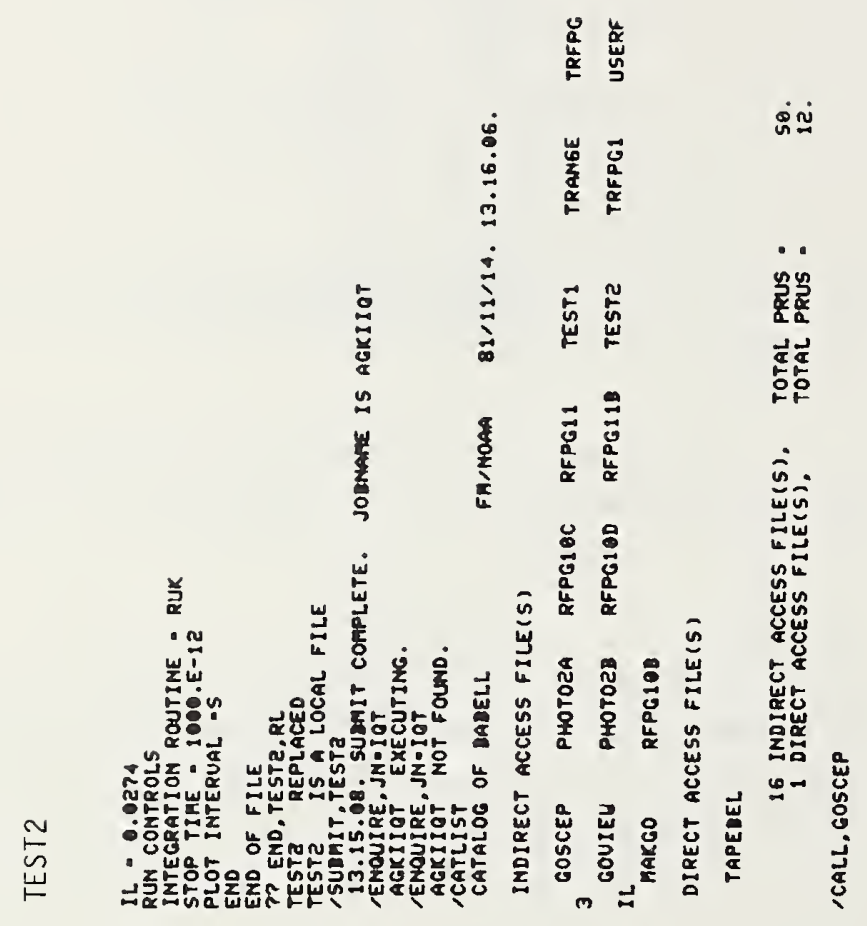

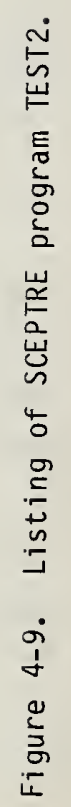




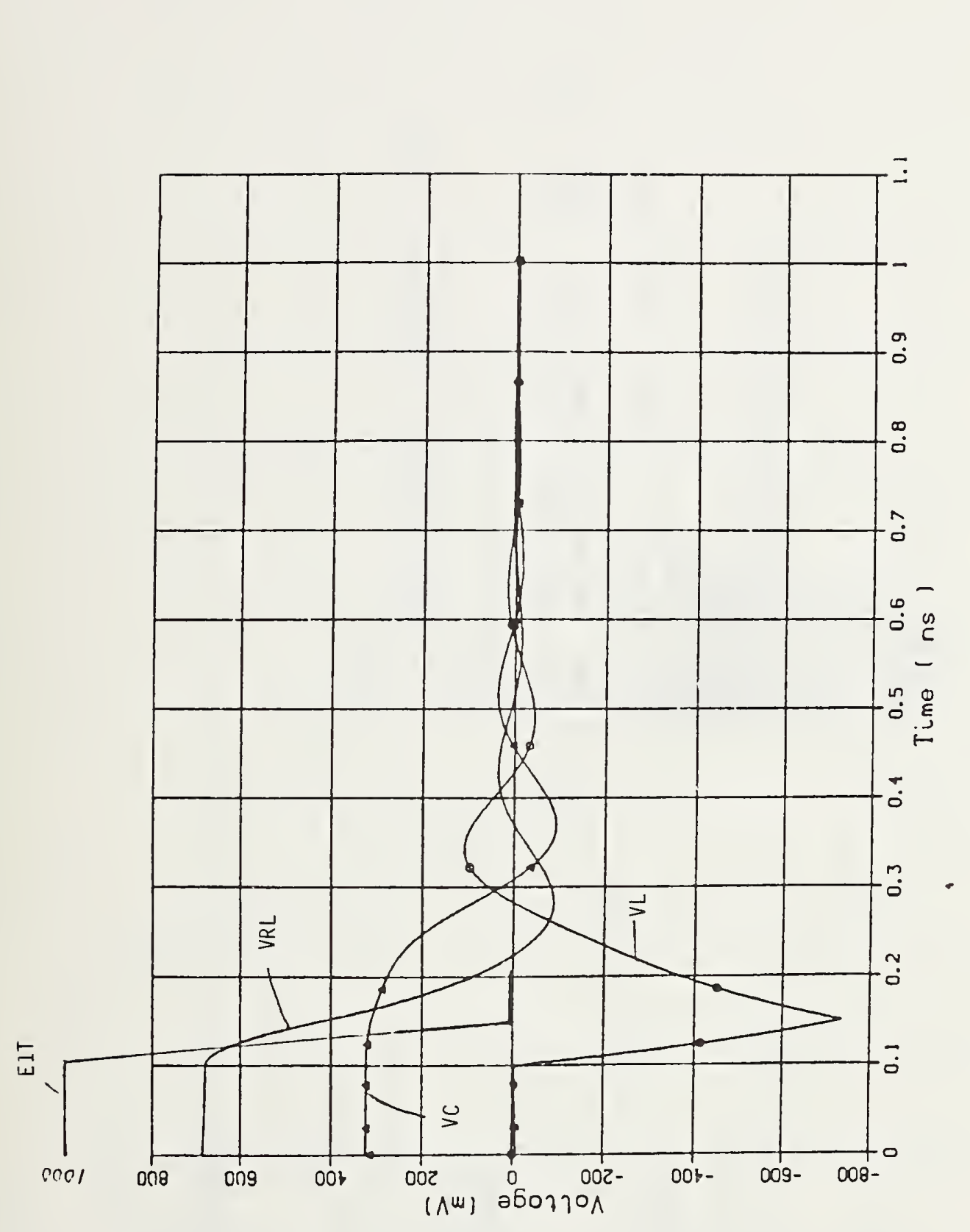

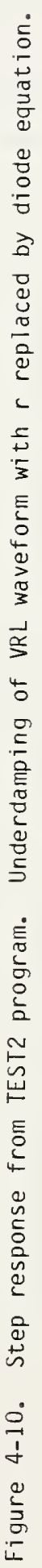




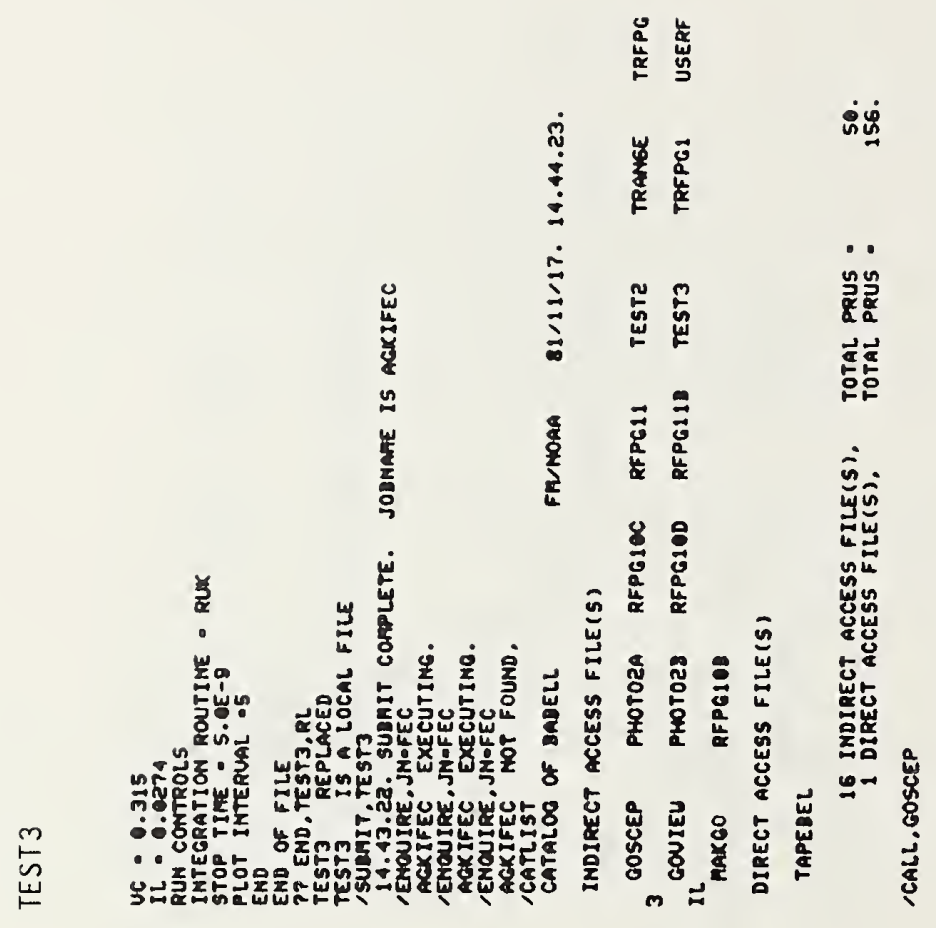

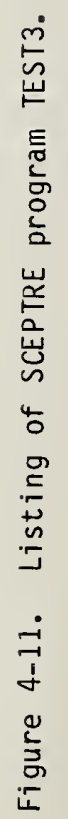

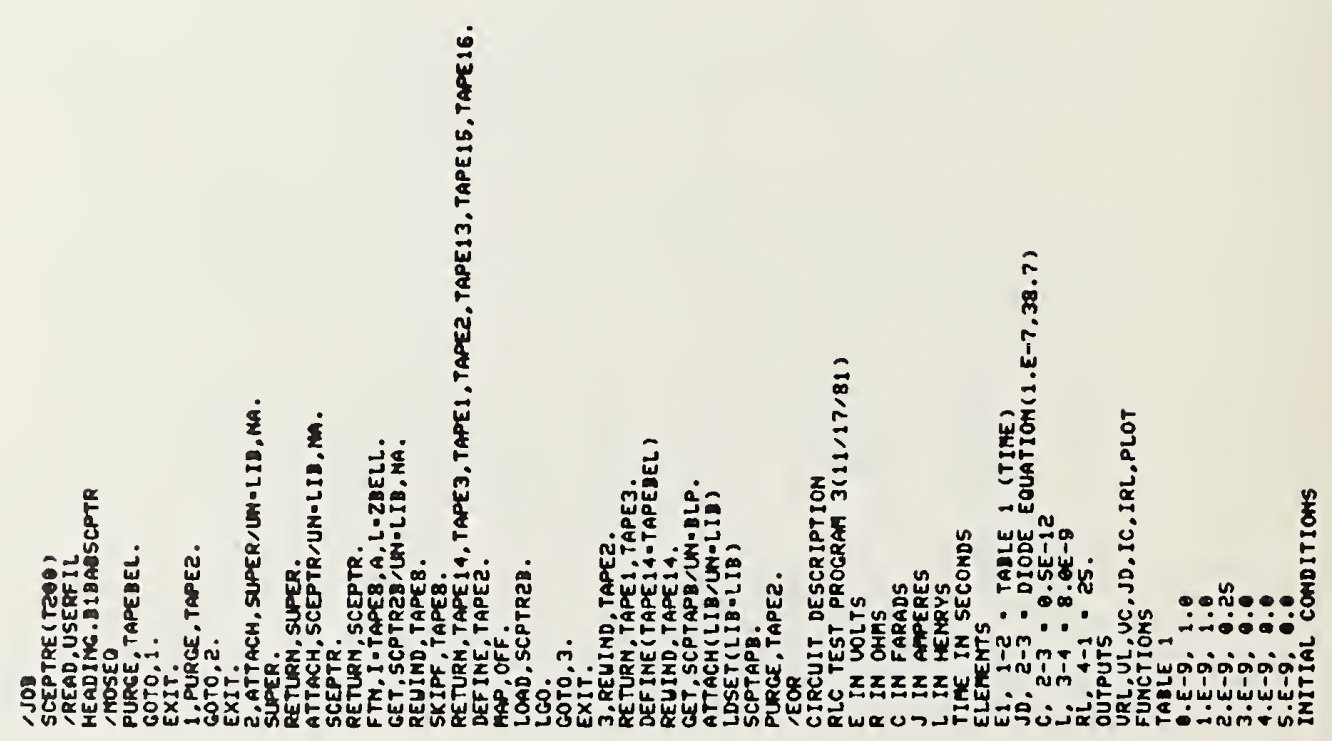




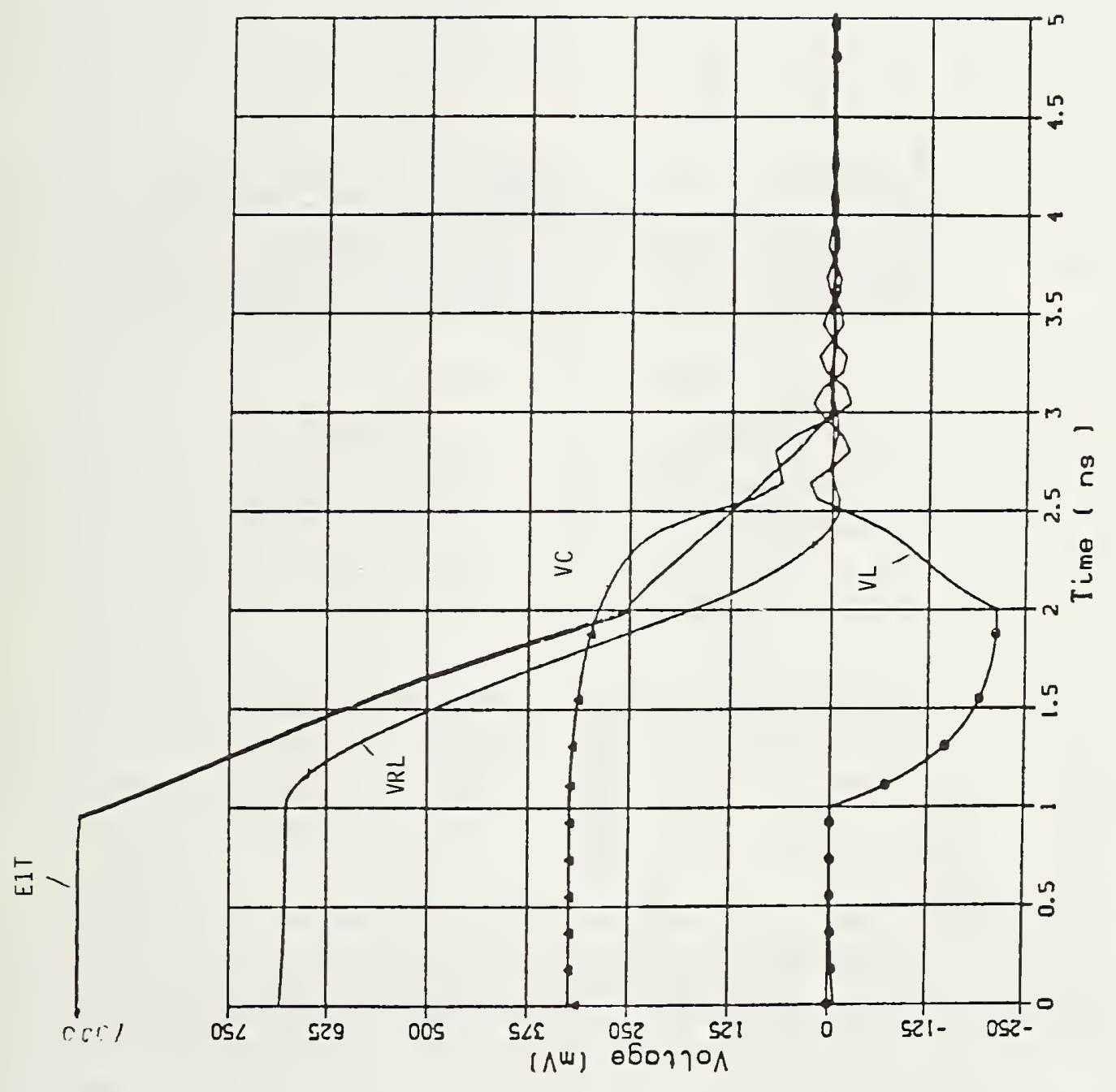

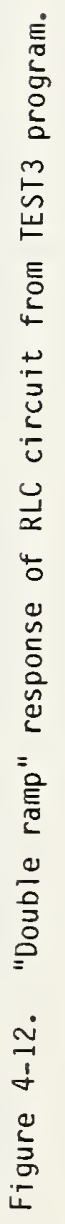




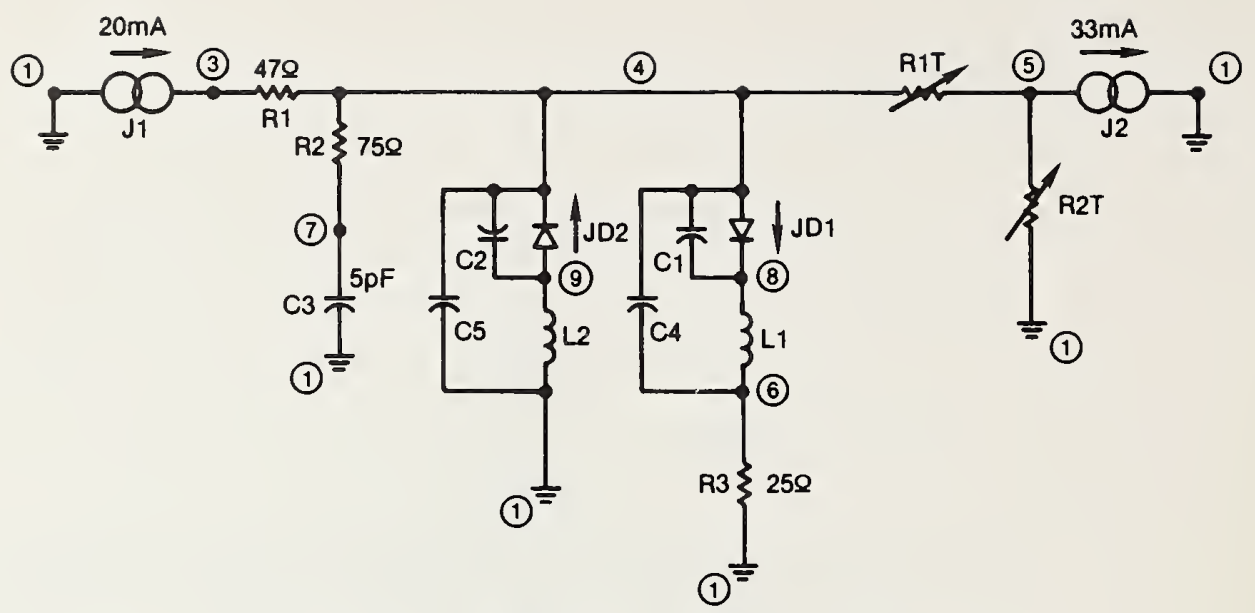

Figure 4-13. An initial RFPG program model.

proper waveform for VC5. This poor approximation of the actual driving node voltage in turn is due to the 300 ps switching from $100 \mathrm{k} \Omega(100 \Omega)$ to $100 \Omega(100 \mathrm{k} \Omega)$ for R1T (R2T). Nevertheless, the simulation does show that with such switching speed, a faster transition fall time than 600 ps could be realized.

\subsection{ECL Drive and Transistor Switching Model via Program TRAN}

Simple circuit modeling of the RFPG output stage, as described briefly in sections 4.2 and 4.3 , reveals that the 600 ps transition duration observed in the actual step-like output waveform is limited by the speed of the switching elements more than by the properties of the output currentsteering diodes. Consequently, work was undertaken to develop a model for the rf switching transistors used in the design of the RFPG and their associated complementary ECL input drive signals.

Figure 4-16 shows the schematic diagram of the SCEPTRE circuit used for this purpose. Node 14 corresponds to node 4 of the RFPG program with R9 at the collector of Q2 representing the load of the RFPG output network. The rf switching transistors, Q1 and Q2, are simulated by using a modified Geller, Mantek, and Boyle (GMB) model for large-signal switching [15]. The J3 constant current source corresponds to $\mathrm{J} 2$ in the RFPG program. The remaining components provide the simulation of the ECL OR gate drive of the actual RFPG circuit.

Regarding the model used for the individual transistors, figure 4-17 shows a simple commonemitter equivalent circuit that was developed for the BFR 90 transistors. The primary difficulty overcome with the use of this model is the effect of the nonlinear base-to-emitter characteristics of the transistor when driven with low driving source impedances. The basic GMB model represents the $B^{\prime}-E$ junction, from charge control theory, as the nonlinear forward resistance of the base-emitter junction $r_{B^{\prime}} E$ (as employed in section 4.2 for the Schottky barrier diode analysis), in parallel with two capacitors. One capacitor is the usual diffusion capacitance of the forward-biased base-emitter junction. The other capacitor is a feedback capacitance due to the component of base current that appears when the collector-to-base depletion layer varies as a function of collector base voltage. The feedback effects of the collector-to-base space charge capacitance are then directly contained in the solution of base current versus time when a finite load resistance ( $R 3$ in fig. 4-17) exists. An analysis to support this modified GMB model can be made by noting that for the forward biased baseemitter junction, 


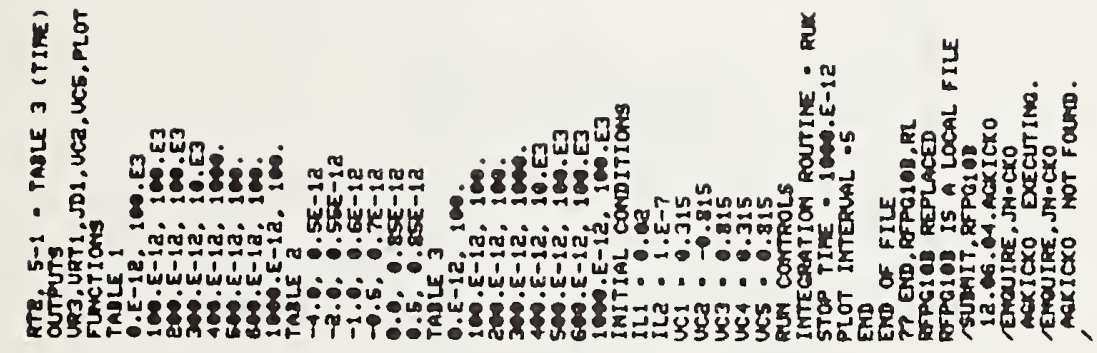

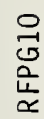

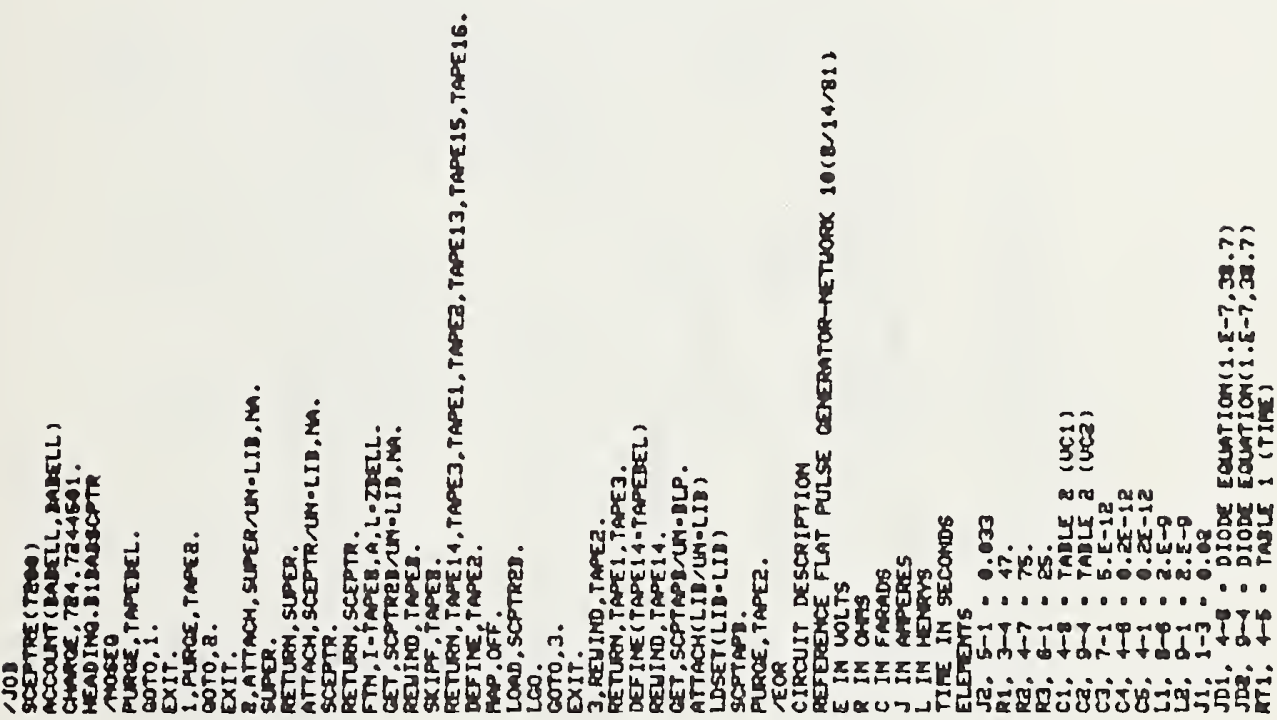




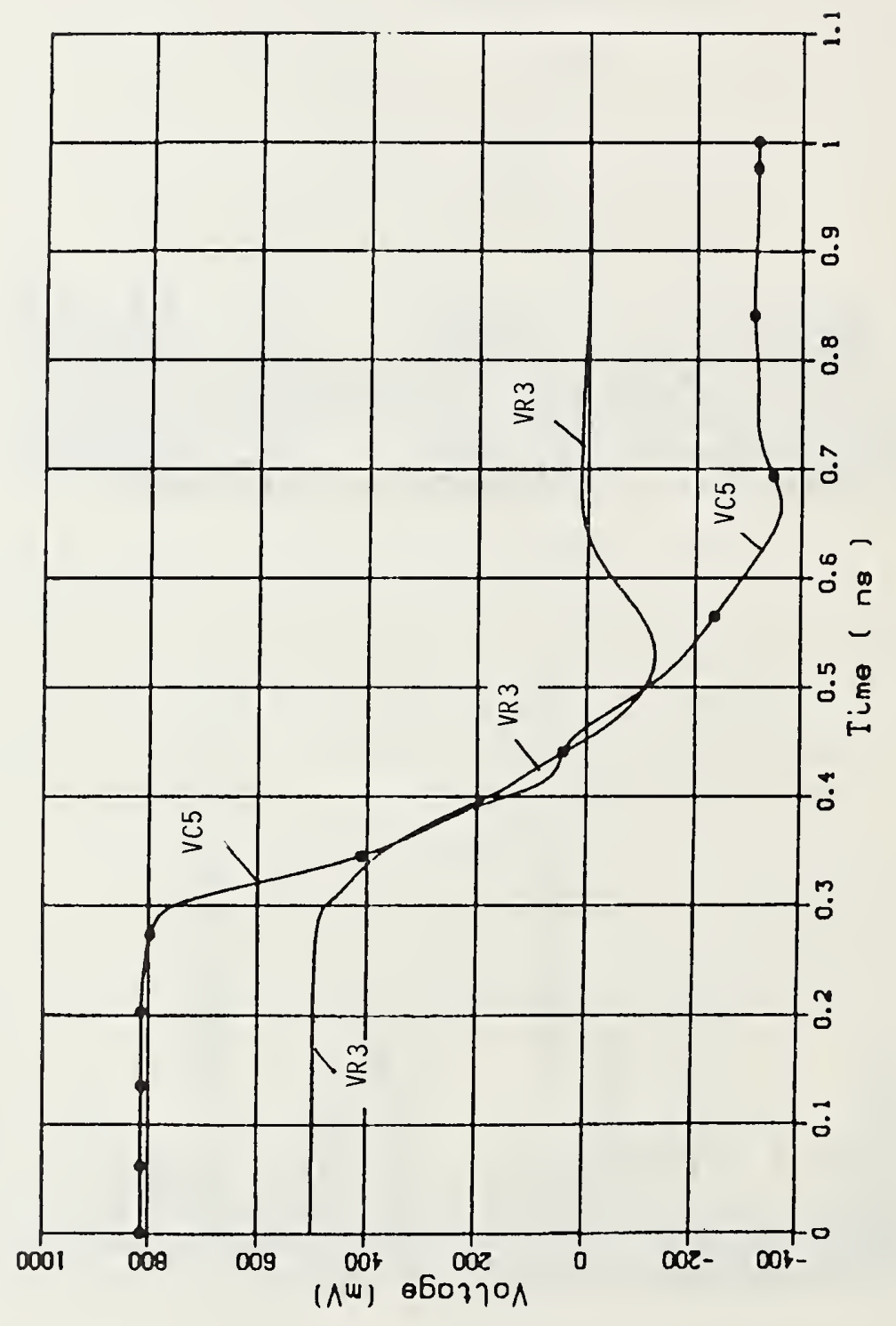

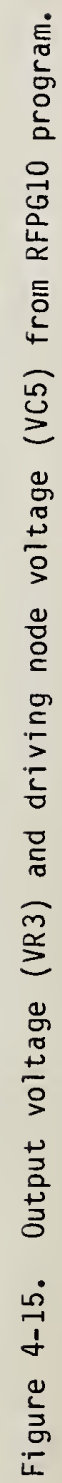




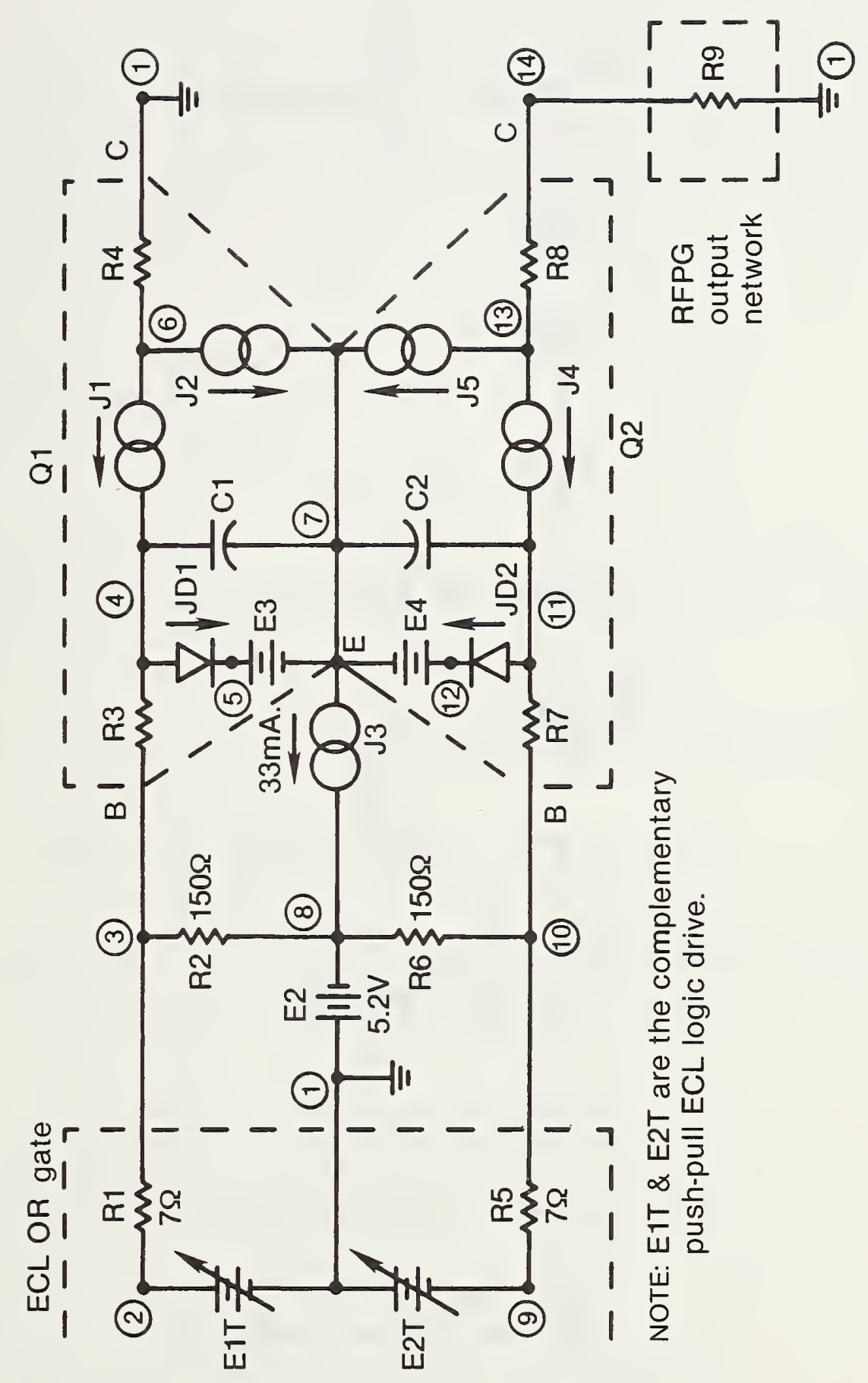

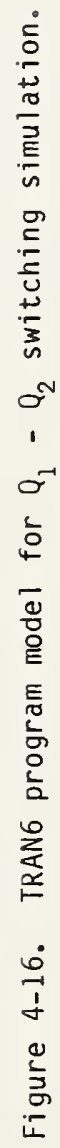




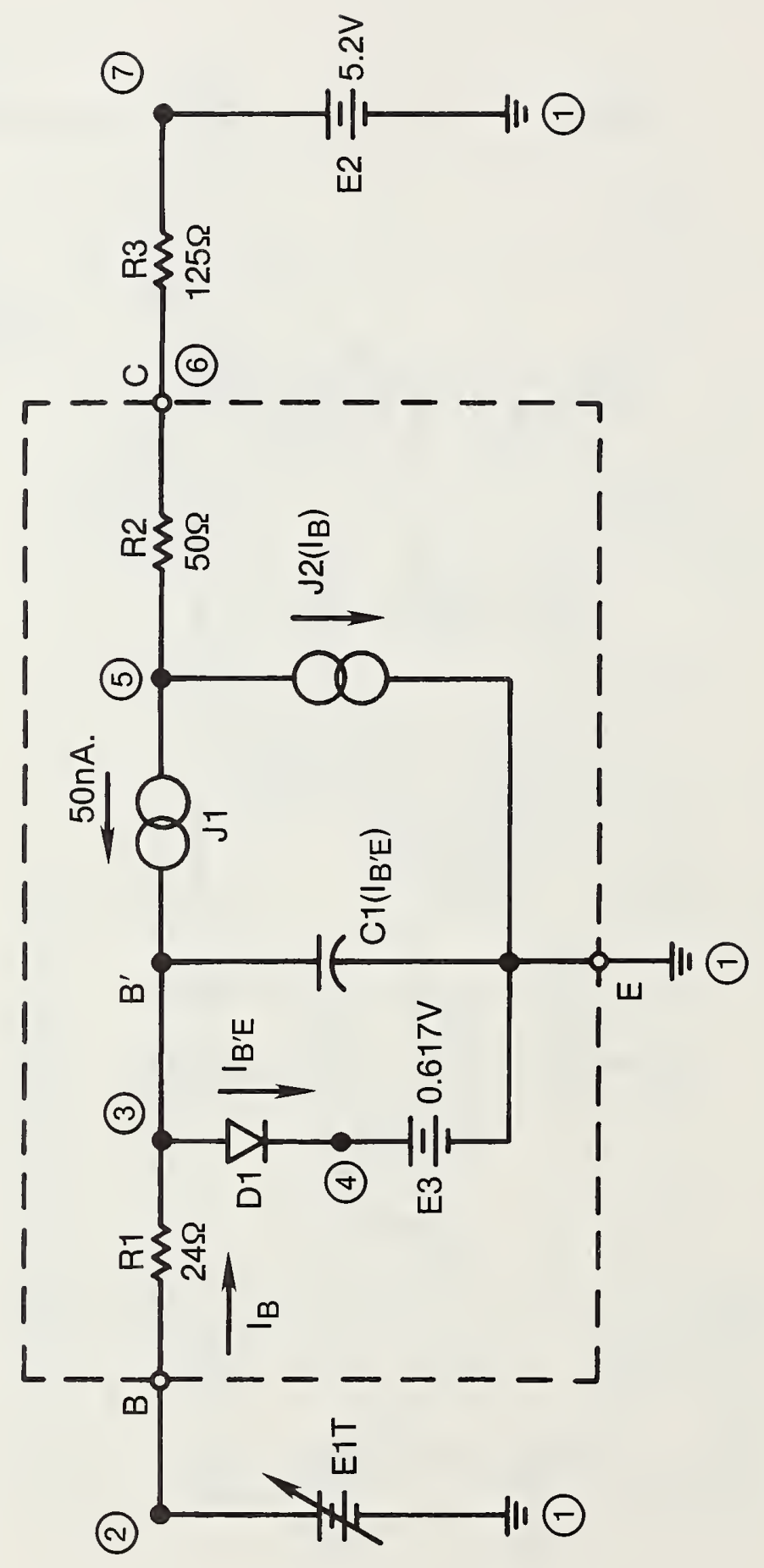

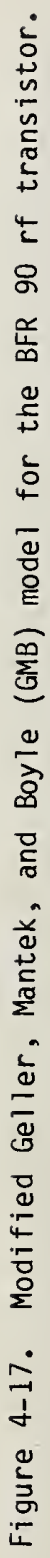




$$
I_{B^{\prime} E}=I_{0}\left[\exp \theta\left(V_{B^{\prime} E}-E 3\right)-1\right]
$$

so that

$$
\frac{1}{r_{B^{\prime} E}}=\frac{d I_{B^{\prime} E}}{d V_{B^{\prime} E}}=\theta\left(I_{B^{\prime} E}+I_{0}\right),
$$

where $\theta=e / k T=38.7$ at $T=300 \mathrm{~K}, I_{0}$ is the base-emitter reverse saturation current, and $E 3$ is an offset voltage described below. It is well known that when the junction transistor is switched by means of a large step of base-current, but does not saturate, the collector current is approximately an exponential function of time [16]. The nonlinear GMB model shown in figure 4-17 simulates this type of response by means of the time constant,

$$
\tau_{B^{\prime}}=r_{B^{\prime} E} C 1
$$

which is considered to be invariant over the entire base current excursion. Consequently, $\mathrm{Cl}$ is seen to be a function of the nonlinear base-emitter current, since

$$
C 1=\frac{\tau_{B^{\prime}}}{r_{B^{\prime} E}}=\theta \tau_{B^{\prime}}\left(I_{B^{\prime} E}+I_{0}\right) \text {. }
$$

Although the nonlinear network elements are constrained to maintain $\tau_{B^{\prime}}$ invariant, the dynamic impedance seen looking into the base-emitter terminals is continuously variable during the resulting transient, as described in reference 15. Appendix $C$ describes the measurement set-up and data taken for determining an estimated value of $\tau_{B^{\prime}}$ for the BFR 90 transistor.

The forward-biased, base-emitter diode is thus modeled as before, except for an offset voltage $E 3=0.617 \mathrm{~V}$, which was determined by measurement of the BFR 90 base-emitter I-V characteristics, as shown in figure 4-18. For the ideal diode (see fig. 4-2),

$$
V_{D}=\frac{1}{\theta} \ln \left[\frac{I_{D}}{I_{0}}+1\right] .
$$

Increasing the vertical scale (current sensitivity) in figure 4-18 shows that at $I_{B}=10 \mu A, V_{B E}$ $\cong 730 \mathrm{mV}$. Using $\theta=38.7$ as before and $I_{0}=126 \mathrm{~mA}$ (average of reverse saturation current readings taken with Keithley Model 150A nanoameter), then

$$
V_{D}=\frac{1}{38.7} \ln \left[\frac{10,000}{126}+1\right] \cong 113 \mathrm{mV} \text {. }
$$

By neglecting the voltage drop of $I_{B}$ through the bulk resistance $r_{B B}$ at the $10 \mu A$ level (see fig. 4-19), then

$$
E 3=E_{0 F F S E T}=V_{B E}-V_{D}=730-113=617 \mathrm{mV} .
$$

The general expression for the static base-emitter I-V characteristic is given by

$$
V_{B E}=I_{b^{\prime}} r_{B B^{\prime}}+V_{D}+E_{\text {OFFSET }}
$$




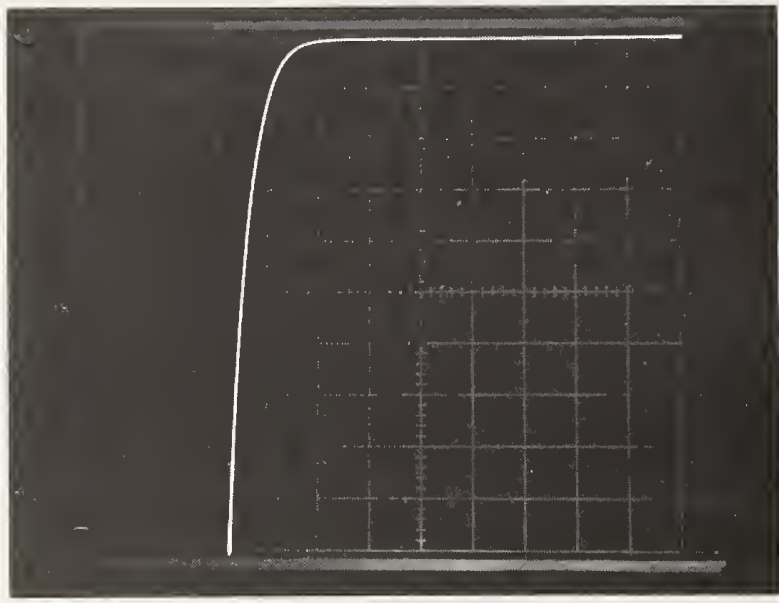

Figure 4-18. Typical BFR 90 base-emitter I-V characteristic. Vertical: $100 \mu \mathrm{A} / \mathrm{div}$. Horizontal: $100 \mathrm{mV} / \mathrm{div}$. Collector circuit: $V_{C C}=4.97 \mathrm{~V}$, $\mathrm{R}_{\mathrm{L}}=150 \Omega$.

so that $r_{B B^{\prime}}$ can be found from rearranging eq (13) and using eq (12) to give

$$
r_{B B^{\prime}}=\frac{V_{B E}-E_{0 F F S E T}-V_{D}}{I_{B}}=\frac{V_{B E}-E_{0 F F S E T}-\frac{1}{\theta} \ln \left[\frac{I_{B}}{I_{0}}+1\right]}{I_{B}} .
$$

At $I_{B}=600 \mu A, V_{B E} \cong 850 \mathrm{mV}$. Hence, for the BFR 90 model,

$$
R 1=r_{B B^{\prime}}=\frac{0.850-0.617-\frac{1}{38.7} \ln \left[\frac{600,000}{126}+1\right]}{600 \times 10^{-6}}=23.6 \Omega .
$$

The constant current source $\mathrm{J} 1$ in the GMB model is the leakage current of the back-biased collector-base junction, or the collector cutoff current $\mathrm{I}_{\mathrm{CBO}}$ given as $50 \mathrm{nA}$ in the device specifications [17]. J2 is a secondary dependent current source which is a nonlinear function of the base current $I_{B}$. Figure 4-20 shows the common-emitter collector characteristic for typical BFR 90 transistors. For the $100 \mu \mathrm{A}$ incremental steps of base current, a decreasing increment of collector current is observed. Thus, the $I_{C} / I_{B}$ ratio $\left(\alpha_{F E}\right.$, or $\beta$ ) depends on current level and is best modeled by means of a typical tabular relationship, as shown below. Finally, R2 in the model is the saturation resistance of the collector characteristic, nominally of value $50 \Omega$. The saturation and storage time simulation capabilities of the GMB model were not utilized in this development.

Figure 4-21 shows a listing of the TRAN6E program used in conjunction with the SCEPTRE circuit for the ECL drive and transistor switching simulation given in figure 4-16. The approximate ECL voltage drive waveforms for E1T and E2T, as reflected in tables 1 and 3, were determined by observing nodes 3 and 10 with a sampling oscilloscope. Capacitors $\mathrm{C} 1$ and $\mathrm{C} 2$ are dependent on their respective base-emitter diode currents via eq (11) using $\theta=38.7$ and $\tau_{B^{\prime}}=5 \mathrm{~ns}$. J2 and $\mathrm{J} 5$ are the secondary current sources dependent on base currents JD1 and JD2, respectively. The values used in table 2 approximate the $I_{C} / I_{B}$ relationship and were taken from corresponding $I_{B}-I_{C}$ current values on a $5.2 \mathrm{~V}$, $125 \Omega$ load line drawn on the collector characteristics shown in figure 4-20. 


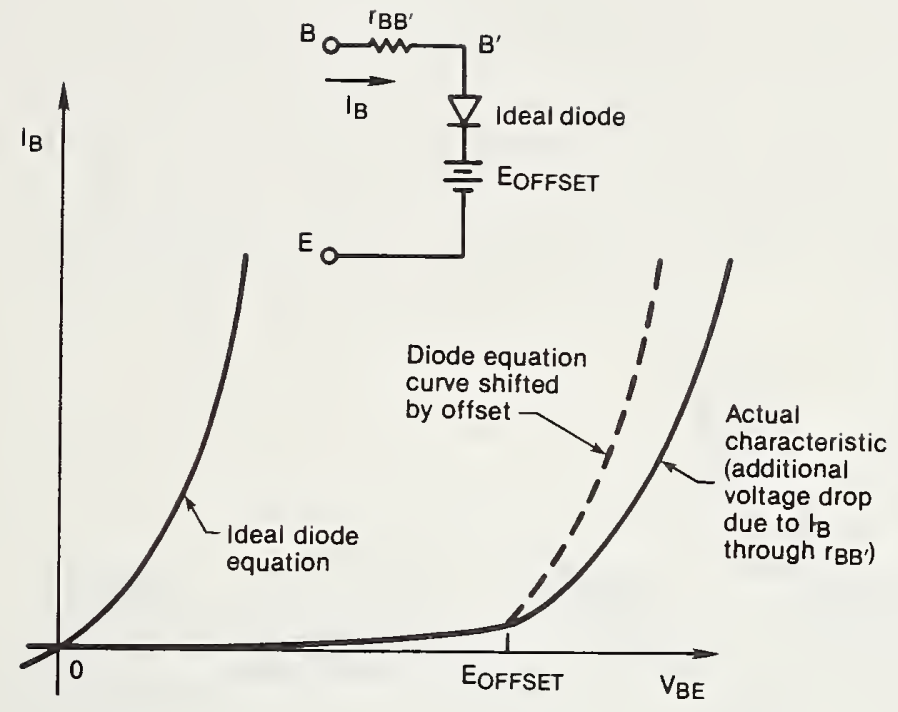

Figure 4-19. Analysis of base-emitter characteristic.

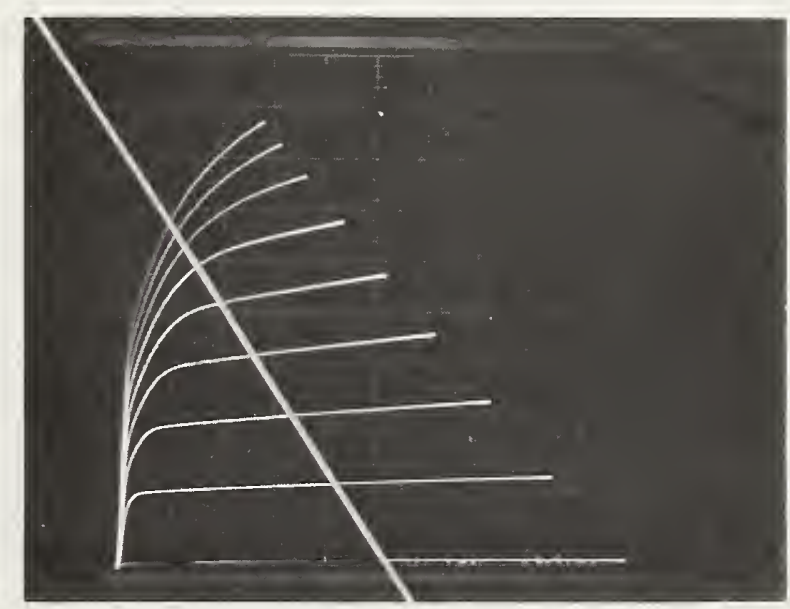

Figure 4-20. Typical BFR 90 common-emitter collector characteristics. Vertical: $5 \mathrm{~mA} / \mathrm{div}$. Horizontal: $1 \mathrm{~V} /$ div. Base current: $100 \mu \mathrm{A} / \mathrm{step}$. 


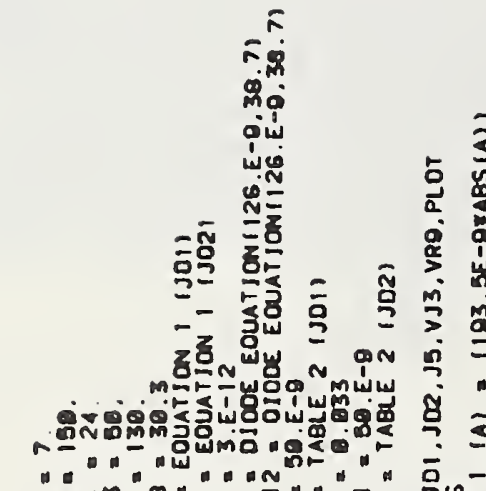

(1)

\section{美}

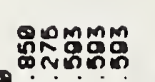

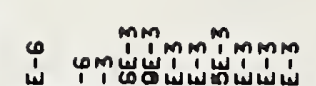

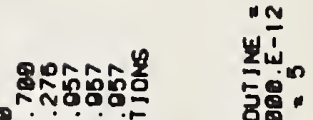
Sㅜ⿻一𠃋十

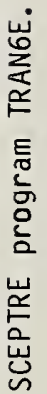

อ. ge日

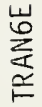

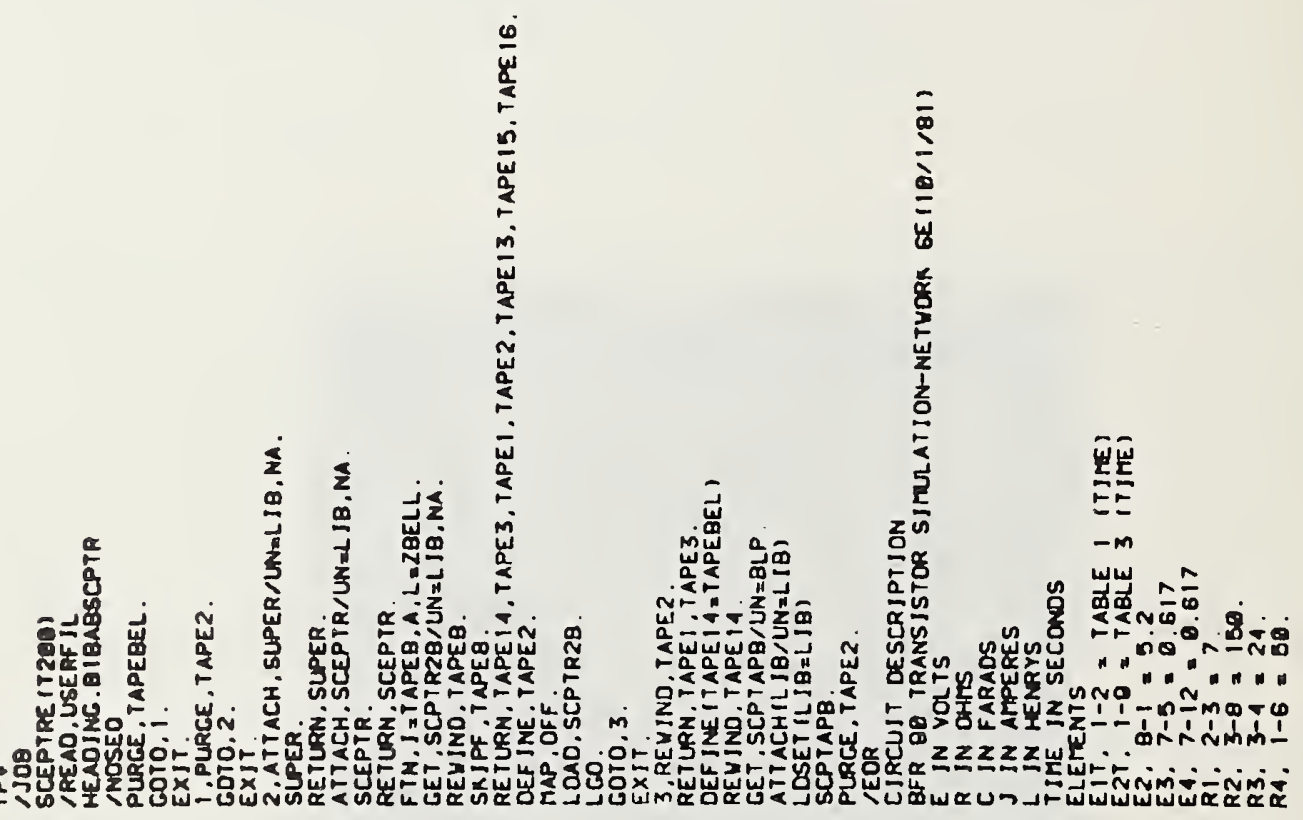


Figures 4-22, 4-23, 4-24, and 4-25 show the results obtained via program TRAN6E for the ECL drive and transistor switching simulation of figure 4-16. The ECL drive waveform in figure 4-22 approximates the $\sim 2$ ns logic swing from around $-1.7 \mathrm{~V}$ to $-0.957 \mathrm{~V}$ observed for E2T. It can be seen in figure 4-23 that by 2 ns ( 1 ns after E2T begins to change), the voltage across the base-emitter capacitor, $\mathrm{C} 2$, of transistor $\mathrm{Q} 2$ has risen up to the $750 \mathrm{mV}$ level. As previously determined from the base-emitter characteristics (see fig. 4-18), appreciable base current now begins to build up in Q2. Figure $4-24$ shows the JD2 waveform which peaks at $\sim 0.67 \mathrm{~mA}$ a little after $3 \mathrm{~ns}$. The corresponding rise in collector current $J 5$ is seen in figure 4-25. Due to the saturation characteristic, J5 flattens out upon reaching the $33 \mathrm{~mA}$ level at about $2.8 \mathrm{~ns}$. Thus, as anticipated, the switching action of the $B F R$ 90 transistors (and their associated complementary ECL input drive signals) is to produce a current steplike waveform which has a transition time on the order of $600 \mathrm{ps}$.

\subsection{The Total Model via Program TRFPG}

As shown in section 4.3, simple modeling of the output stage of the RFPG produces a simulated output waveform with a much faster transition time and larger undershoot than observed on the actual waveform. Lack of the proper driving node voltage waveform and a slower switching speed on the part of the rf transistors/ECL input drive were likely causes. Section 4.4 above describes the development of a model for the ECL drive and transistor switches (via program TRAN) which confirms the switching speed supposition. To confirm the total model, then, R9 of figure 4-16 is replaced by the initial output stage model of figure $4-13$.

Figure 4-26 shows the merging of figures 4-13 and 4-16 used for programs RFPG and TRAN, respectively. Node 15 at the collector of $Q 2$ is now the driving node for the output stage, corresponding to node 4 of figure 4-13. The output diode and load resistor branch is designated by nodes 19 and 20 .

Figures 4-27, 4-28, 4-29, and 4-30 show the results of SCEPTRE program TRFPGl, simulating the total RFPG model using the same ECL drive signals as in figure 4-22. Figure 4-27 shows that the collector current $J 5$ is maintained as before in figure 4-25. The voltage produced at node 15 (VC5) is shown in figure 4-28. The output diode current, JD4 is plotted in figure 4-29. The output voltage waveform across $R 13$ is given in figure 4-30, and can be seen to begin now to approximate reality. The step-like output waveform is flat until the driving voltage at node 15 begins to fall at 1.75 ns, which is where $J 5$ begins to turn on. VC5 then decreases at a rate comensurate with the increase of 35. Consequently, as analyzed in section 4.2, diode current JD4 decreases even more rapidly as the output diode becomes reverse-biased into cutoff. As seen in the earlier analysis of the diode-load resistor step response, however, the undershoot observed in the output waveform is highly dependent on the driving node voltage waveform, due to the parasitic reactances and nonlinear properties of the diode.

Modifying the essential parts of the model for the RFPG shown in figure 4-26 so that the simulated waveforms better match the actual waveforms observed, therefore, is a matter of accounting for various parasitic and distributed inductances and capacitances in the circuit which help to shape the driving node voltage waveform. Small lead inductances (in the output circuit diodes and in the connections to the driving node) and small capacitances, particularly associated with the driving point node (node 15 in figure 4-26), have a very pronounced effect. Figure 4-31 shows a model, modified from figure 4-26, which gives a reasonably close approximation to the actual observed waveforms of the RFPG. The additional inductances and capacitances (and their associated values) can be attributed to the actual physical devices and structure used in the construction of the RFPG. For example, appendix D describes an analysis for approximating the value of $C 9$ by knowing the typical value of the 


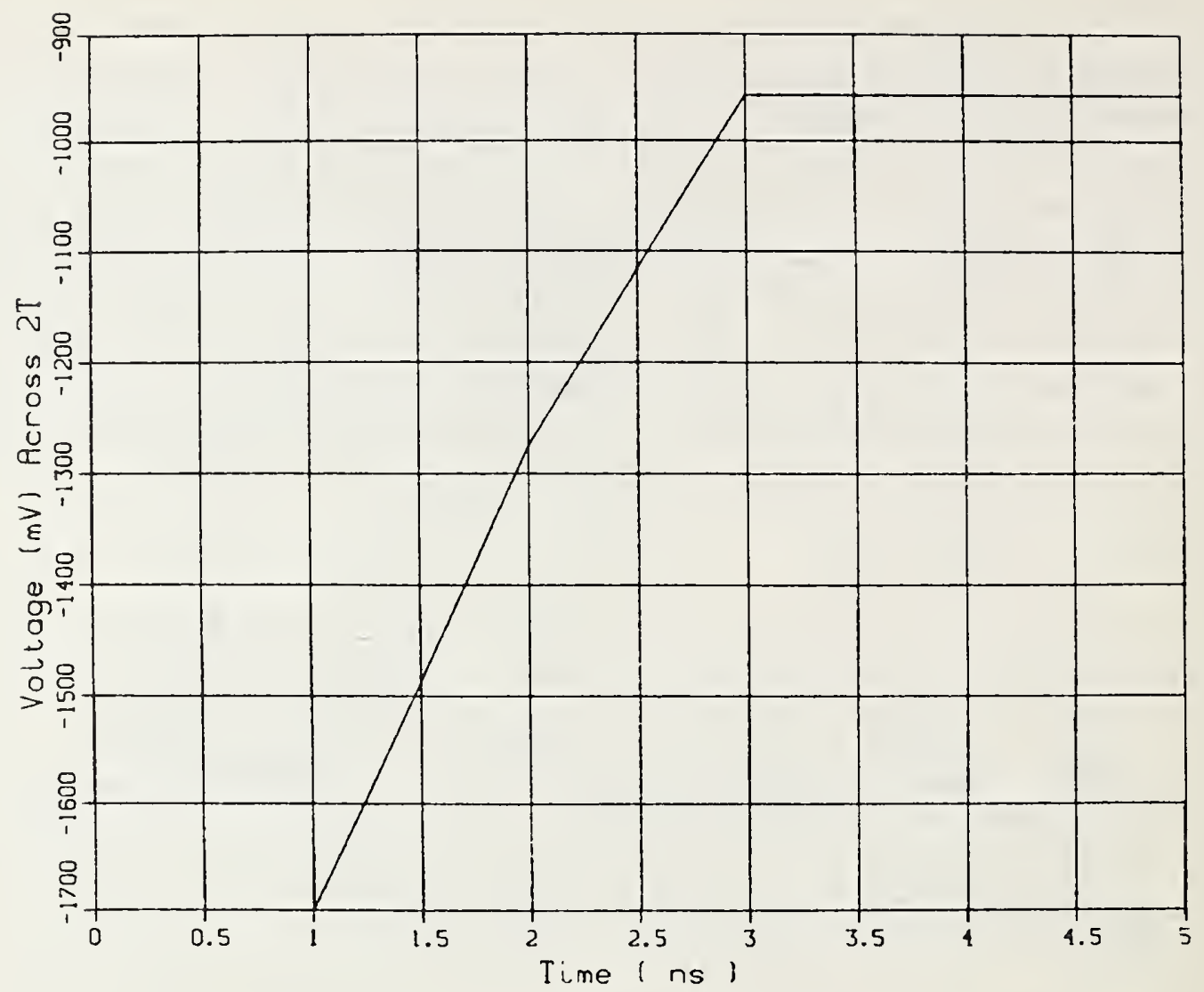

Figure 4-22. ECL drive waveform E2T from TRAN6E program.

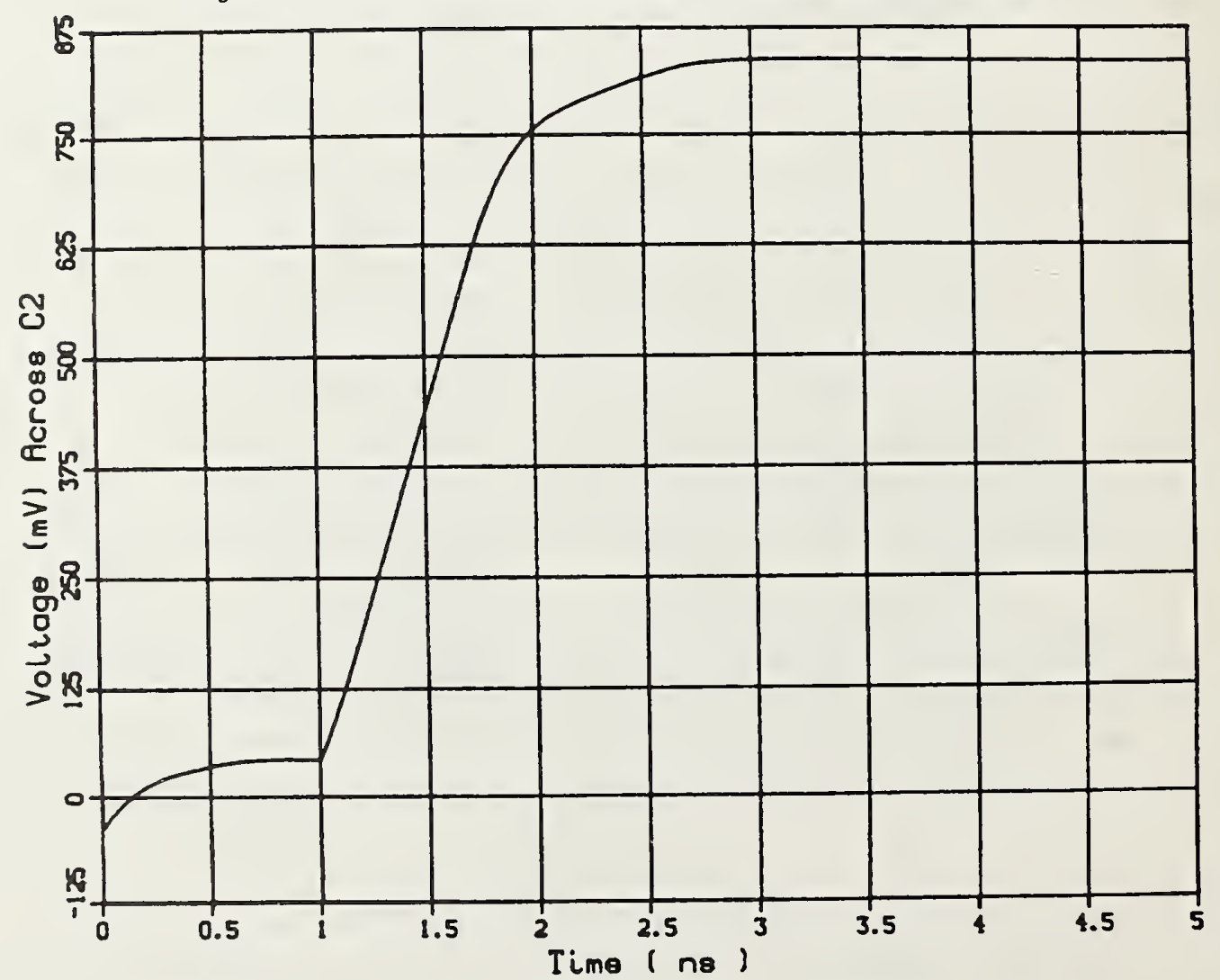

Figure 4-23. Voltage across capacitor C2 in response to E2T (ECL drive waveform of fig. 4-22) from TRAN6E program. 


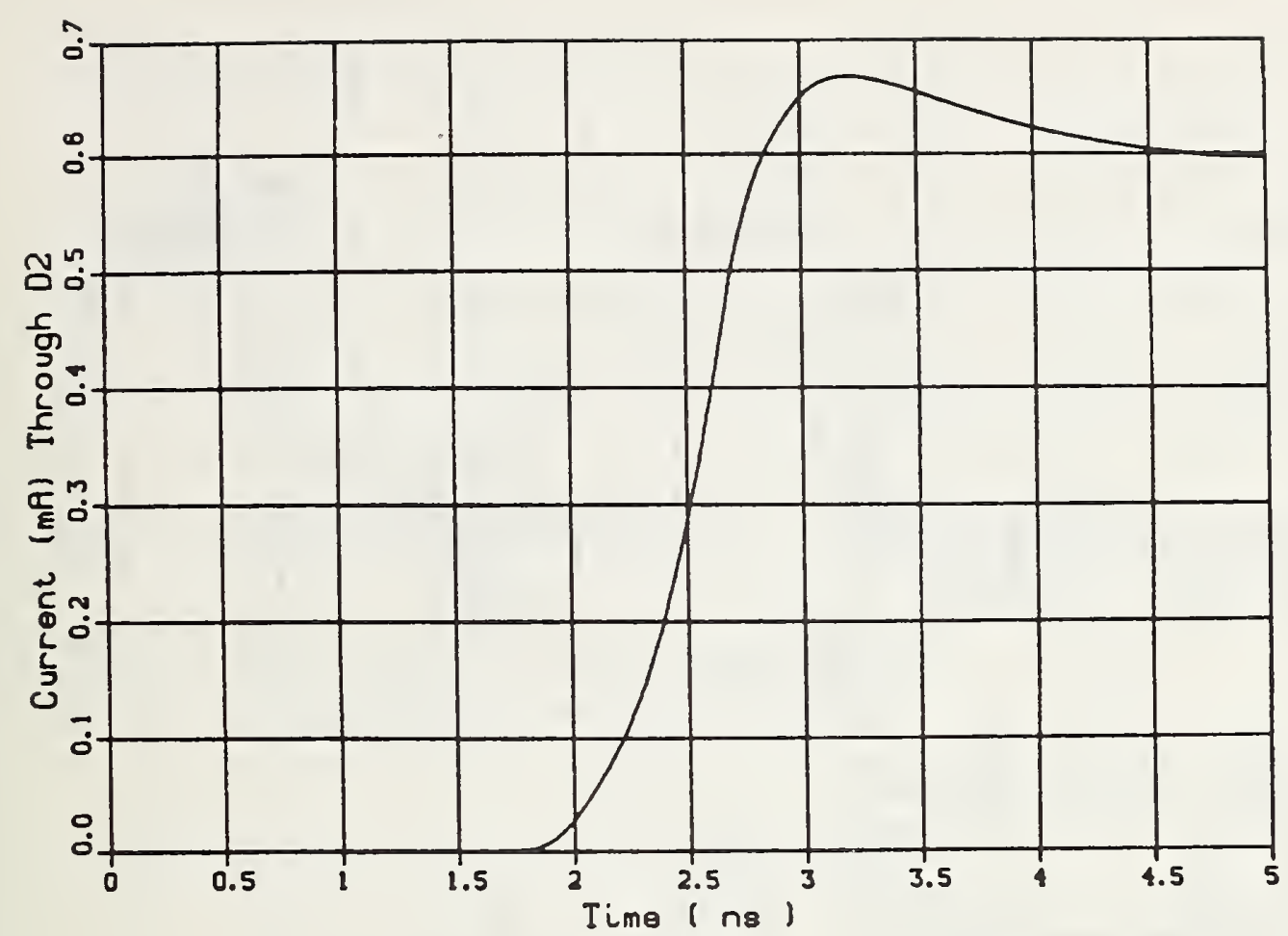

Figure 4-24. Transient current JD2 in response to ECL base drive from TRAN6E program.

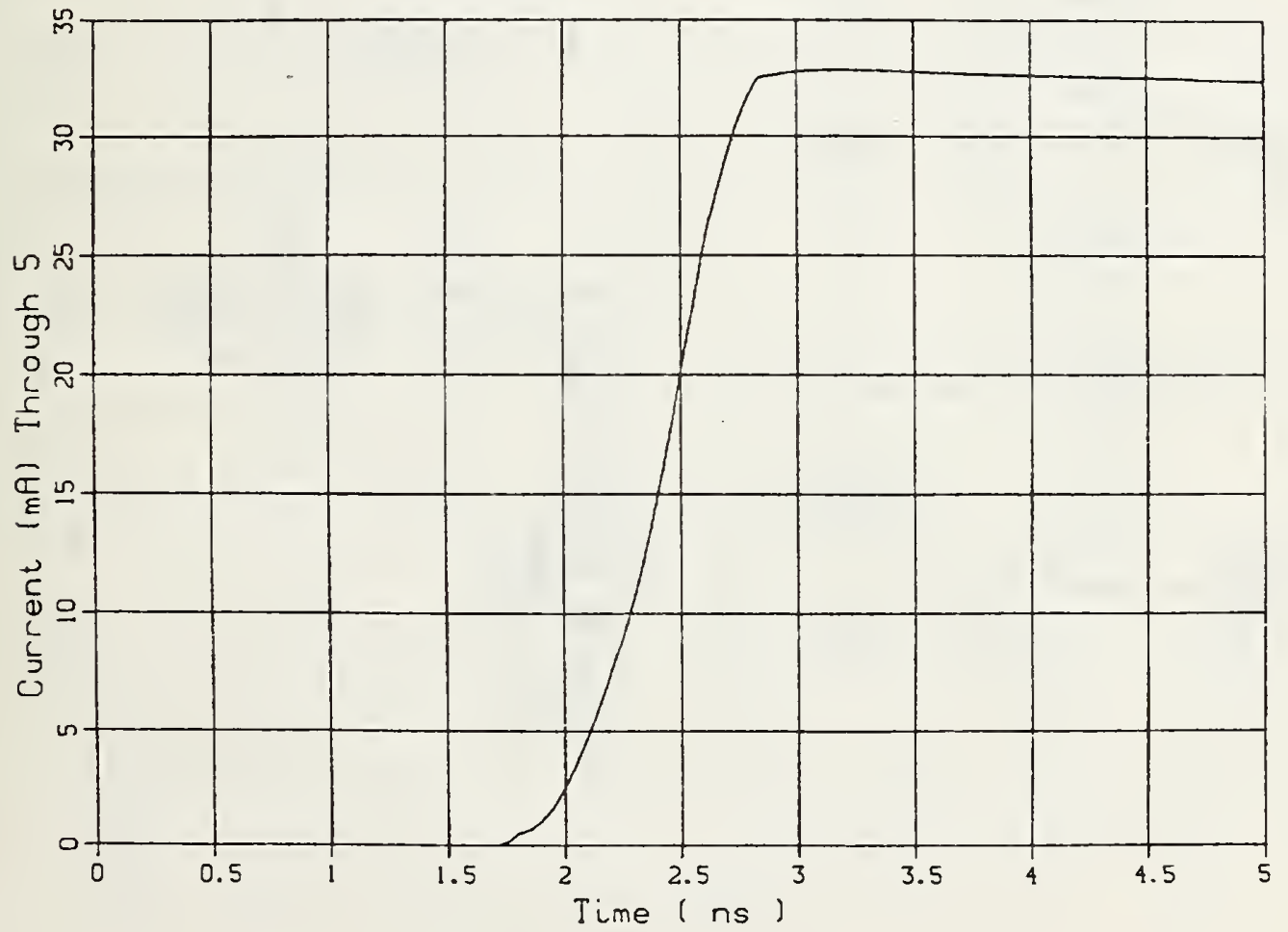

Figure 4-25. Collector current 35 of Q2 from TRAN6E program. 


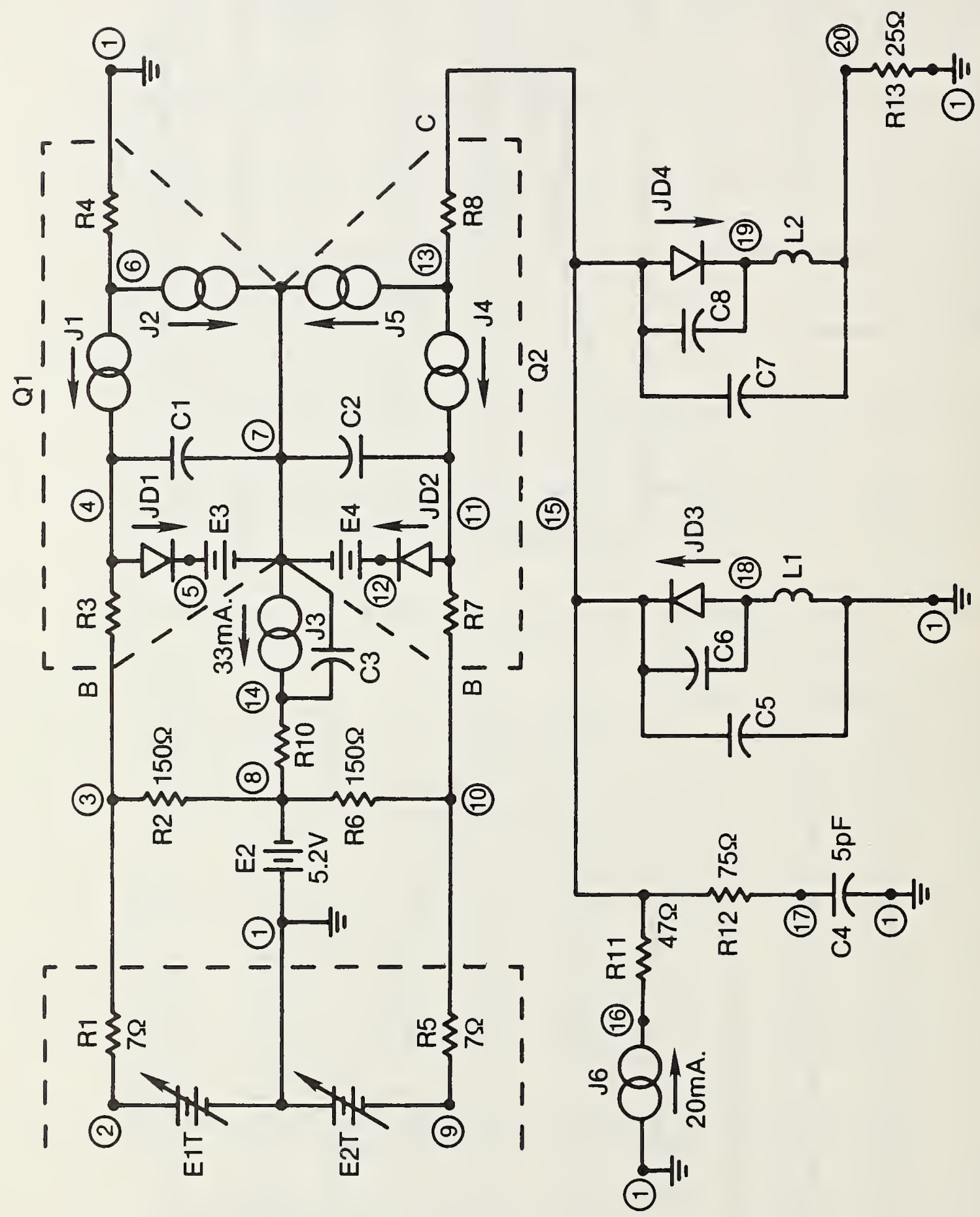

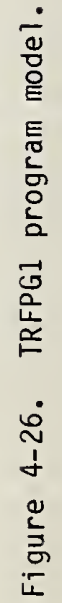




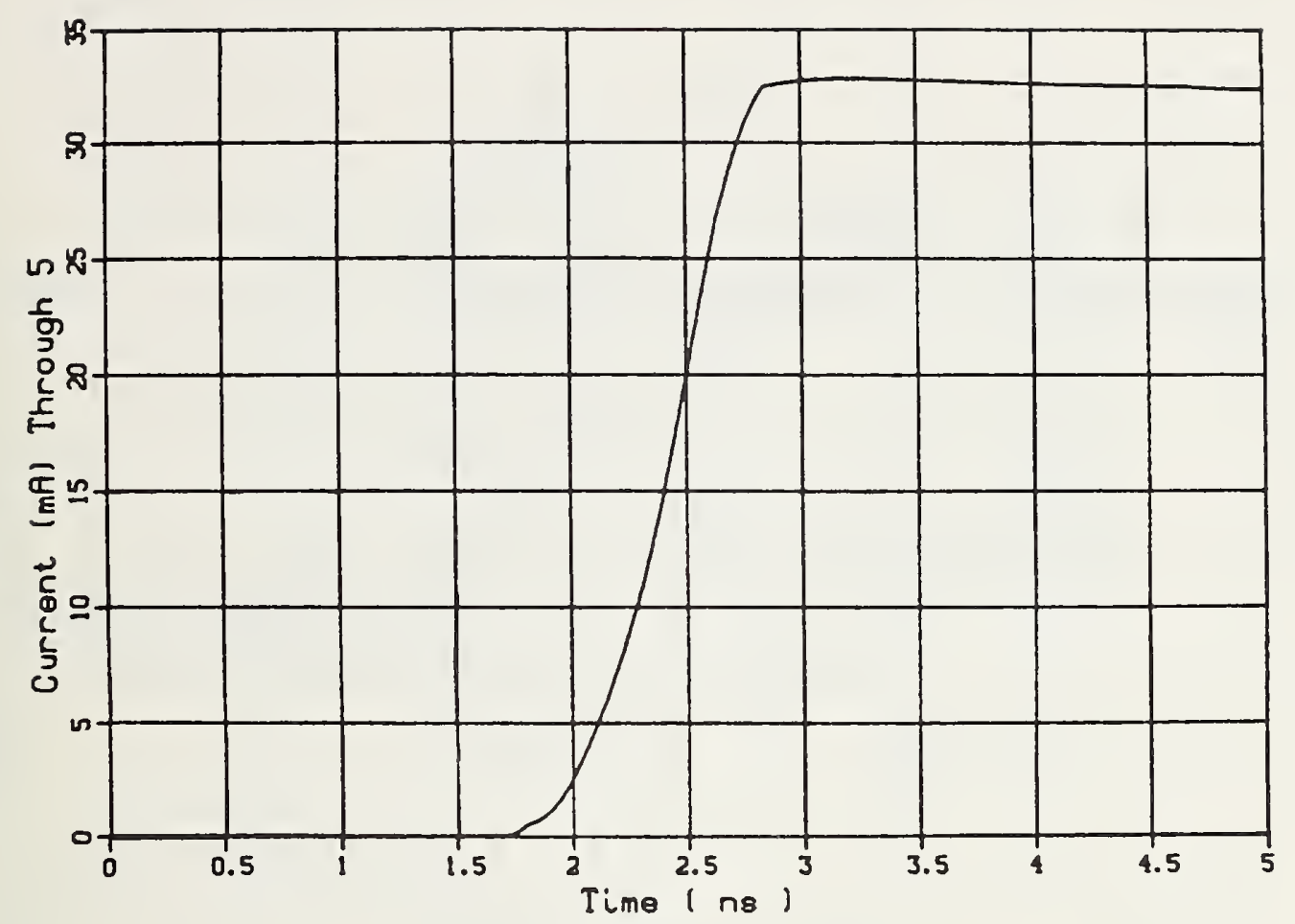

Figure 4-27. Collector current J5 of Q2 from TRFPGI program.

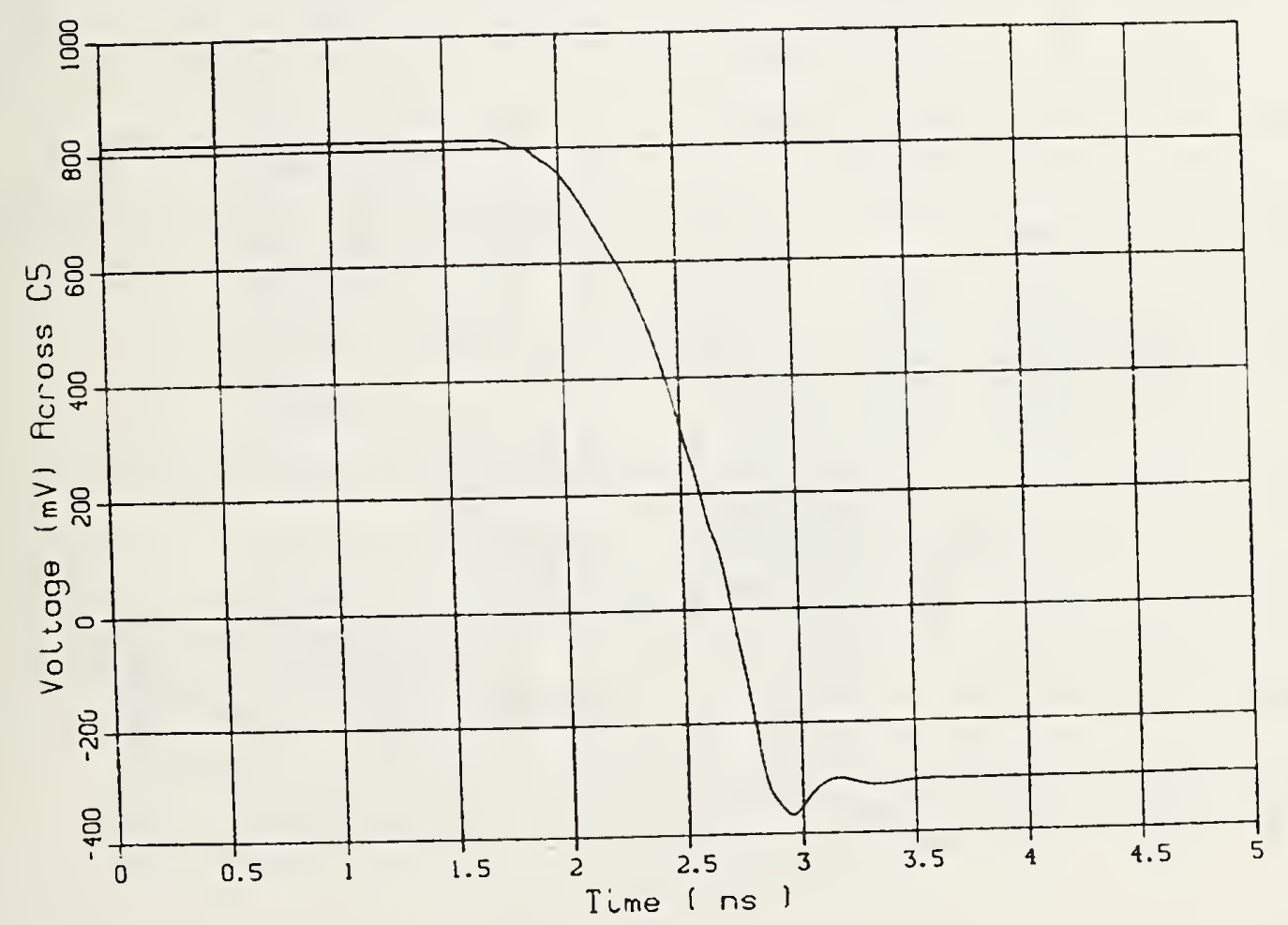

Figure 4-28. Driving node voltage VC5 from TRFPG1 program. 


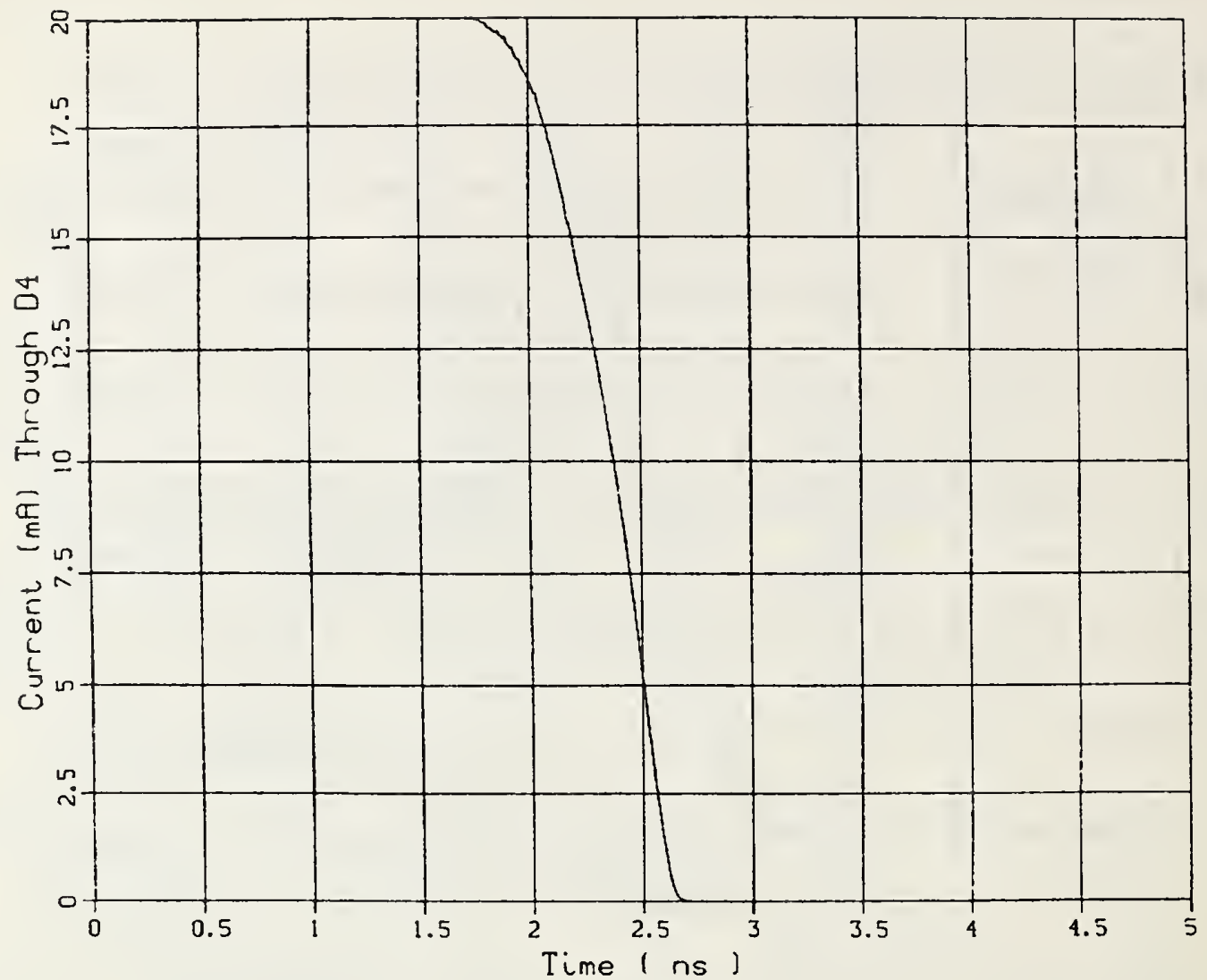

Figure 4-29. Output diode current JD4 from TRFPG1 program.

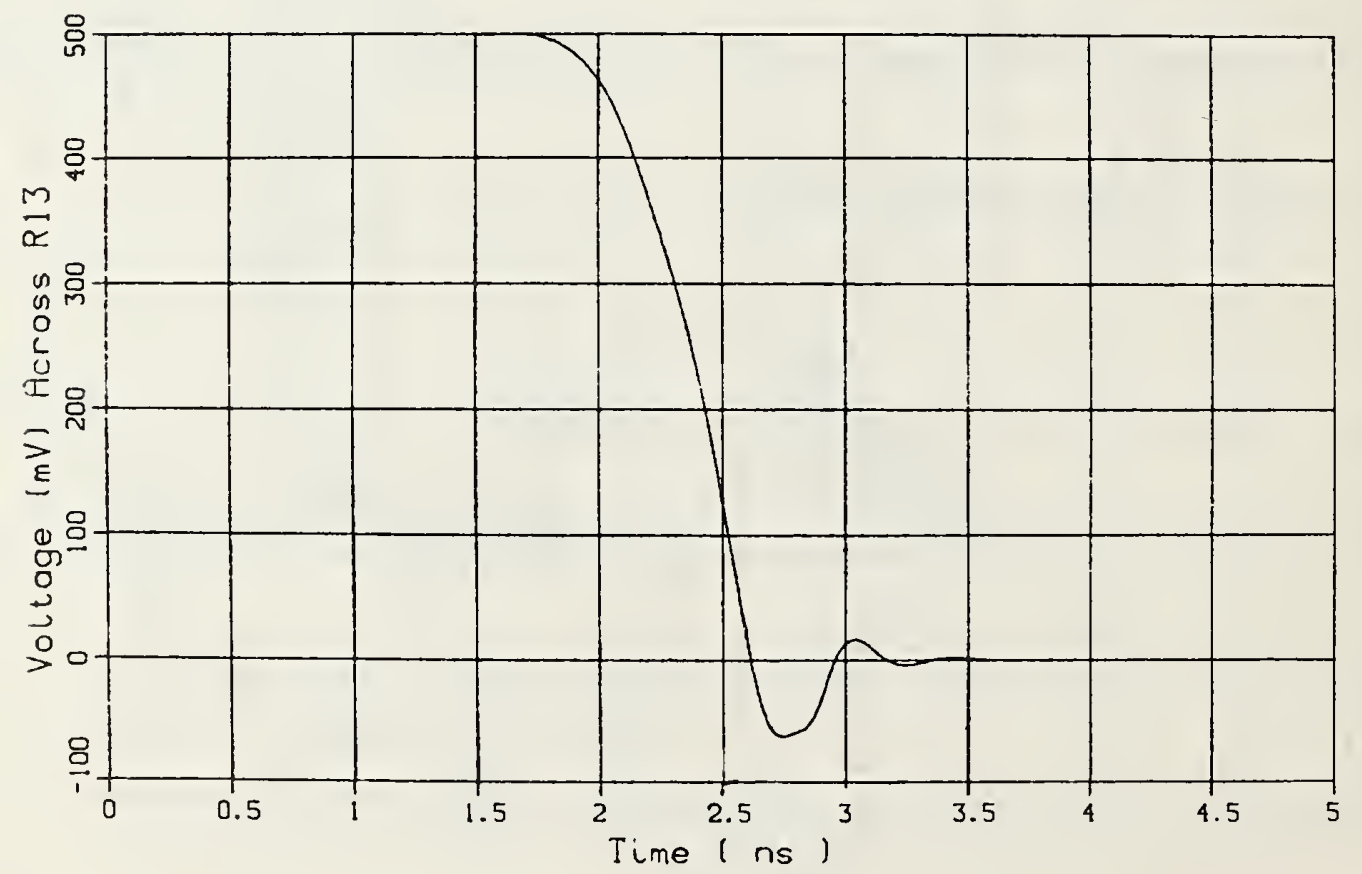

Figure 4-30. Resultant step-1ike output voltage waveform VRI3 from TRFPGl program. 


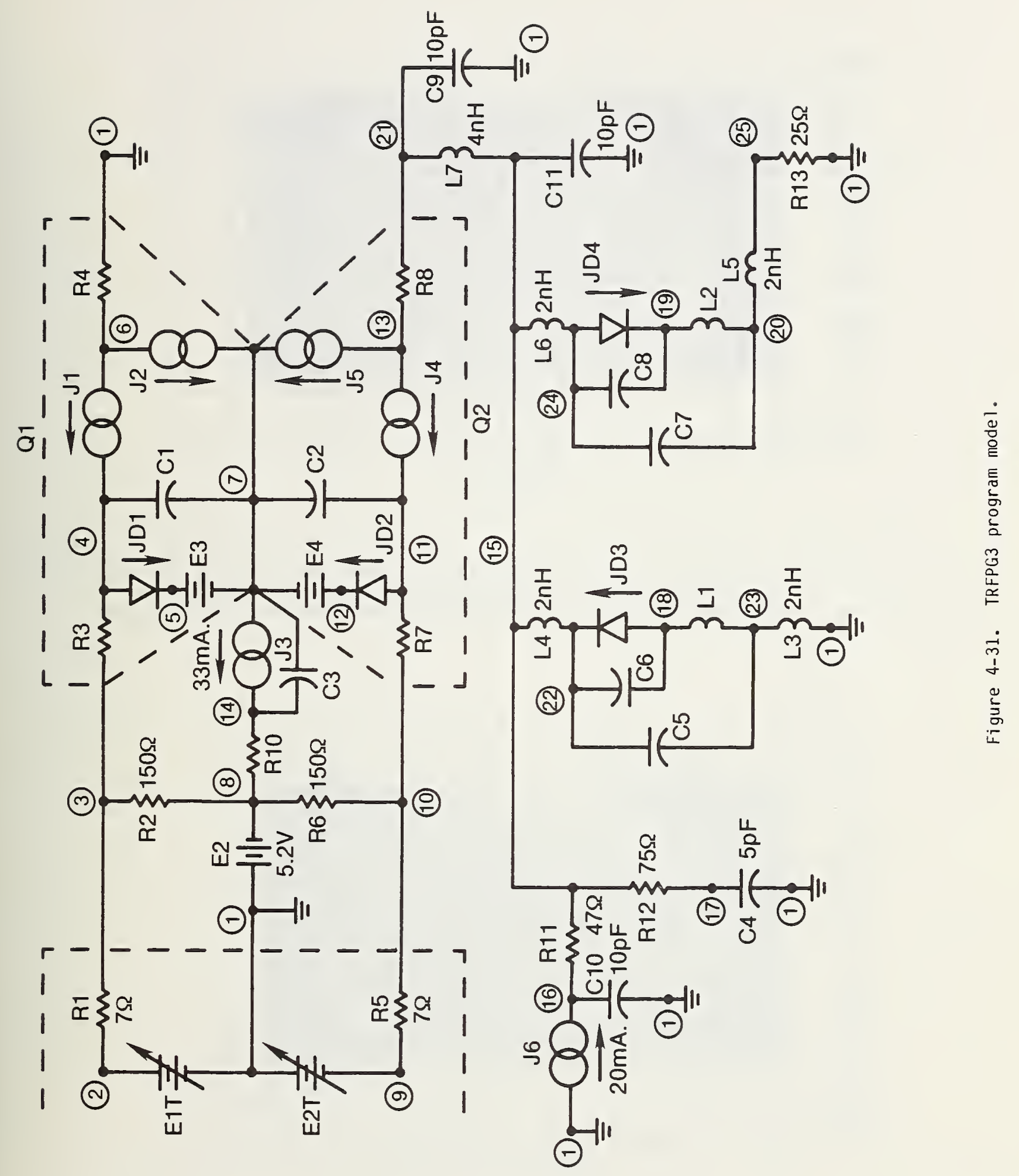




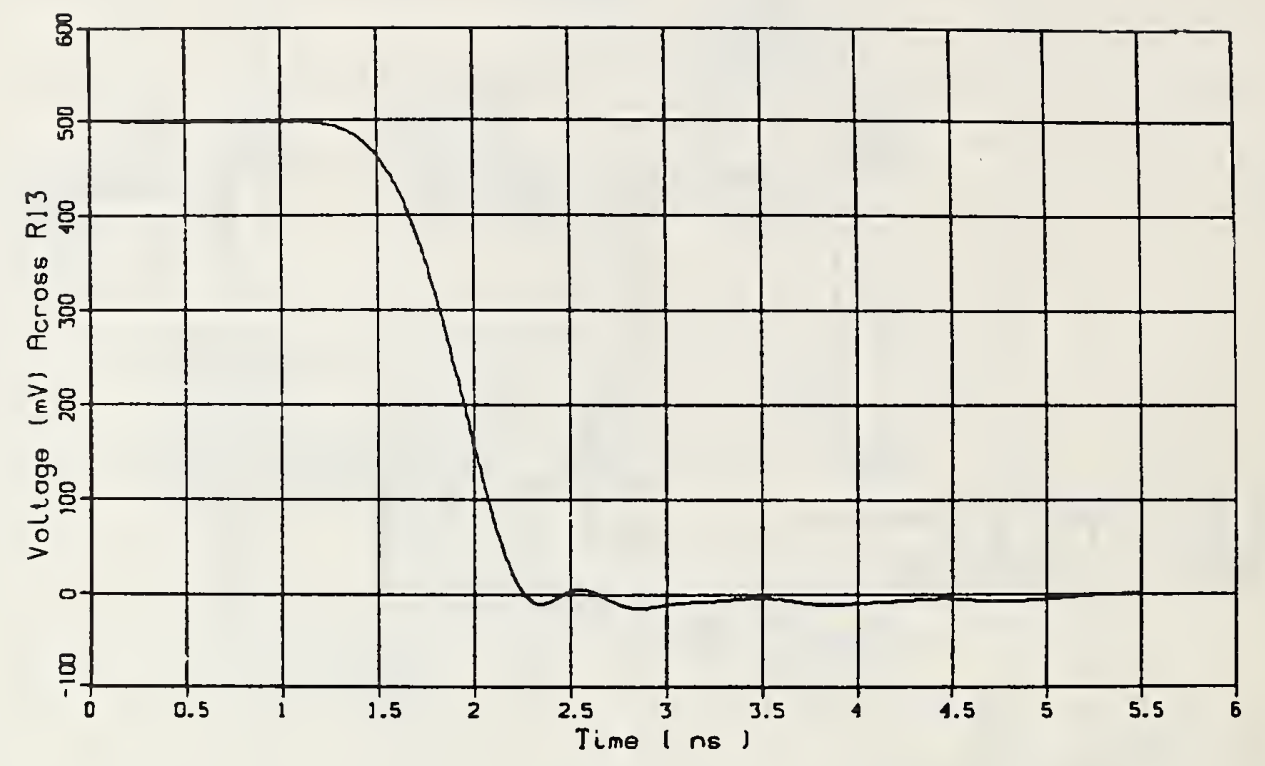

Figure 4-32. Example of predicted available transition waveform from TRFPG3 program.

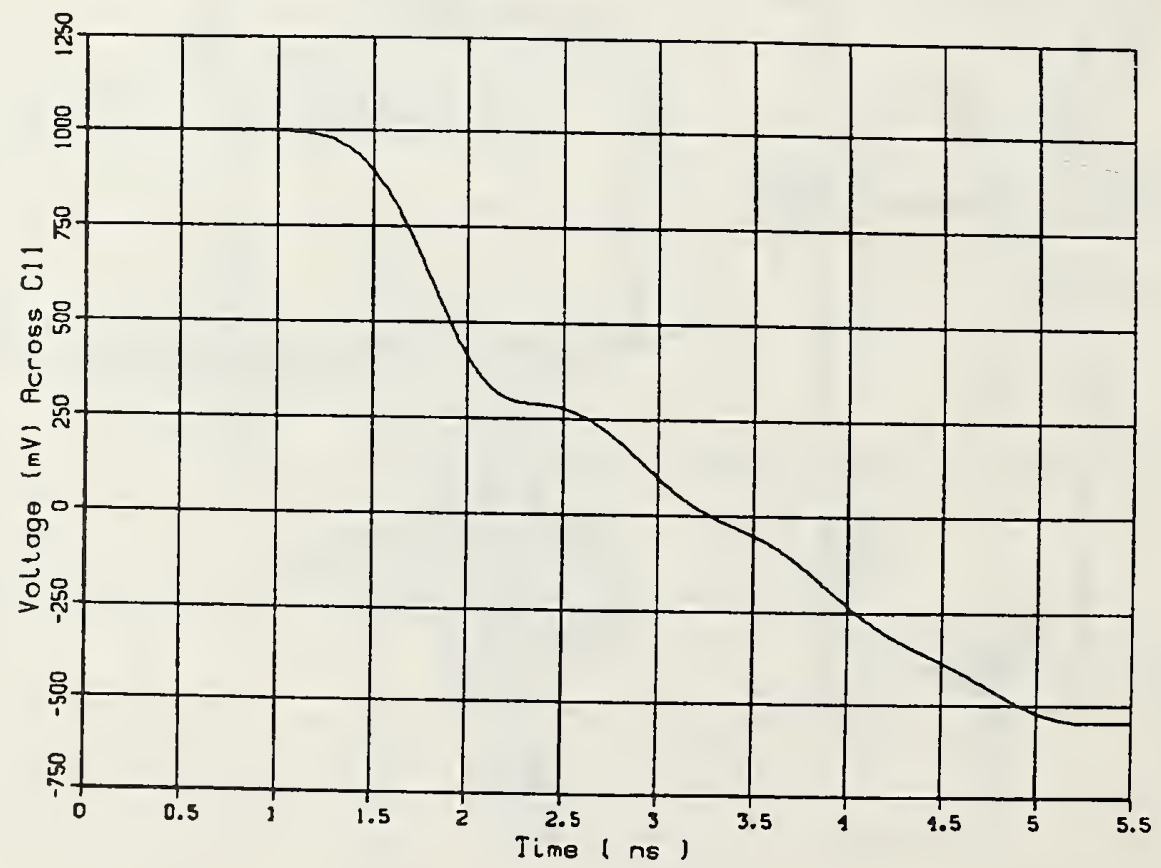

Figure 4-33. Example of corresponding driving node voltage from TRFPG3 program. 


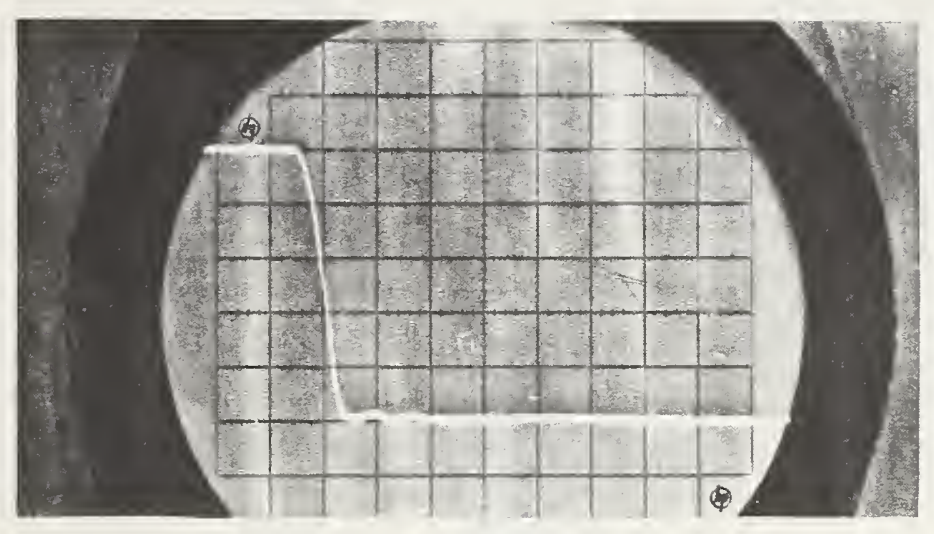

Figure 4-34. Actual output waveform from the RFPG observed with a sampling oscilloscope. Vertical: $100 \mathrm{mV} /$ div. Horizontal: $1 \mathrm{~ns} / \mathrm{div}$.

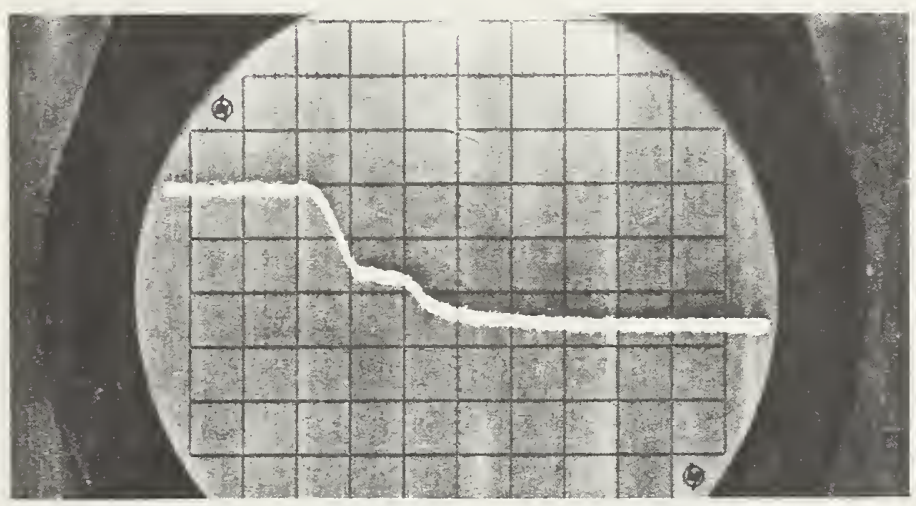

Figure 4-35. Actual driving node voltage waveform from the RFPG observed with a sampling oscilloscope. Vertical: $500 \mathrm{mV} /$ div. Horizontal: $2 \mathrm{~ns} / \mathrm{div}$. 

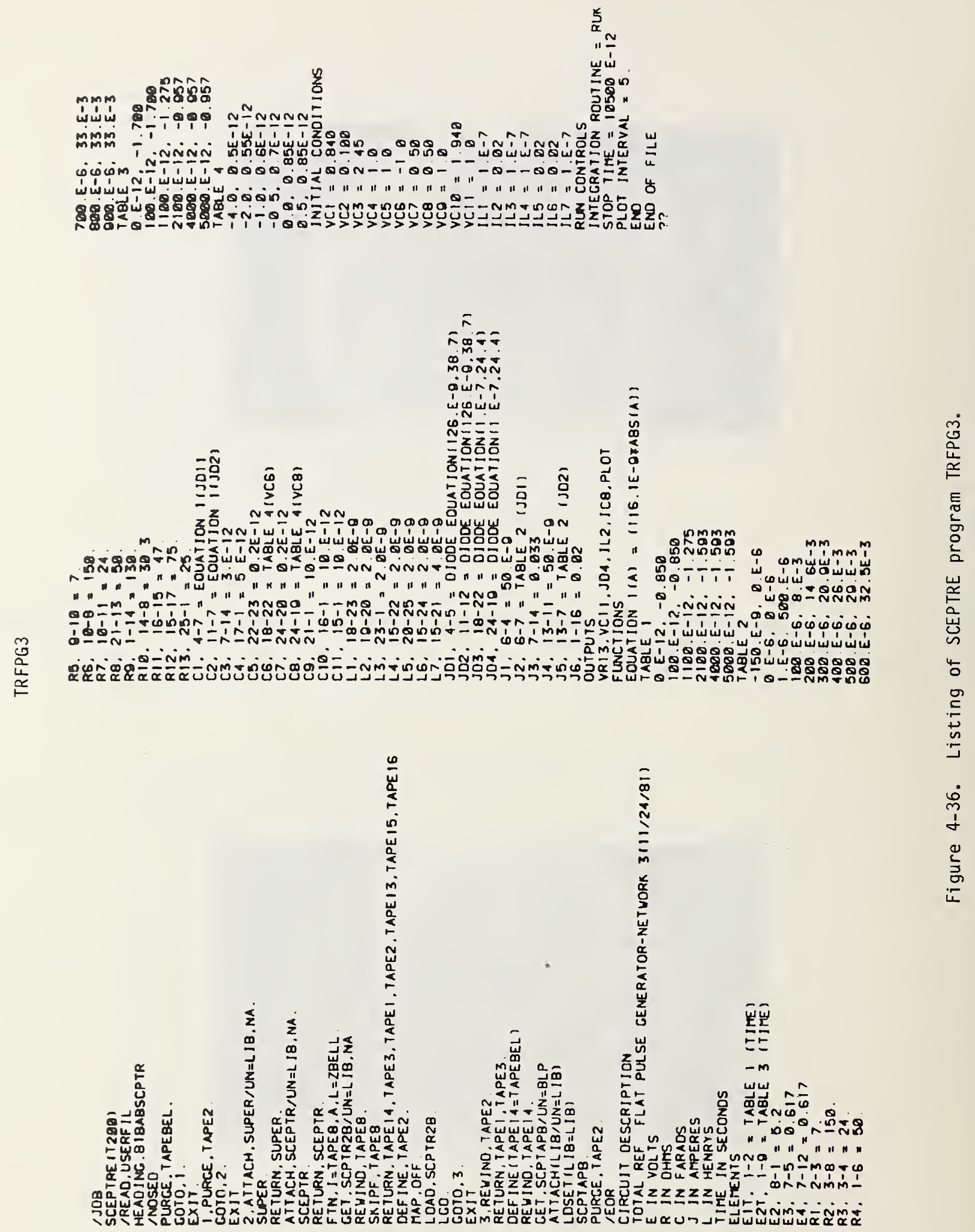
collector-base capacitance of the BFR 90 transistor. The value of $\mathrm{Cll}$, on the other hand, is an approximation of the effective capacitance to ground at the driving point node where the 1 eads of 22 , R11, R12, and the two current steering diodes are all connected together in a relatively large solder joint. The nanohenry values for L3-L7 are best estimates. Obviously, the better these parasitic and distributed L-C values can be determined (by measurements or by calculations), the more exactly this model can be made to approximate the actual waveforms of the RFPG.

Figure 4-32 shows an example of the predicted available transition waveform of the RFPG produced by SCEPTRE program TRFPG3 in which the estimates of the above parasitic elements have been included. Figure 4-33 is an example of the corresponding driving node voltage produced by the same program. These simulated waveforms can be compared with the actual corresponding waveforms shown in figures 4-34 and 4-35, measured with a commercial sampling oscilloscope. The similarities between the simulated and observed waveforms are quite apparent, taking the different vertical and horizontal scales into account. However, additional work remains to determine the exact error function between the simulated and observed available transition waveforms, and thereby to improve the present model for the RFPG. Figure 4-36 gives the listing of the SCEPTRE program TRFPG3.

\section{Summary}

This technical note contains the theory, circuit design, performance specifications, modeling, and computer simulations which describe the NBS Reference Flat Pulse Generator (RFPG). Prior methods used for generating flat baseline and topline pulse generators are discussed, together with their limitations. The present approach used in the RFPG, i.e., steering constant current sources to the load via a fast Schottky barrier diode, is thoroughly described. A complete circuit diagram and description is given for the clock, delay, and pulse duration logic, the current-switching output stages, and the regulated power supplies.

A considerable portion of the report is used to present the development of the circuit analysis programs for the RFPG, written using extended-SCEPTRE hosted on a large computer system. The circuit analysis of the nonlinear step response of a simple diode and series load resistor is used as the basis for examining and evaluating the results obtained for the more complex switching structure of the RFPG. These analyses show that the available transition waveform from the RFPG is also highly dependent on the characteristics of the rf switching transistors used and the associated ECL logic drive, as well as parasitic and distributed inductances and capacitances in the output stage of the RFPG.

Finally, it is recommended that the efforts needed to determine a more exact error function between the simulated and observed waveforms be pursued. This work can provide the basis for an improved model of the NBS RFPG by which to predict its performance when used as a pulse waveform generator standard in either the laboratory or as a dynamic transport standard for field testing purposes.

The authors would like to acknowledge the helpful comments and guidance provided by other members of the NBS technical staff in the development and modeling of the Reference Flat Pulse Generator, including N. S. Nahman, R. A. Lawton, and R. L. Peterson. The efforts of the NBS clerical staff in preparing this report are also gratefully acknowledged, including $M_{0}$. E. Deweese and $P_{\bullet}$. J. Rice. 
6. References

[1] McCaa, W. D.; Nahman, N. S. Generation of reference waveforms by uniform lossy transmission lines. IEEE Trans. Instrum. Meas. IM-21(4): 382-390; 1972 November.

[2] Gans, W. L.; Nahman, N. S. Shielded and balanced coaxial transmission lines--parametric measurements and instrumentation relevant to signal waveform transmission in digital service. Nat. Bur. Stand. (U.S.) Tech. Note 1042; 1981 June.

[3] Holt, D. R.; Nahman, N. S. Coaxial-line pulse-response error due to a planar skin-effect approximation. IEEE Trans. Instr. Meas. IM-21(4): 515-519; 1972 November.

[4] Andrews, J. R.; Bell, B. A.; Nahman, N. S.; Baldwin, E. E. Reference waveform flat pulse generator. IEEE Trans. Instrum. Meas. IM-32(1): 27-32; 1983 March.

[5] a. IEEE standard pulse terms and definitions, IEEE Std. 194-1977:12; 1977 July 26.

b. IEEE standard, IEEE std. 181-

c. International Electrotechnical Commission publication 469-1 and 2, 1974. Part 1: Pulse terms and definitions. Part 2: Pulse measurement and analysis, general consideration.

[6] Schoenwetter, H. K. High-accuracy settling time measurements. IEEE Trans. Instrum. Meas. IM-32(1): 22-26; 1983 March.

[7] Bowers, James C.; Sedore, Stephen R. SCEPTRE: A computer program for circuit and systems analysis. Englewood Cliffs, NJ: Prentice-Hall, Inc.; 1971.

[8] Frye, G. J. A predictable subnanosecond pulse generator. IEEE Trans. Inst. Meas. IM-17(4):324329; 1968 December.

[9] Elliott, B. J. Picosecond pulse measurement of the conduction current vs, voltage characteristics of semiconductor materials with bulk negative differential conductivity. IEEE Trans. Inst. Meas. IM-17(4):330-332; 1968 December.

[10] Andrews, J. R. Picosecond pulse generators using microminiature mercury switches. Nat. Bur. Stand. (U.S.) NBSIR 74-377; 1974 March.

[11] Millman, J.; Taub, H. Pulse, digital \& switching waveforms. New York, NY: McGraw-Hi11; 1965. 101-104.

[12] Andrews, J. R. Stable reference flat top pulse generator. Nat. Bur. Stand. (U.S.) Memorandum to N. S. Nahman and W. D. McCaa; 1970 January 16.

[13] Becker, D. Extended SCEPTRE, Vol. 1., user's manual. GTE Sylvania; 1974 December.

[14] Diode and transistor designer's catalogue. Hewlett-Packard Components, 79-83; 1980.

[15] Geller, S. B.; Mantek, P. A.; Boyle, D. R. A general junction-transistor equivalent circuit for use in large-signal switching analysis. IRE Transactions on Electronic Computers, 670-679; 1961 December.

[16] Ebers, J. J.; Moll, J. L. Large-signal behavior of junction transistors. Proc. IRE 42:1761-1772; 1954 December.

[17] RF data manual, second edition. Motorola Inc., 17-80/82; 1981. 
Appendix A. Flat Pulse Generator Parts List

Integrated Circuits

\begin{tabular}{|c|c|c|c|c|}
\hline IC1 & E.C.L. & \multicolumn{2}{|l|}{ NOR gate } & $95 \mathrm{HO}$ \\
\hline IC2 & $"$ & \multicolumn{2}{|l|}{ divider } & $95 \mathrm{H} 90$ \\
\hline IC3 & $"$ & \multicolumn{2}{|l|}{$"$} & $95 \mathrm{H} 90$ \\
\hline IC4 & $"$ & \multicolumn{2}{|l|}{$"$} & $95 \mathrm{H} 90$ \\
\hline IC5 & $"$ & \multicolumn{2}{|l|}{$"$} & $95 \mathrm{H} 90$ \\
\hline I C6 & $"$ & \multicolumn{2}{|c|}{ NOR gate } & $95 \mathrm{HO}$ \\
\hline IC7 & $"$ & \multicolumn{2}{|c|}{ Flip-flop } & $95 \mathrm{H} 28$ \\
\hline IC8 & $"$ & \multicolumn{2}{|l|}{$"$} & $95 \mathrm{H} 28$ \\
\hline I C9 & $"$ & \multicolumn{2}{|l|}{$"$} & $95 \mathrm{H} 28$ \\
\hline IC 10 & $"$ & \multicolumn{2}{|l|}{ Divider } & $95 \mathrm{H} 90$ \\
\hline IC11 & $"$ & \multicolumn{2}{|l|}{$"$} & $95 \mathrm{H} 90$ \\
\hline IC12 & $"$ & \multicolumn{2}{|l|}{$"$} & $95 \mathrm{H} 90$ \\
\hline IC13 & $"$ & \multicolumn{2}{|c|}{ NOR gate } & $95 \mathrm{HO3}$ \\
\hline IC14 & $"$ & \multicolumn{2}{|l|}{$"$} & $95 \mathrm{HO} 3$ \\
\hline IC15 & Reference & \multicolumn{2}{|c|}{ voltage source } & LM-399H \\
\hline IC16 & Precision & \multicolumn{2}{|l|}{ op-amp } & OP-05C \\
\hline I $\mathrm{C} 17$ & $"$ & \multicolumn{2}{|l|}{$"$} & OP-05C \\
\hline $1 \mathrm{C} 18$ & Voltage $r$ & egulator & $+15 V$ & 7815 \\
\hline $1 \mathrm{C} 19$ & $"$ & $" 1$ & $+12 \mathrm{~V}$ & 7812 \\
\hline $1 C 20$ & $"$ & $"$ & $-5 V$ & 7905 \\
\hline $1 \mathrm{C} 21$ & $"$ & $"$ & $-5 v$ & 7905 \\
\hline $1 \mathrm{C} 22$ & $"$ & $"$ & $-5 V$ & 7905 \\
\hline
\end{tabular}

Transistors

Q1

BFR90

BFR90

2N3904

BFR90

BFR90

2N3904

$2 \mathrm{~N} 4250$

2N3906

$2 \mathrm{~N} 4250$

2N3906

Diodes

$\begin{array}{lll}\text { CR1 } & \text { Light emitting } & \text { HP-5082-4484 } \\ \text { CR2 } & \text { Schottky diode } & \text { HP-2835 } \\ \text { CR3 } & \text { " } & \text { HP-2835 } \\ \text { CR4 } & \text { Light emitting } & \text { HP-5082-4484 } \\ \text { CR5 } & \text { Schottky diode } & \text { HP-2835 } \\ \text { CR6 } & " & \text { HP-2835 } \\ \text { CR7 } & \text { Rectifier, General-Purpose } & \text { IN4004 }\end{array}$


Diodes, cont. CR

IN4004

CR9

"

CR10

CR11

CR12

CR13

Zener diode

I N5240

CR14 Zener "

IN5240

CR15

Light emitting

HP-5082-4484

Resistors $-- \pm 5 \%$ tolerance unless noted otherwise

\begin{tabular}{|c|c|c|}
\hline R1 & Composition & $51 \Omega 1 / 4 \mathrm{~W}$ \\
\hline R2 & $"$ & $51 \Omega 1 / 4 \mathrm{~W}$ \\
\hline R3 & $"$ & $51 \Omega 1 / 4 W$ \\
\hline R4 & $"$ & $680 \Omega 1 / 4 W$ \\
\hline R5 & $"$ & $33 \Omega 1 / 4 \mathrm{~W}$ \\
\hline R6 & $"$ & $47 \Omega 1 / 4 \mathrm{~W}$ \\
\hline R7 & OSM termination & $50 \Omega$ \\
\hline R8 & Selected, used only if needed & \\
\hline R9 & Composition & $680 \Omega 1 / 4 W$ \\
\hline$R 10$ & $"$ & $33 \Omega 1 / 4 \mathrm{~W}$ \\
\hline $\mathrm{R} 11$ & $"$ & $47 \Omega 1 / 4 W$ \\
\hline $\mathrm{R} 12$ & OSM termination & $50 \Omega$ \\
\hline$R 13$ & Selected, used only if needed & \\
\hline R14 & Composition & $1 \mathrm{~K} \Omega$ \\
\hline R15 & Glass film & $4.75 \times 1 \%$ \\
\hline $\mathrm{R} 16$ & Trimmer, multi-turn & $1 \mathrm{~K} \Omega$ \\
\hline R17 & $"$ & $1 \mathrm{~K} \Omega$ \\
\hline $\mathrm{R} 18$ & Carbon film & $1.82 \mathrm{~K} \Omega \quad 1 \%$ \\
\hline $\mathrm{R} 19$ & Composition & $1.3 \mathrm{~K} \Omega 1 / 4 \mathrm{~W}$ \\
\hline $\mathrm{R} 20$ & Precision, wire wound & $100 \Omega \quad 0.1 \%$ \\
\hline $\mathrm{R} 21$ & Composition & $1.3 \mathrm{k} \Omega 1 / 4 \mathrm{~W}$ \\
\hline R22 & Precision, wire wound & $100 \Omega \quad 0.1 \%$ \\
\hline $\mathrm{R} 23$ & Not assigned & \\
\hline $\mathrm{R} 24$ & " " " & \\
\hline R25 & Wire wound & $1 \mathrm{~K} \Omega 2 \mathrm{~W}$ \\
\hline $\mathrm{R} 26$ & Composition & $180 \Omega 1 / 4 W$ \\
\hline $\mathrm{R} 27$ & $"$ & $100 \Omega 1 / 4 \mathrm{~W}$ \\
\hline $\mathrm{R} 28$ & $"$ & $75 \Omega 1 / 8 W$ \\
\hline R29 & $"$ & $150 \Omega 1 / 4 W$ \\
\hline R30 & $"$ & $150 \Omega 1 / 4 W$ \\
\hline R31 & $"$ & $220 \Omega 1 / 4 W$ \\
\hline R32 & $"$ & $150 \Omega 1 / 4 \mathrm{~W}$ \\
\hline R33 & $"$ & $150 \Omega 1 / 4 W$ \\
\hline R34 & $"$ & $75 \Omega 1 / 8 W$ \\
\hline R35 & $"$ & $220 \Omega 1 / 4 \mathrm{~W}$ \\
\hline R36 & $"$ & $100 \Omega 1 / 4 \mathrm{~W}$ \\
\hline
\end{tabular}




\begin{tabular}{|c|c|c|}
\hline $\mathrm{Cl}$ & Disk ceramic & $0.001 \mu \mathrm{F}$ \\
\hline $\mathrm{C} 2$ & Silver mica & $270 \mathrm{pF}$ \\
\hline C3 & Silver mica & $270 \mathrm{pF}$ \\
\hline$c 4$ & Silver mica & $33 \mathrm{pF}$ \\
\hline$C 5$ & Trimmer & $1.8-13 p F$ \\
\hline C6 & Silver mica & $50 \mathrm{pF}$ \\
\hline C7 & Trimmer & $15-60 p F$ \\
\hline c8 & $"$ & $15-60 \mathrm{pF}$ \\
\hline C9 & Silver mica & $50 \mathrm{pF}$ \\
\hline $\mathrm{C} 10$ & Trimmer & $15-60 p F$ \\
\hline C11 & Disk ceramic & $0.001 \mu \mathrm{F}$ \\
\hline C12 & Unassigned & \\
\hline C13 & Silver mica & $3 \mathrm{pF}$ \\
\hline C14 & Disk ceramic & $0.001 \mu \mathrm{F}$ \\
\hline C15 & Unassigned & \\
\hline C16 & Silver mica & $3 p F$ \\
\hline C17 & Ceramic & $1 \mu \mathrm{F}, 25 \mathrm{~V}$ \\
\hline C18 & $"$ & $1 \mu F, 25 V$ \\
\hline C19 & Electrolytic & $100 \mu \mathrm{F}, 25 \mathrm{~V}$ \\
\hline C20 & $"$ & $100 \mu \mathrm{F}, 25 \mathrm{~V}$ \\
\hline C21 & Disk ceramic & $0.01 \mu \mathrm{F}, 100 \mathrm{~V}$ \\
\hline C22 & Electrolytic & $100 \mu \mathrm{F}, 25 \mathrm{~V}$ \\
\hline C23 & Disk ceramic & $0.01 \mu F, 100 \mathrm{~V}$ \\
\hline C24 & Electrolytic & (2) $1000 \mu \mathrm{F}, 25 \mathrm{~V}$ \\
\hline C25 & Tantalum & $1 \mu \mathrm{F}, 35 \mathrm{~V}$ \\
\hline C26 & Electrolytic & $100 \mu \mathrm{F}, 25 \mathrm{~V}$ \\
\hline $\mathrm{C} 27$ & Disk ceramic & $0.05 \mu F$ \\
\hline C28 & Electrolytic & (2) $1000 \mu \mathrm{F}, 25 \mathrm{~V}$ \\
\hline C29 & Tantalum & $1 \mu \mathrm{F}, 35 \mathrm{~V}$ \\
\hline C30 & Elect.rolytic & $100 \mu \mathrm{F}, 25 \mathrm{~V}$ \\
\hline C31 & Disk ceramic & $0.05 \mu \mathrm{F}$ \\
\hline $\mathrm{C} 32$ & Electrolytic & (2) $1000 \mu \mathrm{F}, 25 \mathrm{~V}$ \\
\hline C33 & Tantalum & $1 \mu \mathrm{F}, 35 \mathrm{~V}$ \\
\hline C34 & Electrolytic & $100 \mu \mathrm{F}, 25 \mathrm{~V}$ \\
\hline C35 & Disk ceramic & $0.05 \mu F$ \\
\hline C36 & & $0.001 \mu F$ \\
\hline C37 & $"$ & $0.01 \mu F, 25 \mathrm{~V}$ \\
\hline C38 & Silver mica & $5 \mathrm{pF}$ \\
\hline C39 & Disk ceramic & $0.01 \mu \mathrm{F}, 25 \mathrm{~V}$ \\
\hline $\mathrm{C} 40$ & Silver mica & $5 \mathrm{pF}$ \\
\hline$c 41-59$ & Disk ceramic & $0.01 \mu \mathrm{F}, 100 \mathrm{~V}$ \\
\hline
\end{tabular}


Inductors
L1
rf choke, miniature
$51 \mu \mathrm{Hy}$
L2-4 Ferrite beads

Connectors

Output, Type N, OSN 410-101 or equal, 2 ea.

Terminator, Type 0SM, 0SM-210-1 or equal, 2 ea.

(Shoulder turned down to reduce size)

Switches

S1 Rep. rate, 2 pole, 4 position miniature, Alco switch MRB-2-5 or equal

S2

Delay, 2 pole, 4 position miniature, Alco switch MRB-2-5 or equal

S3

Mode, 1 pole, 3 position center off toggle

Al co MTA 10SE or equal

Knobs

Miniature, 1/8" for S1 and S2, 2 ea.

Miscellaneous

Y1 Crystal, $10 \mathrm{MHz}, \mathrm{FM}-2$ case

Socket, crystal, type FM-2

", I.C., low profile 16 pin D.I.P., 14 ea.

", I.C., 8 pin, Augat 8059-2G5 or equal, 2 ea.

", I.C., 4 pin, Augat 8059-4G4 or equal, 1 ea.

Heat sink pads, 4 ea.

Blank plug-in, Tektronix 040-0652-05

Coax line, semi-rigid, $3.5 \mathrm{~mm}$, TFE, approx. $2 \mathrm{ft}$ length

Printed circuit board, 1/16" thick G-10, double-sided foil pattern per

figure $A-1$. 

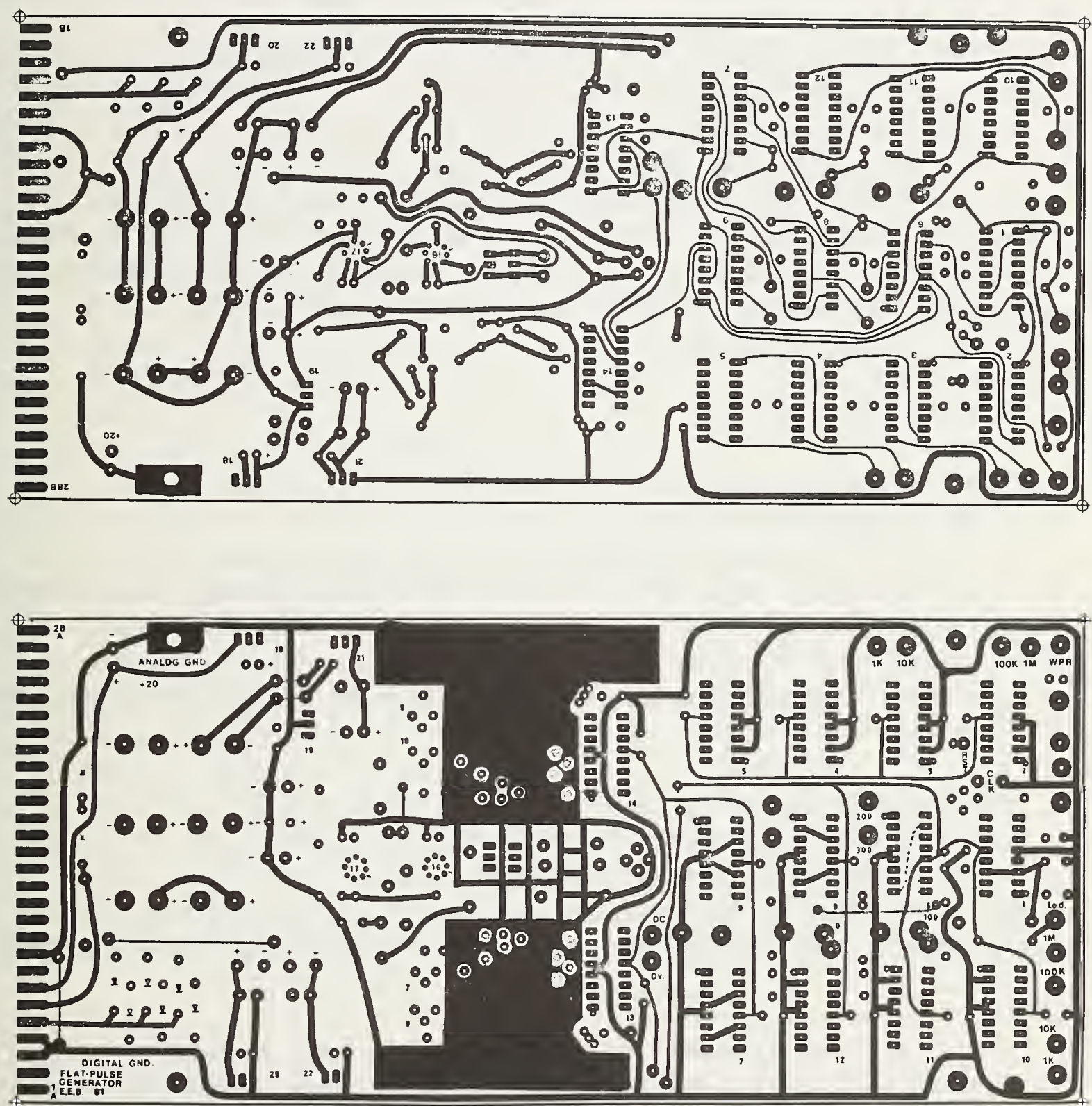

Figure A-1. Printed circuit board for RFPG.

(4. $4^{\prime \prime}$ to $4.45^{\prime \prime}$ by $9.8^{\prime \prime}$ to $9.85^{\prime \prime}$ in size.) 
Appendix B. Alignment/Calibration Procedures

There are a minimal number of adjustments needed for maintaining the proper operation of this generator. These involve the output resistance, dc output voltage levels, trigger repetition rate, and delay (Trigger-to-Pulse) time.

A. Output Impedance Adjustments (Trigger and Pulse outputs)

1. Set the mode switch to $0 \mathrm{~V}$.

2. Connect an accurate ohmeter to the type- $N$ output connector. Be sure that the ohmmeter test voltage on the center conductor is positive.

3. Measure the dc resistance. If it is not $50.00 \Omega \pm 0.5$ percent (may use a tighter specification if desired), then continue to step 4.

4. Select an SMA, microwave, $50 \Omega$ termination, R7 (R12), whose dc resistance is very close to, but slightly greater than, $50.00 \Omega$.

5. Compute the required shunt resistor, $R 8$ ( $R 13)$, using $R 8=50 \times R 7 /(R 7+50)$.

6. Select the nearest standard value $1 / 4 \mathrm{~W}$, carbon composition resistor for $R 8$ (R13) and install it with very short leads to the connection point of CR3 (CR6) and the $3.5 \mathrm{~mm}$ coax. Use adequate heat sinking on the resistor during soldering.

7. Repeat steps 1 through 3 .

B. Output Voltage Adjustment

1. Connect an accurate DVM to the type $N$ output connector.

2. Set the DVM to the $1 \vee$ range.

3. Set the mode switch to 0 V.

4. Check that the output voltage is $0.0 \mathrm{~V} \pm 10 \mu \mathrm{V}$. If $0 \mathrm{~K}$, go to step 6 .

5. If the output is greater than $\pm 10 \mu \mathrm{V}$, then CR3 (CR6) has excessive leakage current and must be replaced.

6. Set the mode switch to DC.

7. Adjust R17 (R16) for a reading of $1.000 \mathrm{~V} \pm 1 \mathrm{mV}$ on the DVM (a tighter specification may be used if desired).

C. Repetition Rate Adjustment

1. Connect an accurate frequency counter to the Trigger output.

2. Set the repetition rate switch to $1000 \mathrm{kHz}$.

3. Set the mode switch to Pulse.

4. Adjust $\mathrm{C} 5$ to set the repetition rate to precisely $1.00 \mathrm{MHz} \pm 0.01$ percent $( \pm 100 \mathrm{~Hz})$.

D. Delay Adjustment

1. Use a dual channel, randum sampling oscilloscope for these adjustments.

2. Remove the internal reverse termination, R7, on the Trigger channel. Connect an SMA, $10 \mathrm{~dB}$ pad and coaxial cable to this point. Connect the other end of the cable to the scope trigger input.

3. Connect the ChA sampler to the SMA CLK (clock) output on PC board.

4. Connect the ChB sampler to the Pulse output.

5. Connect a $50 \Omega$ termination to the Trigger output.

6. Set the generator controls as follows:

Mode: Pulse, Repetition Rate: $1 \mathrm{MHz}$, and Delaý: $200 \mathrm{~ns}$. 


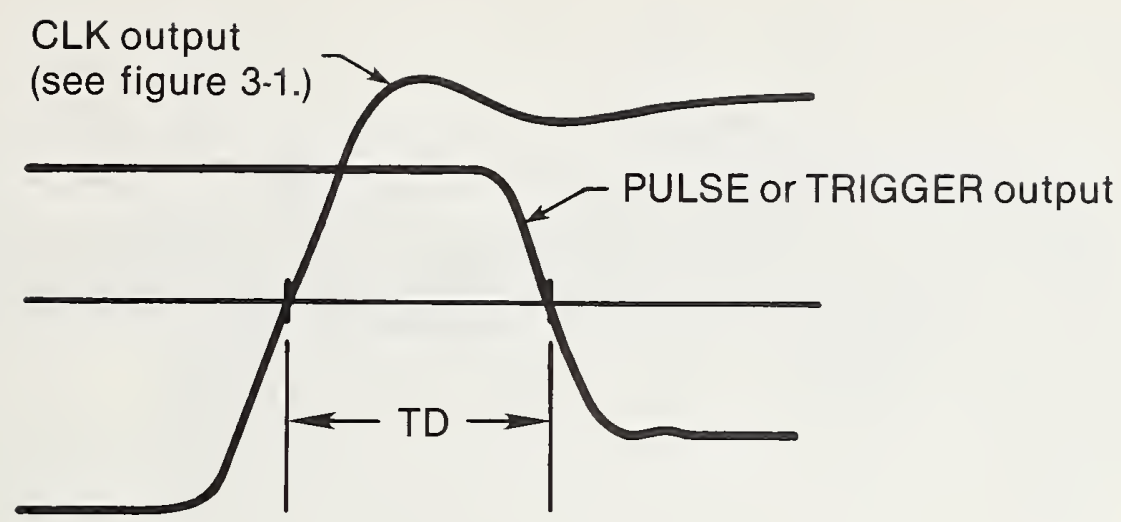

Figure B-1. Time delay adjustment waveforms. Vertical: $100 \mathrm{mV} / \mathrm{div}$. Horizontal: 2 ns/div. (or faster).

7. Set the sampling scope controls as follows:

Mode: Random sampling, Dual Trace, $2 \mathrm{~ns} / \mathrm{cm}$, Trigger: as needed for stable display.

8. Adjust the time position control for a display similar to that shown in figure B-1. Adjust the individual vertical channel delay controls to minimize the time TD between transitions.

9. Measure and record $\mathrm{TD}_{1}=$ ns.

10. Connect the ChB sampler to Trigger output and the $50 \Omega$ termination to Pulse output.

11. Adjust the scope time position control for the figure B-1 display again.

12. Adjust $C 7$ to set TD to precisely the value measured in step 9.

13. Set the delay to 0 ns.

14. Connect the ChB sampler to Pulse output and the $50 \Omega$ termination to the Trigger output.

15. Adjust the time position control for the figure B-1 again.

16. Adjust C10 to set TD to precisely the value measured in step 9.

17. Set the delay to $100 \mathrm{~ns}$.

18. Adjust the time position control for the figure B-l display again.

19. Adjust C8 to set TD to precisely the value measured in step 9.

20. Set the delay to $300 \mathrm{~ns}$.

21. Adjust the time position control for the figure B-l display again.

22. Measure and record $\mathrm{TD}_{3} \cdot \mathrm{TD}_{3}$ should equal $\mathrm{TD}_{1}$, from step $9, \pm 1 / 2$ ns.

23. Remove the $10 \mathrm{~dB}$ pad and replace the internal $50 \Omega$ termination for the Trigger output. 
Appendix C. Measurements of the Effective Time Constant $\left(\tau_{\beta^{\prime}}\right)$

for the BFR 90 Transistor

Besides the parameters that can be obtained from the base-emitter and collector-emitter characteristics, modeling of the BFR 90 transistor using the nonlinear GMB model [15] requires knowledge of the effective collector current exponential response to a step of base current (common-emitter configuration). As described in reference 15, a charge-controlled model of the base-emitter junction (and the associated differential equations) can be used to develop the following common-emitter equivalent circuit for simulation purposes:

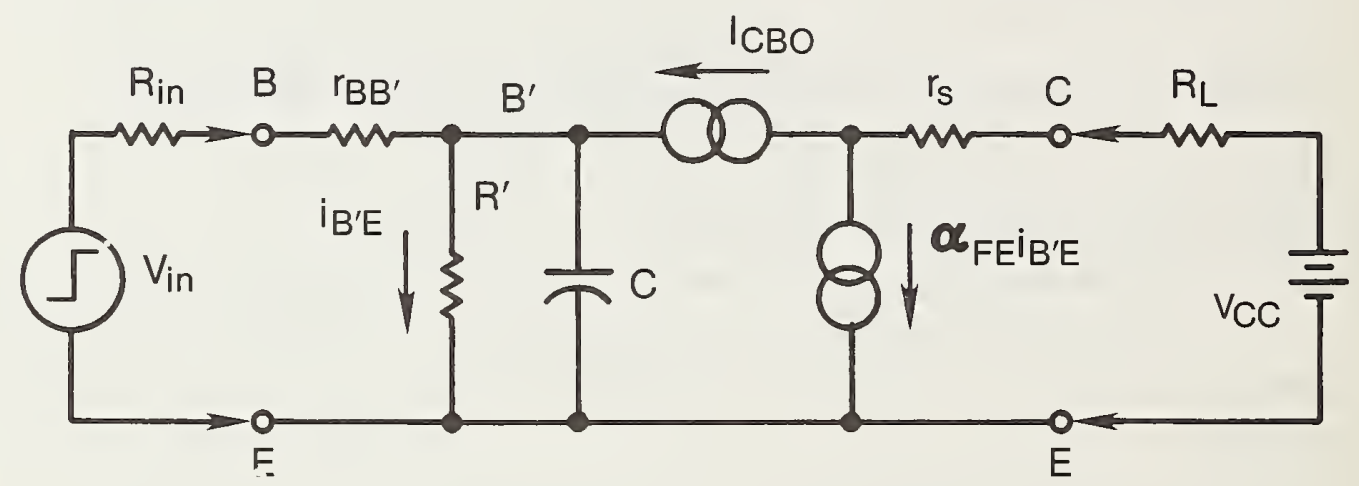

Figure C-1. Common-emitter equivalent circuit (GMB model).

where: $\quad r_{B^{\prime}}{ }^{\prime}=$ bulk or extrinsic base-emitter resistance

$R^{\prime} \quad$ current-dependent base-emitter diode resistance, $r_{B^{\prime}} E$

$C=$ sum of the base-emitter diffusion capacitance $\left(C_{B^{\prime} E}\right)$ and a feedback capacitance $\left(C_{f}\right)$ representative of the collector-base depletion capacitance

${ }^{{ }_{C B O}}=$ leakage (cutoff) current of the collector-base junction

$\alpha_{F E}=i_{C} / i_{B E}$, the common-emitter base to collector current gain, or beta ( $\beta$ )

$r_{S}=$ collector saturation resistance

Although this equivalent circuit is useful for large signal switching analysis, operation in the saturation region where storage time effects must be accounted for is not inherent to the use of the BFR 90 switches used in the RFPG. Therefore, the saturation sensing diode and storage time circuit of the complete GMB model is not included in figure $\mathrm{C}-1$.

The $R^{\prime} C$ time constant is denoted as $\tau_{B^{\prime}}$ where $\tau_{B^{\prime}}=\left(C_{B^{\prime} E}+C_{f}\right) r_{B^{\prime}} E$. This time constant is considered to be constant over the entire base current excursion even though the dynamic impedance between the $B^{\prime}-E$ terminals is continuously variable during the transient step. As pointed out in reference 15, this variation is important when source impedances $\left(R_{i n}\right)$ are of low value since then the input impedance affects the level of current from the driving source. For the RFPG, the driving source to the BFR 90 transistors is the low impedance $(\sim 7 \Omega)$ output from an ECL logic OR gate. A measure of $\tau_{B^{\prime}}$ then allows for a calculation of $C$ since $R^{\prime}$ is determined from the base-emitter characteristics. 


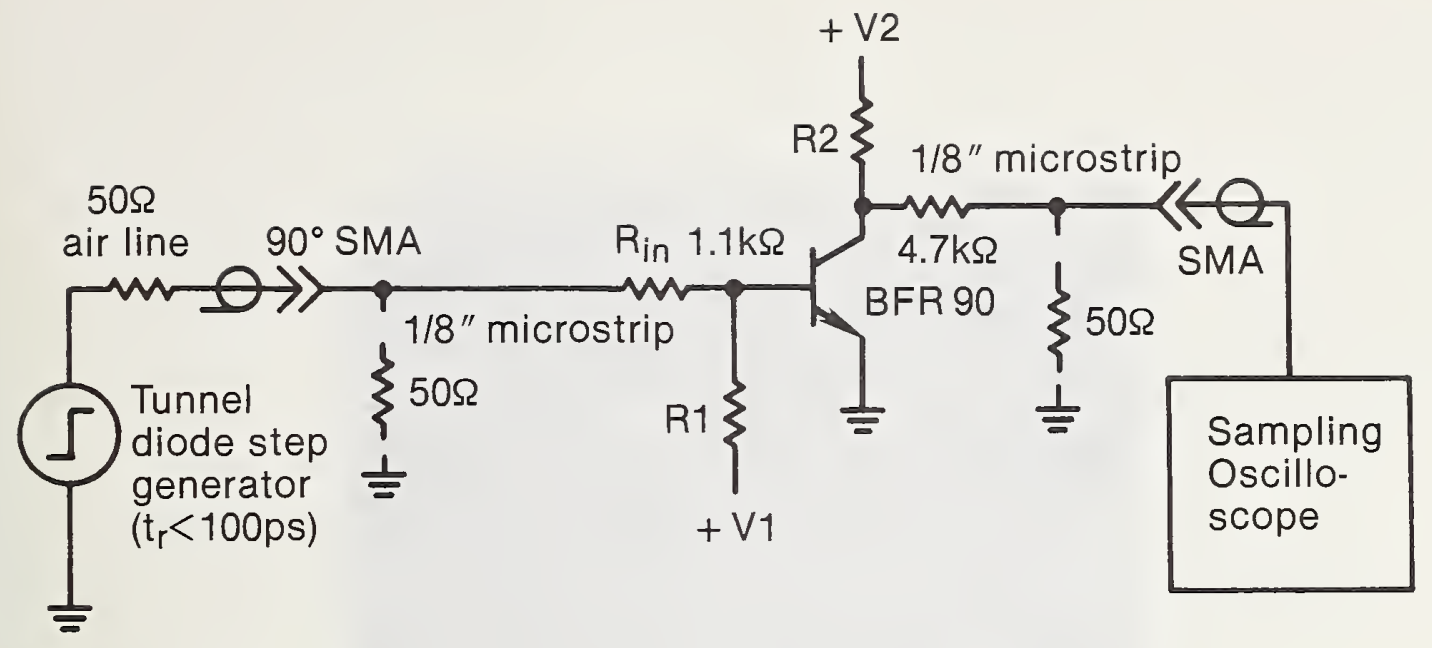

Figure C-2. BFR 90 time constant measurement circuit.

With a large value of $R_{i n}$ (so that $I_{i n}=V_{i n} / R_{i n}=$ constant) and ignoring the second-order effect of $\mathrm{I}_{\mathrm{CBO}}$, the instantaneous collector current can be expressed as

$$
i_{C}(t) \cong \alpha_{F E} I_{i n}\left[1-\exp \left(-t / \tau_{B^{\prime}}\right)\right]
$$

Time constant $\tau_{B^{\prime}}$ is equal in value to the $\sim 63$ percent point of the collector current response to a base current step, measured with ${ }^{i} C$ ranging from cutoff to just saturation (with the desired value of load resistor $R_{L}$ in the collector circuit).

A test board using microstrip lines and miniature connectors for a broadband $50 \Omega$ environment (developed for time domain reflectometry testing purposes) was used to make the ${ }^{\tau_{B}}{ }^{\prime}$ measurements. The circuit board and test setups are shown in figure $\mathrm{C}$-2.

The bias supplies $V 1$ and $V 2$ were provided by a bank of NiCad batteries. R2 is the effective load resistor $\left(R_{L}\right)$ as indicated in figure $C-1$. Using $50 \Omega$ microstrip lines with $1 / 8$ inch wide copper foil on glass-epoxy printed circuit board, the step generator and sampling oscilloscope were connected via miniature high-frequency connectors. Observation of the tunnel diode step generator with the sampling scope output of the standard $50 \Omega$ air dielectric line indicated a step transition duration ( $t_{r}$ ) of less than $100 \mathrm{ps}$.

Photographs taken of the step response of a typical BFR 90 transistor in the test circuit given in figure $\mathrm{C}-2$ are shown on figures $\mathrm{C}-3$ and $\mathrm{C}-4$.

The results of the step response tests run on three BFR 90 transistors are tabulated in the table C.1. The data from this table are plotted in figure C-5 showing that for large signal collector current swings up to approximately $30 \mathrm{ma}$ (corresponding to load resistance of about $200 \Omega$ ), the effective $\tau_{B}$ ' is around 3 ns. 


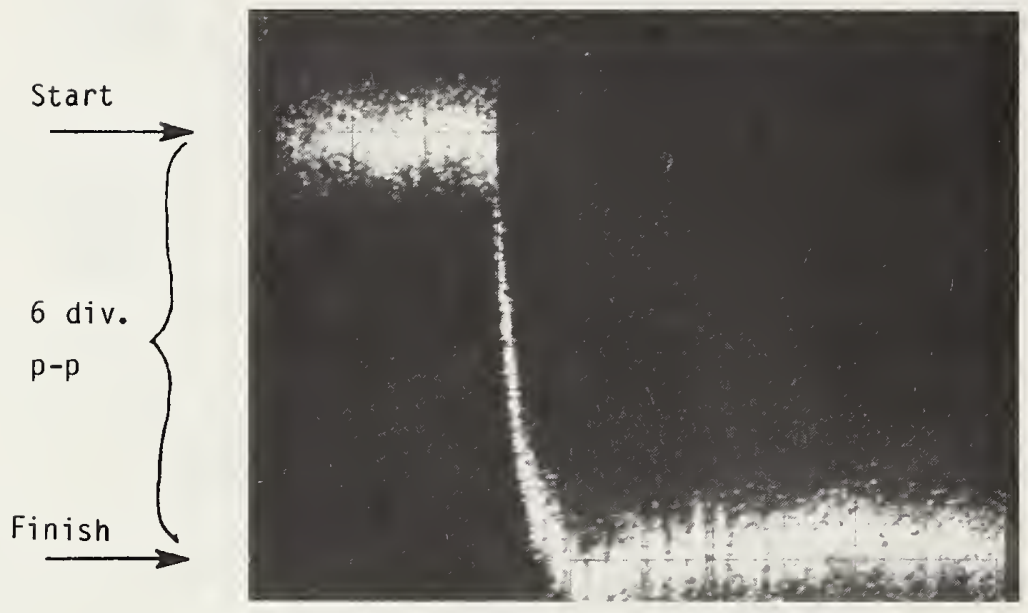

(a)

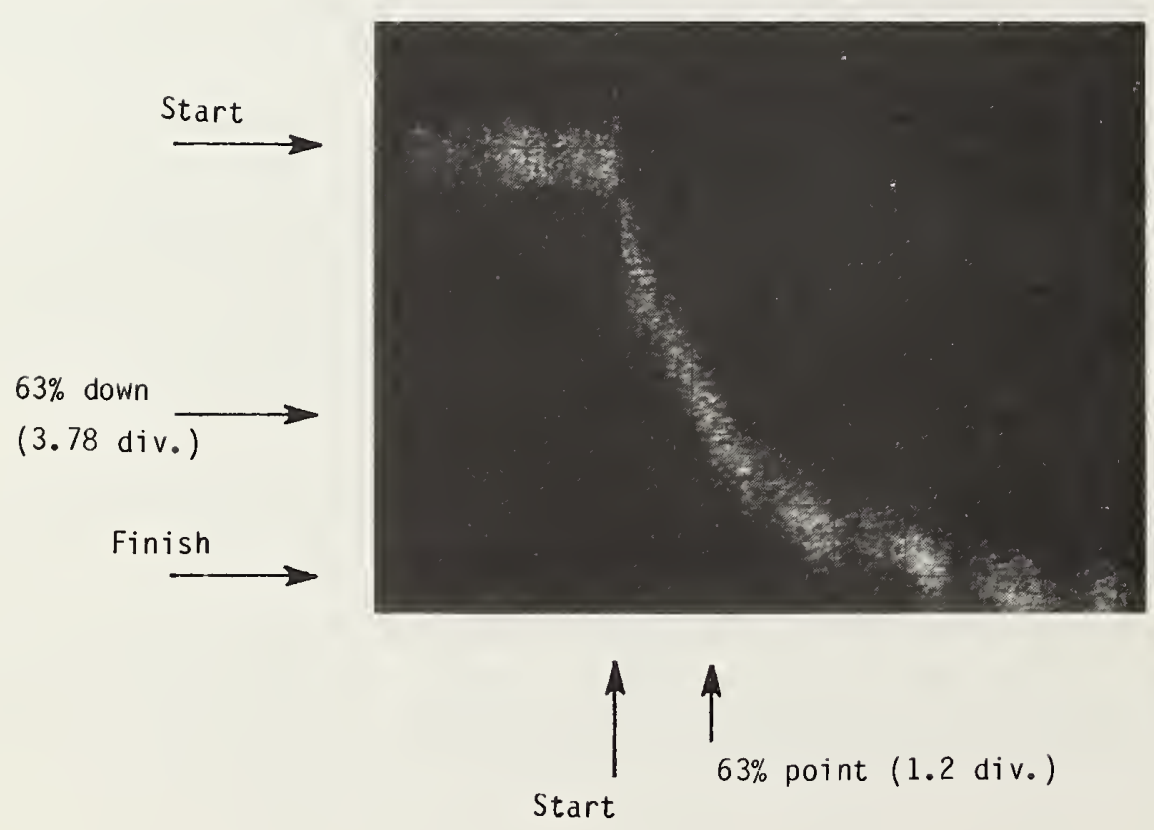

(b)

Finish

Figure $C-3$. Step response ( $\tau_{b}$ ' measurement) photos of a typical BFR 90 transistor (150 $\Omega$ load resistance).

(a) Vertical: $5 \mathrm{mV} / \mathrm{div}$. Horizontal: $10 \mathrm{~ns} / \mathrm{div}$. Test conditions: $\mathrm{V} 1=\mathrm{V} 2=6.3 \mathrm{~V}, \mathrm{R} 1=$ $6.2 \mathrm{k} \Omega, R 2=150 \Omega_{0} V_{C E}$ swing: 6 div $p-p ;+1.5 \mathrm{~V}$ (saturation), $+4.9 \mathrm{~V}$ (cutoff).

(b) Vertical: $5 \mathrm{mV} / \mathrm{div}$. Horizontal: $2 \mathrm{~ns} / \mathrm{div}$. Test conditions: same as above. $63 \% \times$ 6 div. $=3.78$ div. $\tau_{b^{\prime}} \cong 1.2$ div. $\times 2$ ns/div. $\cong 2.4 \mathrm{~ns}$. 


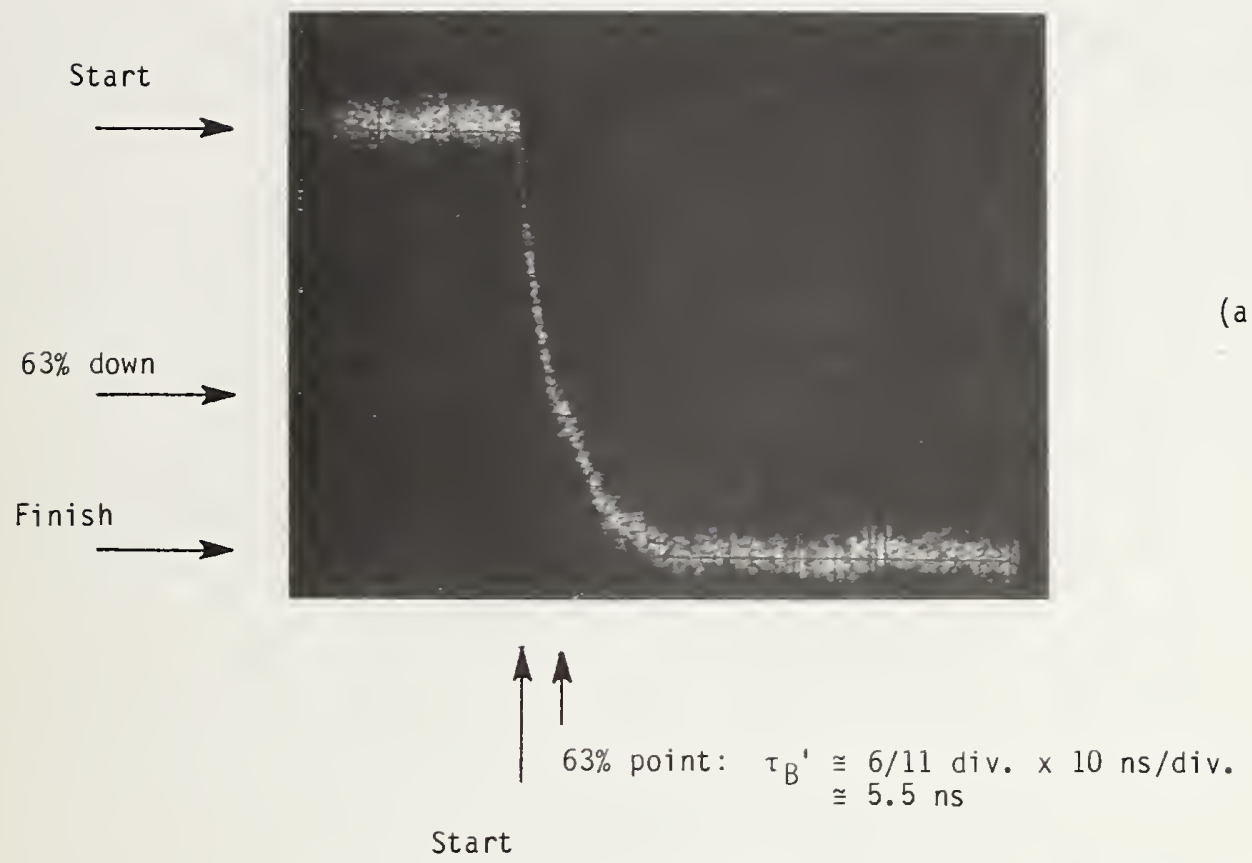

(a)

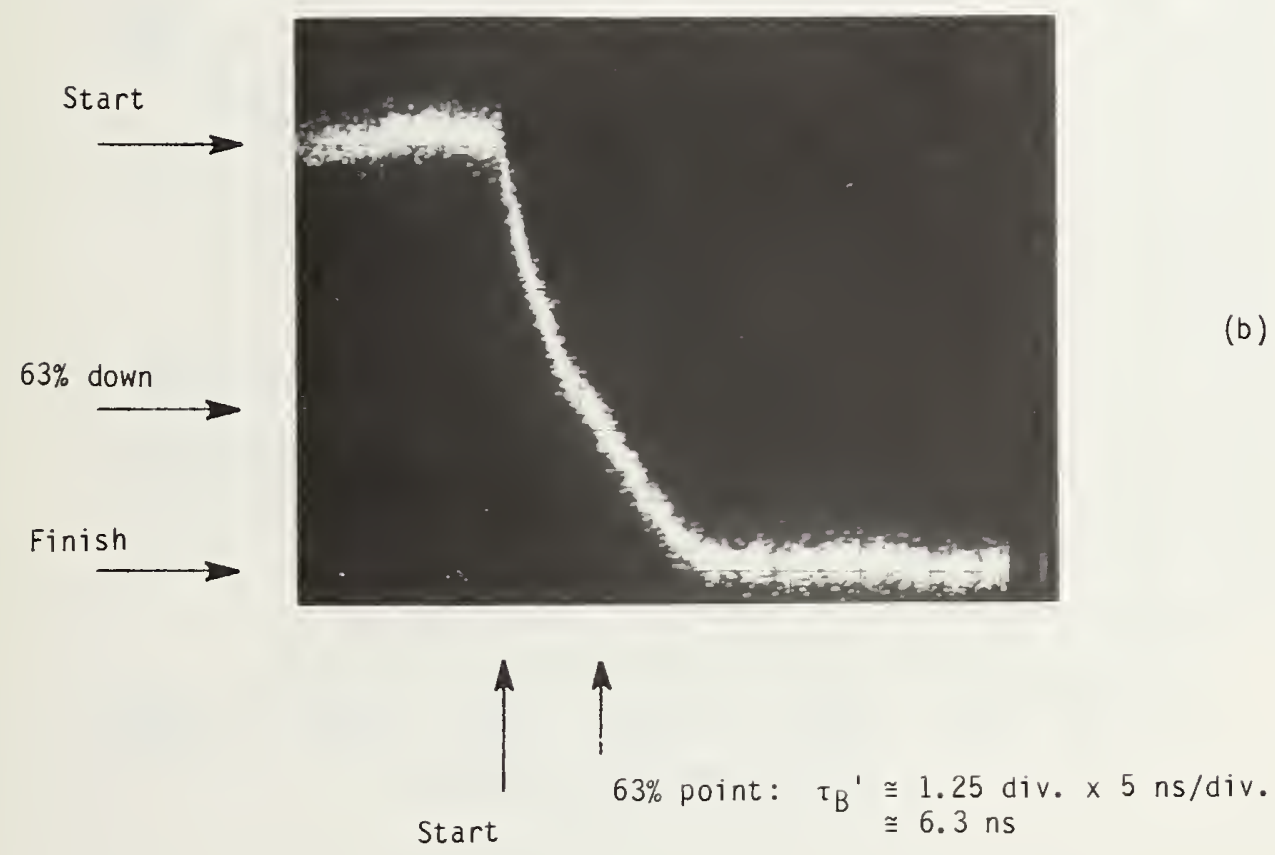

Figure C-4. Step response ( $\tau_{b}$ ' measurement) of a typical BFR 90 transistor $(300 \Omega$ and $620 \Omega$ load resistance): $($ ) Vertical: 6 div. p-p. Horizontal: $10 \mathrm{~ns} /$ div. Test conditions: $v 1=5.02 \mathrm{~V}, \mathrm{~V} 2=$ (a) Vertical: $6 \mathrm{div} . \mathrm{p}-\mathrm{p}$. Horizontal: $10 \mathrm{~ns} / \mathrm{div}$. Test conditions: $\mathrm{V} 1=5.02 \mathrm{~V}$,
$6.3 \mathrm{~V}, \mathrm{R} 1=6.2 \mathrm{k} \Omega, \mathrm{R} 2=300 \Omega$. $\mathrm{V}_{\mathrm{CE}}$ swing: to. $6 \mathrm{~V}$ (saturation), $+5.8 \mathrm{~V}$ (cutoff). (b) Vertical: 6 div. p-p. Horizontal: 5 ns/div. Test conditions: same as above except $R 2=620 \Omega$. $V_{C E}$ swing: $+0.6 \mathrm{~V}$ (saturation), $+5.6 \mathrm{~V}$ (cutoff). 
Table C.1. Summary

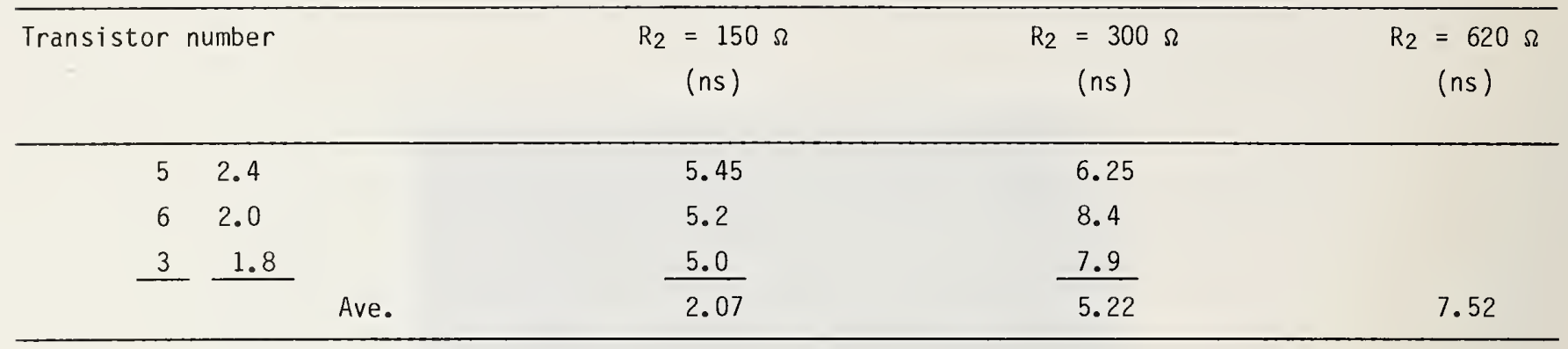

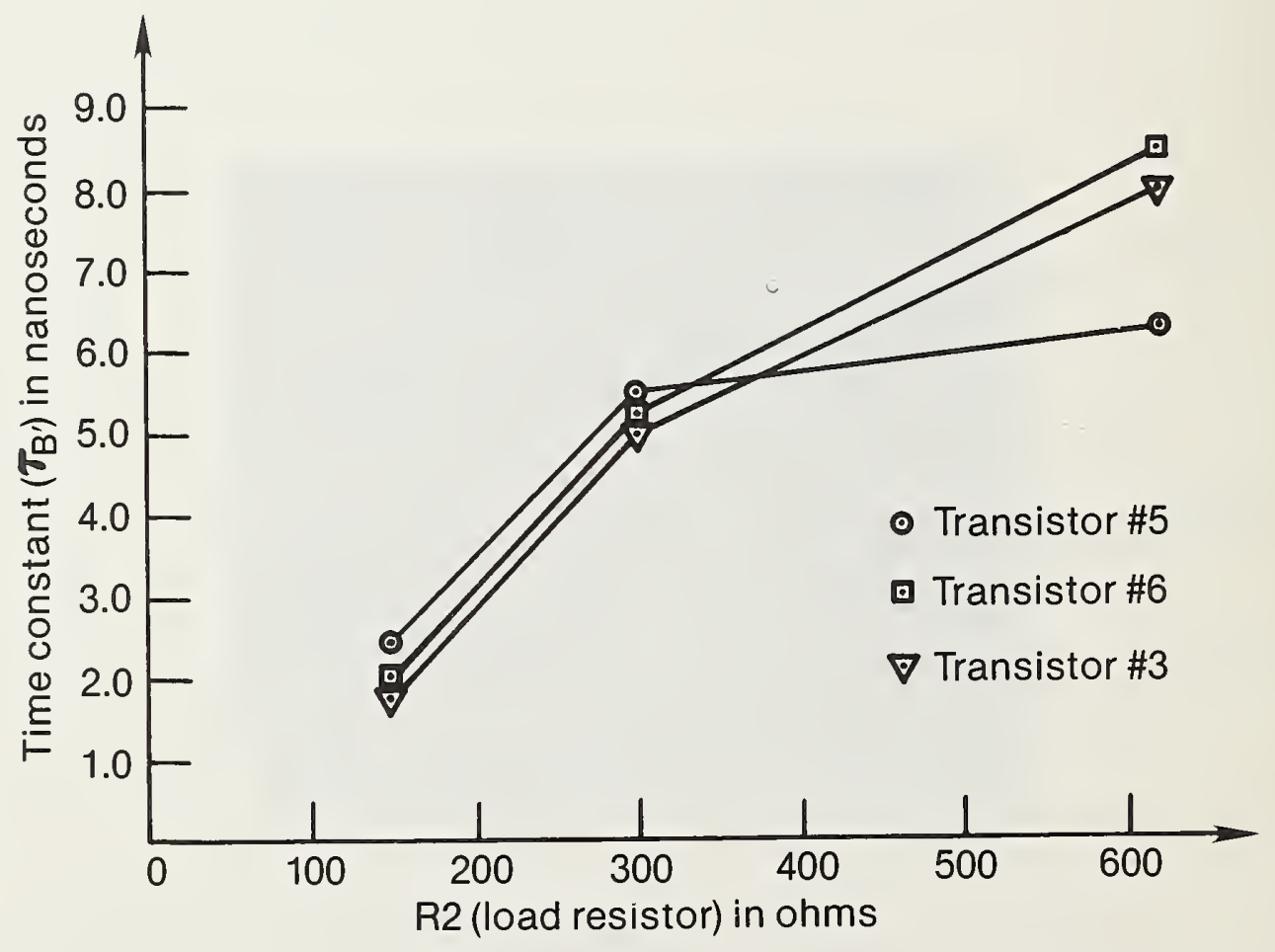

Figure C-5. Plot of $\tau_{B^{\prime}}$ data on BFR 90 transistors. 
Appendix D. Collector Capacitance Equivalency

Given the circuits shown in figures D-1 and D-2 on the following page, it is desired to determine the step response voltage at the collector node due to either the known collector-base capacitance or an equivalent capacitance between collector and circuit common. Letting $X(s)=\Sigma[x(t)]$ denote the Laplace transform representation of the instantaneous value of the circuit variables for figure $D-1$, then

$$
I_{b}(s)=I_{b^{\prime}} e^{(s)+I_{f}(s),}
$$

where, assuming zero initial conditions,

$$
I_{f}(s)=s C_{f} V_{b}{ }^{\prime} C(s) \text {. }
$$

The collector-base voltage $V_{b}{ }^{c} c(s)$ is determined by

$$
V_{b^{\prime} c^{\prime}}(s)=I_{b^{\prime} e^{\prime}}(s) R+V_{0}(s)
$$

where $V_{0}(s)=I_{\ell}(s) R_{\ell}$ is the collector output node voltage. Since

$$
I_{\ell}(s)=B I_{b} e^{(s)}-I_{f}(s)
$$

then

$$
V_{0}(s)=\left[\beta I_{b^{\prime}} e^{\left.(s)-I_{f}(s)\right] R_{\ell}}\right.
$$

or, by substituting for $I_{f}(s)$, using eq (D-1),

$$
V_{0}(s)=\left[I_{b^{\prime}} e^{\left.(s)(1+\beta)-I_{b}(s)\right] R} \ell_{\ell} \cdot\right.
$$

By solving for $V_{b}{ }^{c} c(s)$ in eq $(D-2)$, and using eq $(D-3)$,

$$
I_{b^{\prime}} e^{(s) R}+V_{0}(s)=I_{f}(s) / s C_{f}
$$

or,

$$
R C_{f} s I_{b^{\prime} e}(s)+C_{f} s V_{0}(s)=I_{f}(s)=I_{b}(s)-I_{b^{\prime}}(s) .
$$

Solving for $I_{b}{ }^{\prime}(s)$ gives

$$
I_{b^{\prime}} e(s)=\frac{I_{b}(s)-C_{f} s V_{o}(s)}{1+R_{2} C_{f} s}
$$

Substituting for $I_{b^{\prime}} e^{(s)}$ in eq (D-6),

$$
V_{0}(s)=\left[\left(\frac{I_{b}(s)-C_{f} s V_{0}(s)}{1+R_{2} C_{f} s}\right)(1+\beta)-I_{b}(s)\right] R_{\ell} \text {. }
$$




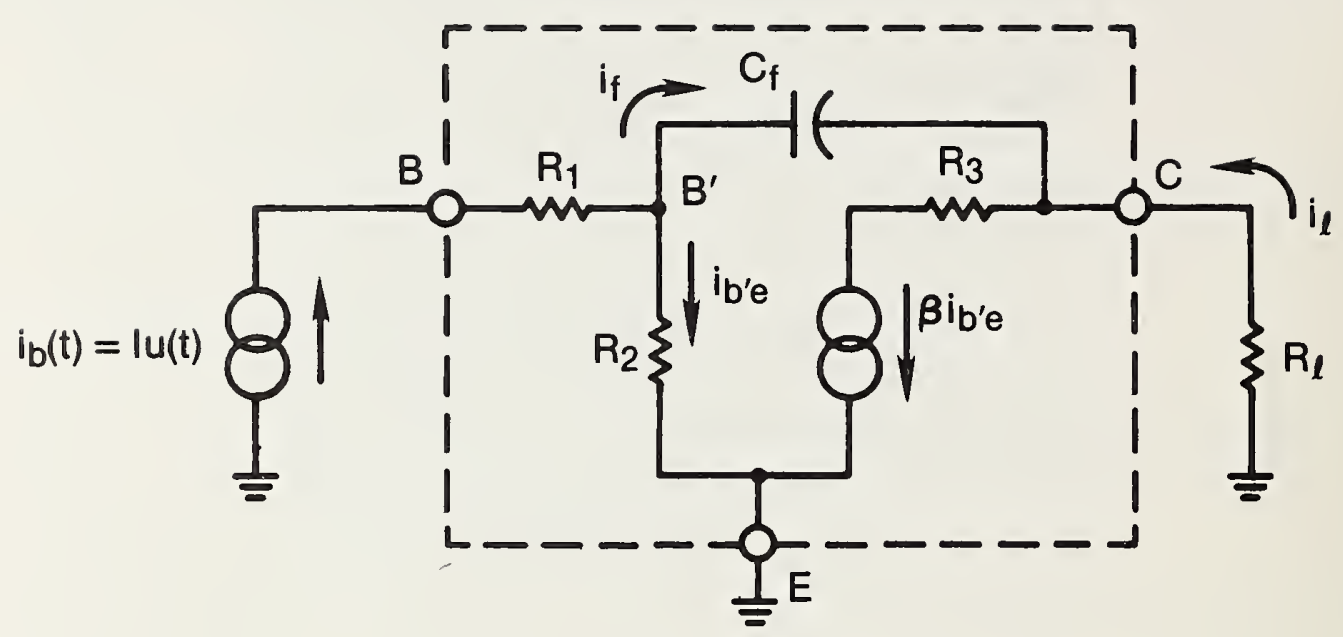

Figure D-1. Simplified transistor model using collector-base capacitance for step response.

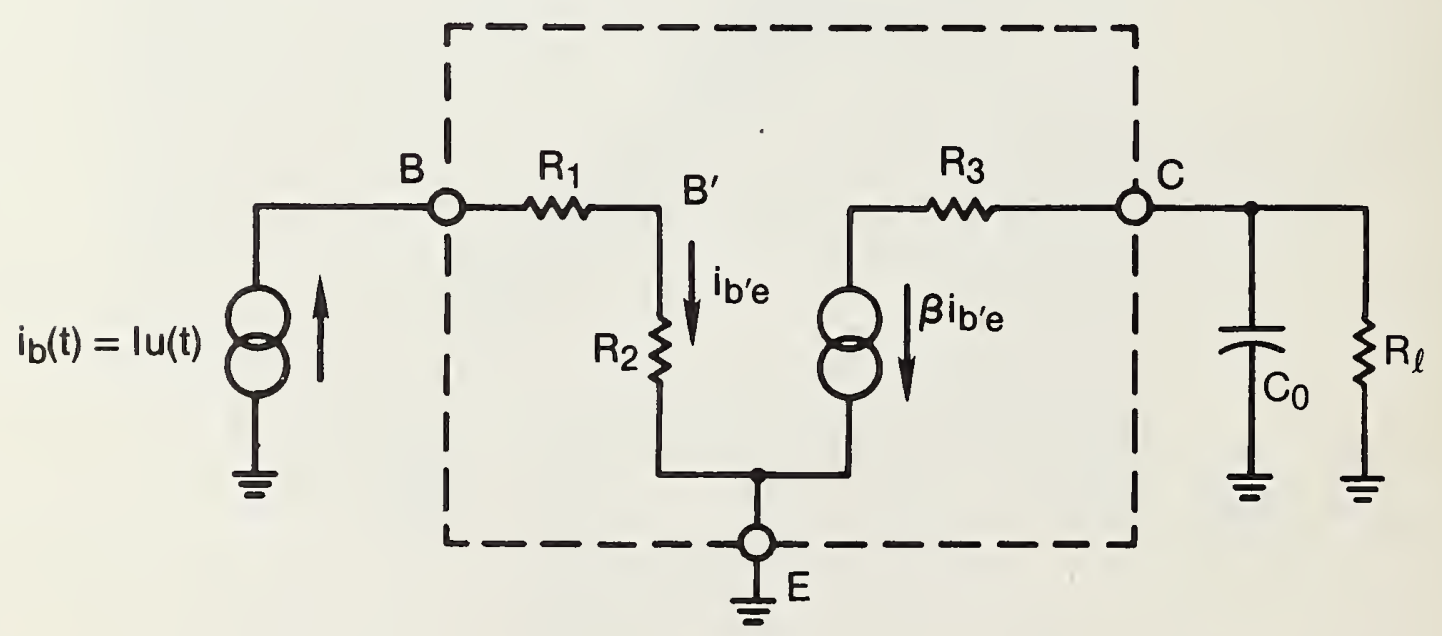

Figure D-2. Simplified transistor model using equivalent common-collector capacitance for step response. 
With appropriate rearrangement,

$$
V_{0}(s)=\frac{\left(\beta-R_{2} C_{f} s\right) R_{\ell} I_{b}(s)}{1+\left[R_{2}+(1+\beta) R_{\ell}\right] C_{f} s}
$$

For $i_{b}(t)=I u(t)$, an input step of base current of $I$ amperes, so that $I_{b}(s)=I / s$,

$$
V_{0}(s)=\frac{\left(\beta-R_{2} C_{f} s\right) R_{\ell} I}{s\left\{1+\left[R_{2}+(1+\beta) R_{\ell}\right] C_{f} s\right\}}
$$

or,

$$
V_{0}(s)=\frac{B_{\ell} I}{s\left\{1+\left[R_{2}+(1+\beta) R_{\ell}\right] C_{f} s\right.}-\frac{R_{2} C_{f} R_{\ell} I}{1+\left[R_{2}+(1+\beta) R_{\ell}\right] C_{f} s} .
$$

By using partial fraction expansion,

$$
\begin{array}{r}
V_{0}(s)=\frac{\beta R_{\ell} I}{s}-\frac{\beta R_{\ell} I}{s+\frac{1}{\left[R_{2}+(1+\beta) R_{\ell}\right] C_{f}}} \\
-\frac{\left(\frac{R_{2} R_{\ell}}{R_{2}+(1+\beta) R_{\ell}}\right) I}{s+\frac{1}{\left[R_{2}+(1+\beta) R_{\ell}\right] C_{f}}}
\end{array}
$$

or,

$$
V_{0}(s)=\beta R_{2} I\left[\frac{1}{s}-\frac{1}{s+1 / \tau_{1}}\right]-\frac{R_{p} I}{s+1 / \tau_{1}},
$$

where: $\tau_{1}=\left[R_{2}+(1+\beta) R_{\ell}\right] C_{f}$

$$
R_{p}=\frac{R_{2} R_{\ell}}{R_{2}+(1+\beta) R_{\ell}} \text {. }
$$

The step response voltage at the collector node is thus

$$
V_{0}(t)=\beta R_{\ell} I\left[1-\exp \left(-t / \tau_{1}\right)\right]-R_{p} I \exp \left(-t / \tau_{1}\right)
$$

For figure D-2,

$$
\beta I_{b^{\prime} e}(s)=\beta I_{b}(s) \text {. }
$$

The load impedance at the collector node is

$$
Z_{\ell}(s)=\frac{R_{\ell}}{1+R_{\ell} C_{0} s}
$$

so that the collector output node voltage is

$$
V_{0}(s)=\beta I_{b}(s) Z_{\ell}(s)
$$


or,

$$
V_{0}(s)=\frac{\beta R_{\ell} I_{b}(s)}{1+R_{\ell} C_{0} s}
$$

which corresponds to eq $(D-11)$ for figure $D-1$. Again, for $I_{b}(s)=I / s$, corresponding to an input step of base current of I amperes,

$$
V_{0}(s)=\frac{\beta R_{\ell} I}{s\left[1+R_{\ell} C_{0} s\right]}
$$

By partial fraction expansion,

or,

$$
V_{0}(s)=\frac{\beta R_{\ell} I}{s}-\frac{\beta R_{\ell} I}{s+\frac{1}{R_{\ell} C_{0}}},
$$

$$
V_{0}(s)=\beta R_{\ell} I\left[\frac{1}{s}-\frac{1}{s+1 / \tau_{2}}\right]
$$

where $\tau_{2}=R_{\ell} C_{0}$. The step response voltage is then

$$
V_{0}(t)=\beta R_{\ell} I\left[1-\exp \left(-t / \tau_{2}\right)\right]
$$

For equivalent response times,

$$
\tau_{1}=\left[R_{2}+(1+\beta) R_{\ell}\right] C_{f}=\tau_{2}=R_{\ell} C_{0}
$$

For typical values, $(1+\beta) R_{\ell} \gg R_{2}$. Hence,

$$
(1+\beta) R_{\ell} C_{f} \cong R_{\ell} C_{0},
$$

or,

$$
C_{0}=(1+\beta) C_{f}
$$

In the case for a BFR 90 transistor, from reference 17, typically

$$
\begin{aligned}
& C_{f}=C_{C b}=0.5 \mathrm{pF} \\
& \beta=h_{F E}=25_{\min } \text { to } 250_{\text {max }} .
\end{aligned}
$$

From actual observed collector characteristics (see fig. 4-20), typical $\beta$ values are 40 to 80 . Using $\beta=60$ and $C_{f}=0.5 \mathrm{pF}$ in eq $(D-27)$,

$$
C_{0}(\text { typical }) \cong(61) 0.5 \mathrm{pF}=30.5 \mathrm{pF} \text {. }
$$

A value of $C_{0}=C_{9}=10 \mathrm{pF}$ was found to produce good results in the TRFPG program model shown in figure 4-31. 
NBS-1) HA (REV. 2-8C)

U.S. DEPT. OF COMM.

BIBLIOGRAPHIC DATA

SHEET (See instruction s)

1. PUBLICATION OR
REPORT NO.
NBS TN-1067

2. Performing Organ. Report No.

3. Publication Date

October 1983

4. TITLE AND SUBTITLE

Reference Flat Pulse Generator

5. $A U T H O R(S)$

J. R. Andrews, B. A. Bel1, E. E. Baldwin

6. PERFORMING ORGANIZATION (If joint or other than NBS, see instructions)

7. Contract/Grant No.

NATIONAL BUREAU OF STANDARDS

DEPARTMENT OF COMMERCE

WASHINGTON, D.C. 20234

9. SPONSORING ORGANIZATION NAME AND COMPLETE ADDRESS (Street, City. State, ZIP)

8. Type of Report \& Period Covered

10. SUPPLEMENTARY NOTES

[ Document describes a computer program; SF-185, FIPS Software Summary, is attached.

11. ABSTRACT (A 200-word or less factual summary of most significant information. If document includes a significant bibliography or literature survey. mention it here)

A reference step-like pulse generator is described which has been develoned at NBS. This generator can be used for accurately characterizing the step resnonse of various kinds of transient recording equipment (oscilloscopes, waveform recorders, transient digitizers, etc.). Basic design principles are given as well as complete circuit diagrams and descriptions. An analysis of the output stage of the generator is presented together with the circuit models for developina a time-domain computer simulation program using extended-SCEPTRE. Preliminary specifications indicate that the NBS Reference Flat Pulse Generator provides a negative-going reference transition duration (90 to 10 percent) of 600 ps, \pm 2 percent after 5 ns.

12. KEY WORDS (Six to twelve entries; alphabetical order; capitalize only proper names; and separate key words by semicolons) available waveform; baseline; circuit analysis; flat pulse generator; modeling; step response; topline; transfer standard; transition duration

\section{AVAILABILITY}

X Unlimited

$\square$ For Official Distribution. Do Not Release to NTIS

X] Order From Superintendent of Documents, U.S. Government Printing Office, Washington, D.C. 20402.

Order From National Technical Information Service (NTIS), Springfield, VA. 2216I
14. NO. OF PRINTED PAGES

72

15. Price

$\$ 4.50$ 



\section{NBS TECHNICAL PUBLICATIONS}

\section{PERIODICALS}

JOURNAL OF RESEARCH-The Journal of Research of the National Bureau of Standards reports NBS research and develop. ment in those disciplines of the physical and engineering sciences in which the Bureau is active. These include physics, chemistry, engineering, mathematics, and computer sciences. Papers cover a broad range of subjects, with major emphasis on measurement methodology and the basic technology underlying standardization. Also included from time to time are survey articles on topics closely related to the Bureau's technical and scientific programs. As a special service to subscribers each issue contains complete citations to all recent Bureau publications in both NBS and nonNBS media. Issued six times a year. Annual subscription: domestic $\$ 18$; foreign $\$ 22.50$. Single copy, $\$ 5.50$ domestic; $\$ 6.90$ foreign.

\section{NONPERIODICALS}

Monographs-Major contributions to the technical literature on various subjects related to the Bureau's scientific and technical activities.

Handbooks-Recommended codes of engineering and industrial practice (including safety codes) developed in cosperation with interested industries, professional organizations, and regulatory bodies.

Special Publications-Include proceedings of conferences sponsored by NBS. NBS annual reports, and other special publications appropriate to this grouping such as wall charts, pocket cards, and bibliographies.

Applied Mathematics Series-Mathematical tables, manuals, and studies of special interest to physicists, engineers, chemists, biologists, mathematicians, computer programmers, and others engaged in scientific and technical work.

National Standard Reference Data Series-Provides quantitative data on the physical and chemical properties of materials, compiled from the world's literature and critically evaluated. Developed under a worldwide program coordinated by NBS under the authority of the National Standard Data Act (Public Law 90-396).

NOTE: The principal publication outlet for the foregoing data is the Journal of Physical and Chemical Reference Data (JPCRD) published quarterly for NBS by the American Chemical Society (ACS) and the American Institute of Physics (AIP). Subscriptions. reprints, and supplements available from ACS, 1155 Sixteenth St., NW, Washington, DC 20056.
Building Science Series-Disseminates technical information develoyed at the Bureau on building materials, components, systems, and whole structures. The series presents research results, test methods, and performance criteria related to the structural and environmental functions and the durability and safety characteristics of building elements and systems.

Technical Notes-Studies or reports which are complete in themselves but restrictive in their treatment of a subject. Analogous to monographs but not so comprehensive in scope or definitive in treatment of the subject area. Often serve as a vehicle for final reports of work performed at NBS under the sponsorship of other government agencies.

Voluntary Product Standards-Developed under procedures published by the Department of Commerce in Part 10. Title 15, of the Code of Federal Regulations. The standards establish nationally recognized requirements for products, and provide all concerned interests with a basis for common understanding of the characteristics of the products. NBS administers this program as a supplement to the activities of the private sector standardizing organizations.

Consumer Information Series-Practical information, based on NBS research and experience, covering areas of interest to the consumer. Easily understandable language and illustrations provide useful background knowledge for shopping in today's technological marketplace.

Order the above NBS publications from: Superintendent of Documents, Government Printing Office, Washington, DC 20402.

Order the following NBS publications-FIPS and NBSIR's-from the National Technical Information Service. Springfield. VA 22161.

Federal Information Processing Standards Publications (FIPS PUB)-Publications in this series collectively constitute the Federal Information Processing Standards Register. The Register serves as the official source of information in the Federal Government regarding standards issued by NBS pursuant to the Federal Property and Administrative Services Act of 1949 as amended. Public Law 89.306 (79 Stat. 1127), and as implemented by Executive Order 11717 (38 FR 12315, dated May 11, 1973) and Part 6 of Title 15 CFR (Code of Federal Regulations).

NBS Interagency Reports (NBSIR)-A special series of interim or final reports on work performed by NBS for outside sponsors (both government and non-government). In general, initial distribution is handled by the sponsor: public distribution is by the National Technical Information Service, Springfield, VA 22161. in paper copy or microfiche form. 
U.S. Department of Commerce

National Bureau of Standards

Washington, D.C. 20234

Official Business

Penalty for Private Use $\$ 300$

POSTAGE AND FEES PAID US DEPARTMENT OF COMMER COM-215

FIRST CLASS 